\title{
In Situ Determination of Rheological Properties and Void Fraction in Hanford Waste Tank 241-SY-101
}
C. W. Stewart
C. L. Shepard
J. M. Alzheimer
T. I. Stokes
G. Terrones

August 1995

Prepared for the U.S. Department of Energy under Contract DE-AC06-76RLO 1830

Pacific Northwest Laboratory Operated for the U.S. Department of Energy by Battelle Memorial Institute 


\section{DISCLAIMER}

This report was prepared as an account of work sponsored by an agency of the United States Government. Neither the United States Government nor any agency thereof, nor Battelle Memorial Institute, nor any of their employees, makes any warranty, expressed or implied, or assumes any legal tiability or responsibility for the accuracy, completeness, or usefulness of any information, apparatus, product, or process disclosed, or represents that its use would not infringe privately owned rights. Reference herein to any specific commercial product, process, or service by trade name, trademark, manufacturer, or otherwise does not necessarily constitute or imply its endorsement, recommendation, or favoring by the United States Government or any agency thereof, or Battelle Memorial Institute. The views and opinions of authors expressed herein do not necessarily state or reflect those of the United States Government or any agency thereof.

PACIFIC NORTHWEST LABORATORY

operated by

BATTELLE MEMORIAL INSTITUTE

$$
\begin{aligned}
& \text { for the } \\
& \text { UNITED STATES DEPARTMENT OF ENERGY }
\end{aligned}
$$

under Contract DE-AC06-76RLO 1830 


\section{DISCLAIMER}

Portions of this document may be illegible in electronic image products. Images are produced from the best available original document. 
PNL-10682

UC-510

In Situ Determination of Rheological

Properties and Void Fraction in Hanford Waste Tank 241-SY-101

CW Stewart

CL Shepard

JM Alzheimer

TI Stokes

G Terrones

August 1995

Prepared for

the U.S. Department of Energy

under Contract DE-AC06-76RLO 1830

Pacific Northwest Laboratory

Richland, Washington 99352 



\section{Abstract}

This report presents the results of the operation of the void fraction instrument (VFI) and ball rheometer in Hanford Tank 241-SY-101, which contains approximately one million gallons of radioactive waste. These instruments provided the first direct assay of the waste condition in the tank after more than a year of mixer pump operation. The two instruments were deployed in the tank in late 1994 and early 1995 to gather much-needed data on the effect prolonged mixer pump operation has on gas retention in the waste. The information supplied by these instruments has filled a great gap in our quantitative knowledge of the waste condition. The results show that the solids are well-mixed by the current mixer pump to within less than a meter of the tank bottom. Undisturbed sludge remains only on the lowest $10-30 \mathrm{~cm}$ and contains $10-12 \%$ void. The mixed slurry above contains less than $1 \%$ void and has no measurable yield strength and a shear-thinning viscosity of approximately 6 Poise at $1 \mathrm{sec}^{-1}$. Estimating the gas volumes in each of the four layers based on VFI data yields a total of $221 \pm 57 \mathrm{~m}^{3}(7,800 \pm 2,000 \mathrm{SCF})$ of gas at 1 atmosphere. Given the current waste level of $10.2 \mathrm{~m}$ ( 400 inches), the degassed waste level would be $9.8 \mathrm{~m}$ (386 inches). These results confirm that the mixer pump in Tank 241-SY-101 has performed the job it was installed to do-thoroughly mix the waste to release stored gas and prevent gas accumulation. 



\section{Summary}

Operation of the void fraction instrument (VFI) and ball rheometer in Tank 241-SY-101 provided the first direct assay of the waste condition in the tank after more than a year of mixer pump operation. While mitigation of flammable gas releases from SY-101 is not in question, we still needed to estimate the amount of gas remaining in the waste, its location, and the effects of mixer pump operation on the waste. The test results therefore add considerably to our knowledge of the long-term effects of mixer pump operation on the waste and provide a reasonably accurate estimate of stored gas volume and location.

The VFI was first deployed in riser 11B in Tank 241-SY-101 on December 21, 1994, and again in riser 4A on January 17, 1995. In both tests the VFI measured zero void fraction down to about one meter from the bottom, where the void fraction increased rapidly to 8-12\% within about $60 \mathrm{~cm}$ of the bottom. The VFI data are consistent with the waste configuration inferred from temperature profiles. The highest void fractions below $61 \mathrm{~cm}$ ( 2 feet) represent the undisturbed sludge, while the $1-5 \%$ void fractions up to $1.2 \mathrm{~m}$ ( $4 \mathrm{feet}$ ) are consistent with the loosely settled layer from the temperature profiles.

The ball rheometer was deployed in the same two risers (11B and 4A) in Tank 241-SY101 as the VFI three months later. The ball was lowered through riser 4A March 27, 1995, and through riser 11B on April 5. The measured drag on the ball was minimal until it began increasing over about the last $60 \mathrm{~cm}$ ( 24 in.) of travel. The ball came to rest at $1018 \mathrm{~cm}$ (400.8 in.) below the waste surface. In the next test one week later, there was minimal drag on the ball until it reached about $30 \mathrm{~cm}$ (12 in.) from where it became supported about $79 \mathrm{~cm}(31$ in.) above the tank bottom.

The data and observations from the VFI and the ball rheometer lead to the following general conclusions about the current character of the waste in 241-SY-101:

- The solids are well-mixed by the current mixer pump, as evidenced by the nearly uniform temperature, void fraction, and viscosity from just below the crust to within less than a meter of the tank bottom.

- The density profile indicates that heavier solids settle out of the slurry into a layer $\sim 50 \mathrm{~cm}$ thick within 3-4 days following a pump run. This loosely settled layer has a small yield strength $(\sim 25 \mathrm{~Pa})$ and a viscosity of 200 Poise, and it exhibits shear thickening behavior.

- The mixed slurry has no measurable yield strength $(<\sim 2 \mathrm{~Pa})$ and a shear-thinning viscosity of about 6 Poise (measured at $1 \mathrm{sec}^{-1}$ ).

- The mixed slurry contains less than $1 \%$ void. The lowest 30 to $40 \mathrm{~cm}$ of has $10-12 \%$ void, and the one-meter of loosely settled layer above averages $2.5 \%$ void.

- There is relatively little undisturbed sludge left on the tank bottom. The data from riser 11B indicated a sludge depth of less than one meter while riser $4 \mathrm{~A}$ and temperature profiles from $17 \mathrm{~B}$ and $17 \mathrm{C}$ indicate only a few centimeters of sludge. 
- The total gas volume in the tank estimated from VFI data is $221 \pm 57 \mathrm{~m}^{3}(7,800 \pm$ $2,000 \mathrm{SCF}$ ) of gas at 1 atmosphere. Given the current waste level of $10.2 \mathrm{~m}$ (400 inches), the degassed waste level would be $9.8 \mathrm{~m}$ (386 inches).

These results confirm that the mixer pump in Tank 241-SY-101 has performed the job it was installed to do-thoroughly mix the waste to release stored gas and prevent future gas accumulation. Uncertainty is still large due to the limited number of measurements, but the information supplied by the VFI and ball rheometer has filled a great gap in our quantitative knowledge of the waste condition. The success of their respective deployment campaigns gives us confidence that we will also obtain valuable data from the next tanks scheduled for inspection. 


\section{Contents}

Abstract $\ldots \ldots \ldots \ldots \ldots \ldots \ldots \ldots \ldots \ldots \ldots \ldots \ldots \ldots \ldots \ldots \ldots \ldots$

Summary $\ldots \ldots \ldots \ldots \ldots \ldots \ldots \ldots \ldots \ldots \ldots \ldots \ldots \ldots \ldots \ldots \ldots$

1.0 Introduction $\ldots \ldots \ldots \ldots \ldots \ldots \ldots \ldots \ldots \ldots \ldots \ldots \ldots \ldots \ldots \ldots$

1.1 Mitigation of Tank $241-S Y-101$ by Mixing $\ldots \ldots \ldots \ldots \ldots \ldots \ldots$

1.2 Summary of Mixer Pump Testing $\ldots \ldots \ldots \ldots \ldots \ldots \ldots \ldots$

1.3 Principles of Operation $\ldots \ldots \ldots \ldots \ldots \ldots \ldots \ldots \ldots \ldots \ldots$

1.3.1 Ball Rheometer Operation $\ldots \ldots \ldots \ldots \ldots \ldots \ldots \ldots \ldots \ldots$

1.3.2 Void Fraction Instrument Operation $\ldots \ldots \ldots \ldots \ldots \ldots \ldots$

1.4 Summary of the Instrument Development Program $\ldots \ldots \ldots \ldots \ldots \ldots$

1.4.1 Ball Rheometer Development and Testing $\ldots \ldots \ldots \ldots \ldots$

1.4.2 Void Fraction Instrument Development $\ldots \ldots \ldots \ldots \ldots \ldots$

2.0 Summary of Results $\ldots \ldots \ldots \ldots \ldots \ldots \ldots \ldots \ldots \ldots \ldots \ldots \ldots \ldots \ldots$

2.1 Pre-Test Waste Condition $\ldots \ldots \ldots \ldots \ldots \ldots \ldots \ldots \ldots \ldots \ldots \ldots \ldots \ldots$

2.2 Data from the Void Fraction Instrument $\ldots \ldots \ldots \ldots \ldots \ldots \ldots$

2.3 Results of the Ball Rheometer Tests $\ldots \ldots \ldots \ldots \ldots \ldots \ldots$

2.4 Overall Interpretation of Results $\ldots \ldots \ldots \ldots \ldots \ldots \ldots \ldots \ldots \ldots$

3.0 Rheological Properties $\ldots \ldots \ldots \ldots \ldots \ldots \ldots \ldots \ldots \ldots \ldots \ldots \ldots \ldots \ldots$

3.1 System Description $\ldots \ldots \ldots \ldots \ldots \ldots \ldots \ldots \ldots \ldots \ldots \ldots \ldots \ldots$

3.2 Testing Procedure $\ldots \ldots \ldots \ldots \ldots \ldots \ldots \ldots \ldots \ldots \ldots \ldots$

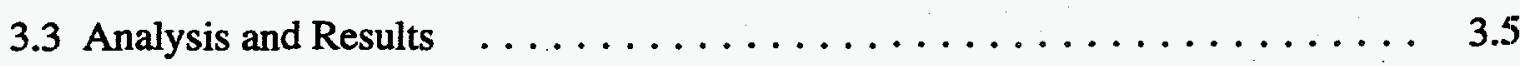

3.3.1 Data Reduction $\ldots \ldots \ldots \ldots \ldots \ldots \ldots \ldots \ldots \ldots \ldots \ldots$

3.3.2 Rheology of the Mixed Fluid Region $\ldots \ldots \ldots \ldots \ldots \ldots$

3.3.3 Rheology of the Settled Sludge Region . . . . . . . . . . . . 3.13

3.3.4 Density $\ldots \ldots \ldots \ldots \ldots \ldots \ldots \ldots \ldots \ldots \ldots \ldots \ldots \ldots . \ldots \ldots$ 


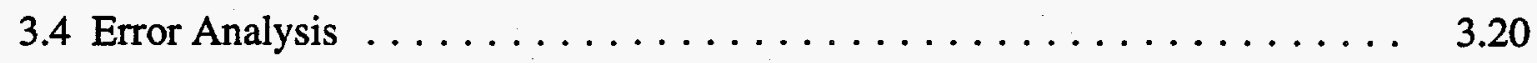

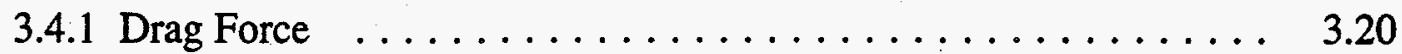

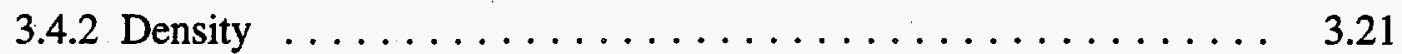

4.0 Void Fraction $\ldots \ldots \ldots \ldots \ldots \ldots \ldots \ldots \ldots \ldots \ldots \ldots \ldots \ldots \ldots \ldots \ldots \ldots \ldots \ldots \ldots$

4.1 Description Of Void Fraction Instrument $\ldots \ldots \ldots \ldots \ldots \ldots \ldots \ldots .1$

4.1.1 Pressurizing Chamber and Connecting Line $\ldots \ldots \ldots \ldots \ldots .4 .1$

4.1.2 Sample Chamber $\ldots \ldots \ldots \ldots \ldots \ldots \ldots \ldots \ldots \ldots .4 .4$

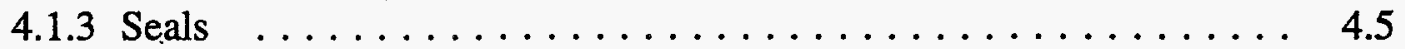

4.1.4 Deployment of the VFI $\ldots \ldots \ldots \ldots \ldots \ldots \ldots \ldots \ldots$

4.2. Calculation of the Void Fraction $\ldots \ldots \ldots \ldots \ldots \ldots \ldots \ldots \ldots .8$

4.2.1 Analytic Model Formulation $\ldots \ldots \ldots \ldots \ldots \ldots \ldots \ldots \ldots .8$

4.2.2 System Uncertainty Analysis $\ldots \ldots \ldots \ldots \ldots \ldots \ldots \ldots$

4.2 .3 Overall Sampling Uncertainty $\ldots \ldots \ldots \ldots \ldots \ldots \ldots \ldots .13$

4.3 VFI Data from Tank $241-S Y-101 \ldots \ldots \ldots \ldots \ldots \ldots \ldots \ldots \ldots$

5.0 References $\ldots \ldots \ldots \ldots \ldots \ldots \ldots \ldots \ldots \ldots \ldots \ldots \ldots \ldots \ldots \ldots .6 .1$

Appendix A: Ball Rheometer Tests $\ldots \ldots \ldots \ldots \ldots \ldots \ldots \ldots \ldots \ldots \ldots \ldots \ldots \ldots \ldots$ A.1

Appendix B: Selected Raw Data from Void Fraction Instrument $\ldots \ldots \ldots \ldots \ldots \ldots$ B.1

Appendix C: Determination of VFI System Volumes ............... C.1

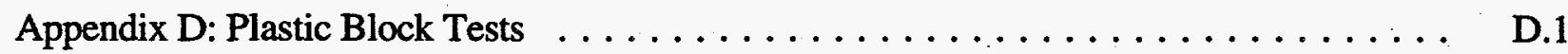

Appendix E: System Error Analysis $\ldots \ldots \ldots \ldots \ldots \ldots \ldots \ldots \ldots \ldots \ldots \ldots$ E.1 


\section{Figures}

2.1 Tank $241-S Y-101$ Plan View $\ldots \ldots \ldots \ldots \ldots \ldots \ldots \ldots \ldots \ldots \ldots \ldots \ldots \ldots \ldots \ldots \ldots \ldots .2$

2.2 Temperature Profiles from the $17 \mathrm{C}$ MIT Validation Probe $\ldots \ldots \ldots \ldots \ldots \ldots .2$

2.3 Temperature Profiles from the 17B MIT Validation Probe $\ldots \ldots \ldots \ldots \ldots \ldots .2 .3$

2.4 Void Fraction Measurements $\ldots \ldots \ldots \ldots \ldots \ldots \ldots \ldots \ldots \ldots \ldots \ldots \ldots \ldots \ldots$

2.5 Apparent Viscosity of $241-$ SY-101 Mixed Slurry $\ldots \ldots \ldots \ldots \ldots \ldots \ldots \ldots \ldots$

2.6 Yield Stress of the Loosely Settled Layer in $241-S Y-101 \ldots \ldots \ldots \ldots \ldots \ldots \ldots$

2.7 Rheogram of the Loosely Settled Layer in $241-S Y-101 \ldots \ldots \ldots \ldots \ldots \ldots \ldots$

2.8 Density Profiles from the Ball Rheometer $\ldots \ldots \ldots \ldots \ldots \ldots \ldots \ldots \ldots \ldots$

3.1 Ball Rheometer System $\ldots \ldots \ldots \ldots \ldots \ldots \ldots \ldots \ldots \ldots \ldots \ldots \ldots \ldots \ldots \ldots \ldots \ldots .2$

3.2 Cable Tension as Ball Passes the Liquid Level $\ldots \ldots \ldots \ldots \ldots \ldots \ldots \ldots \ldots .4$

3.3 Tension Measurements for Downward and Upward Ball/Cable Motion $\ldots \ldots \ldots \ldots$

3.4 Combined Ball and Cable Drag Force Versus Elevation $\ldots \ldots \ldots \ldots \ldots \ldots \ldots . .8$

3.5 Shear Stress Variation in the Mixed Fluid Region $\ldots \ldots \ldots \ldots \ldots \ldots \ldots \ldots$

3.6 Velocity Field Induced by a Cable Moving Along Its Axis $\ldots \ldots \ldots \ldots \ldots \ldots$

3.7 Region of Apparent Viscosities as a Function of Strain Rate $\ldots \ldots \ldots \ldots \ldots \ldots .13$

3.8 Combined Ball and Cable Drag Force in the Settled Region $\ldots \ldots \ldots \ldots \ldots \ldots$

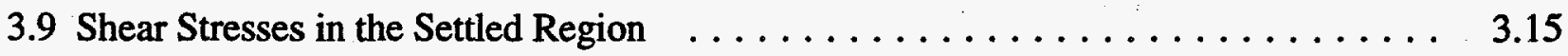

3.10 Parameters $\mathrm{K}$ and $\mathrm{N}$ Versus Elevation in the Settled Region $\ldots \ldots \ldots \ldots \ldots .17$

3.11 Yield Stress Versus Elevation in the Settled Region $\ldots \ldots \ldots \ldots \ldots \ldots \ldots$

3.12 Static Density Versus Elevation $\ldots \ldots \ldots \ldots \ldots \ldots \ldots \ldots \ldots \ldots \ldots . \ldots \ldots$

3.13 Density by the Dynamic Method Versus Elevation $\ldots \ldots \ldots \ldots \ldots \ldots \ldots$

4.1 Void Fraction Instrument Deployed in a Tank $\ldots \ldots \ldots \ldots \ldots \ldots \ldots \ldots . \ldots \ldots$

4.2 Void Fraction Instrument Rotating Arm Components $\ldots \ldots \ldots \ldots \ldots \ldots \ldots . . \ldots$

4.3 Void Fraction Instrument Sample Chamber $\ldots \ldots \ldots \ldots \ldots \ldots \ldots \ldots \ldots . \ldots \ldots$ 


\section{Tables}

2.1 Waste Layering in Tank $241-\mathrm{SY}-101 \ldots \ldots \ldots \ldots \ldots \ldots \ldots \ldots \ldots \ldots \ldots \ldots \ldots$

2.2 Sludge Depth Data from MITs, VFI, and Ball Rheometer $\ldots \ldots \ldots \ldots \ldots \ldots$

2.3 Volume of Gas Stored in Waste Layers $\ldots \ldots \ldots \ldots \ldots \ldots \ldots \ldots \ldots \ldots$

3.1 Power Law Coefficients That Correspond to the Viscosity Curves in Figure $3.8 \quad \ldots \quad 3.13$

4.1 Void Fraction Parameter Error Estimates $\ldots \ldots \ldots \ldots \ldots \ldots \ldots \ldots \ldots . \ldots \ldots$

4.2 Estimate of Error Contributions for System Parameters . . . . . . . . . . 4.12

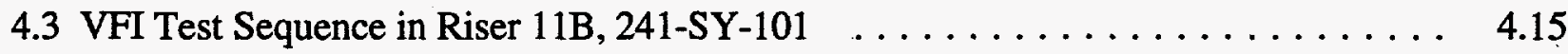

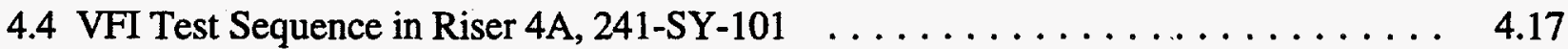

4.5 Temperatures and Pressures Used to Calculate Void Fraction, Riser 11B $\ldots \ldots \ldots . \quad 4.20$

4.6 Temperatures and Pressures Used to Calculate Void Fraction, Riser 4A . . . . . 4.22 


\subsection{Introduction}

Since 1943, large underground concrete storage tanks (currently numbering 177) have been used at Hanford to store byproducts of plutonium production. The tanks are steel-lined, up to

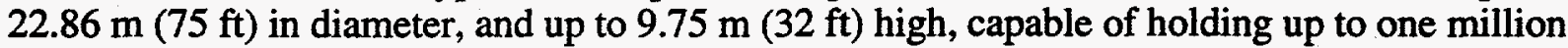
gallons of waste. The waste in these tanks is chemically complex and ranges from mostly liquid to thick, sticky sludge and crystalline salt cake. Twenty-five of these tanks are currently on the Flammable Gas Watch List (FGWL) because the waste in them is either known or suspected to be generating, storing, and periodically releasing flammable gases.

While awaiting retrieval and ultimate disposition, each FGWL tank must be maintained in a safe condition. The accumulation of flammable gases in the waste must be controlled so that potentially hazardous episodic releases of large volumes of gas are prevented. The actions to accomplish this (if any are required) constitute mitigation as it pertains to the flammable gas safety issue.

Criteria have been proposed for Hanford FGWL tanks that potentially require mitigation (Hopkins 1994; Johnson 1995). Listed tanks either exhibit periodic gas releases in which the flammable gas concentration in the dome space exceeds one-fourth of the lower flammability limit (LFL) or contain a volume of gas that could cause concentrations to exceed the LFL if released.

The void fraction instrument (VFI) and the ball rheometer are designed specifically to assay the gas content and rheology of the waste and to provide data to estimate potential gas releases. The VFI measures the amount and location of undissolved gas bubbles trapped in the waste. The ball rheometer provides the yield stress, viscosity and density as a function of depth. This knowledge allows us to estimate the amounts of gas stored in the waste, the distribution of the gas in the waste, the capability of the waste to retain gas, and the expected release rate of gas in the event of a rollover. These data provide much of the information that is needed to perform a safety assessment and to decide whether a tank requires mitigation.

The two instruments were deployed in Tank 241-SY-101 in late 1994 and early 1995 to gather much-needed data on the effect prolonged mixer pump operation has on gas retention in the waste. This report presents the results of this testing.

\subsection{Mitigation of Tank 241-SY-101 by Mixing}

Flammable gas mitigation efforts were first focused on Tank 241-SY-101 because that tank was releasing large quantities of hydrogen, nitrous oxide, ammonia, and other gases during and after the gas release events (GREs) that had been occurring every 100 to 150 days since about 1981 (Antoniak 1993). Vapor space samples, crust samples, and full-depth core samples were obtained and analyzed. The tank monitoring system was upgraded with the installation of a video camera, radar surface-level gauge, and additional gas-monitoring equipment. 
Core samples taken in mid-1991 showed that the waste in Tank 241-SY-101 was stratified in layers that were distinct in composition and rheology. The layers nominally consisted of a 102$\mathrm{cm}$ (40-in.) "crust" floating on about $4.1 \mathrm{~m}$ (160 in.) of liquid with a 5.1-m (200-in.) layer of settled solid material, or sludge, on the bottom (Babad et al. 1992; Stewart et al. 1994). Based on the vertical temperature profiles, the liquid has been termed the "convective" layer, because a uniform temperature profile indicated that the layer is free to circulate in response to natural convection, while the solid, sludge layer at the bottom, which exhibited a parabolic temperature profile, is called the "nonconvective" layer. The large, nearly isothermal liquid layer had a relatively low solids content, while the bottom layer contained large quantities of settled solids. The relatively thin crust layer (about one meter thick) provided thermal insulation from the dome space ventilation system as evidenced by a nearly linear temperature profile.

Video recordings in Tank 241-SY-101 showed that the episodic GREs were accompanied by extensive and violent disruption of the waste surface, suggesting that these gas releases involved large-scale movement of waste from the lower layers, or "rollovers." The thickness of the sludge layer and the amount of solids suspended in the convective layer varied depending on the size and origin of the last GRE.

The GRE sequence in Tank 241-SY-101 and similar waste tanks derives from the retention of gas in the cohesive sludge (Babad et al. 1992; Allemann 1993). The local density decreases as gas is generated, and the sludge eventually becomes buoyant with respect to the liquid above it. When the buoyancy of the gas-retaining mass exceeds the cohesive forces, a portion of the sludge breaks loose. The buoyant sludge rises quickly through the convective layer and breaks through the crust to the waste surface, where the bulk of the gas is released immediately. The remaining gas continues to evolve at a relatively slow rate until the gas content is insufficient for buoyancy. The sludge then begins to sink, and the remaining gas is recompressed as the hydrostatic head increases.

Without intervention, the cycle of gas retention and release would continue indefinitely. The aim of all the mitigation concepts is to destroy the ability of the waste to retain gas so that it is released at the same rate as it is generated, eliminating large GREs.

A spare $112 \mathrm{~kW}(150-\mathrm{hp})$ mixing pump from the Hanford Grout Program was installed just west of the centerline in Tank 241-SY-101 on July 3, 1993, and is still operating. It pulls in liquid from the 6.6-m (260-in.) level and injects it as a high-speed jet through two opposing 6.6$\mathrm{cm}$ (2.6-in.) nozzles about $61 \mathrm{~cm}(2 \mathrm{ft})$ from the tank bottom. Operating less than two hours per week, the mixer pump has homogenized the original convective and nonconvective layers to a great extent, as evidenced by a nearly isothermal temperature profile extending through much of the waste's depth. Also, since December 1993 the waste surface level has remained essentially constant, indicating that gas is no longer accumulating in the sludge.

The results of mixer pump operation in Tank 241-SY-101 since July 1993 have been extensively documented (Allemann et al. 1994; Stewart et al. 1994). The following sections summarize the two major testing campaigns and the sludge excavation period that followed as an introduction to the waste condition into which the VFI and ball rheometer were deployed. The principles of operation of these two devices and their development histories are then briefly described. 


\subsection{Summary of Mixer Pump Testing}

High-speed mixer pump testing began October 21, 1993, with the objective of proving that mixing would mitigate the tank. Initial mixing of the sludge layer released a large volume of retained gas over the first few weeks of testing and reduced the waste level to a historic low of $1016 \mathrm{~cm}$ (400 in.). By early December the pump jets had apparently mixed most of the gasbearing sludge, and there were no large gas releases for the balance of the test period that ended December 17, 1993. The uniform vertical temperature profiles shown at two in-tank thermocouple trees showed that the waste was mixed well except for approximately $130 \mathrm{~cm}$ (50 in.) of sludge at the bottom and the crust layer on top.

The Full-Scale test program was run from February 4 to April 13, 1994, to confirm the long-term operational strategy for mitigation and to show that the mixer pump could control the gas release and waste level. Four test periods were conducted. From February 4-25 the pump was run one hour at $750 \mathrm{rpm}$ three days per week, incrementing the nozzle azimuth 30 degrees before each run to represent nominal long-term operation. From February 28-March 25, minimal operations were run to investigate how rapidly the waste level would grow if the pump were not run. On March 28 and 30, full tank sweeps at $750 \mathrm{rpm}$ were run to release gas and reduce the waste level as quickly as possible. Finally, on April 4, 6, 12, and 13 the jet penetration test series explored the ability of the pump to cause flow near the tank wall. The pump was run for 40 minutes at $920 \mathrm{rpm}$ or 25 minutes at $1000 \mathrm{rpm}$ with the nozzles in line with a thermocouple tree to assess the effects of the jet. The thermocouple response clearly indicated that these four runs reduced the sludge depth to less than $41 \mathrm{~cm}$ (16 in.) in these specific sections of the tank.

Even though the tank was considered mitigated after high-speed testing (Allemann et al. 1994), an average of about $130 \mathrm{~cm}$ (50 in.) remained after Full-Scale testing in April 1994 (Stewart et al. 1994). It was thought that this layer might hold a large volume of gas that could be released suddenly. The potential consequences of a conservatively large release were included in the Mixer Pump Safety Assessment (Sullivan 1995). As a result, the operating limits for the mixer pump became much more restrictive. Because of the success of the jet penetration test at reducing sludge depth in a single direction, a campaign of aggressive mixing was begun to 'excavate' the sludge more uniformly over the entire tank. Twenty excavation runs were performed from June through August 1994, mainly in three azimuths, with as many as six sequential runs in a single direction.

In September 1994, the Test Review Group (TRG) became concerned that excavating in a single direction was not mixing the other regions of the tank sufficiently. Accordingly, the TRG decided that the 'nominal' pump operation should be a 25 -minute, 1000 rpm excavation, and three excavations should be run each week with the nozzle azimuth incremented 30 degrees each time. As of April 1995, over 100 of these excavation runs have been performed, about evenly divided among the six nominal azimuths.

This campaign has been effective not only at keeping the tank thoroughly mixed but also at reducing the volume of undisturbed sludge and thereby the total volume of flammable gas still stored in the waste. The primary indications of the progress of excavation have been the waste 
temperature profiles and response to pump runs. But this could only show the approximate depth of the nonconvective material, not its gas content. The VFI and ball rheometer were built to supply this information.

They have already proven their value in SY-101. The initial tests of the VFI (confirmed later by the ball rheometer) indicated that a considerable amount of sludge potentially remained between the normal nozzle orientations. Consequently, the TRG directed that the pump azimuths be shifted 15 degrees. This change in operation was made May 12, 1995, and the increase in the amount of gas released in each pump run showed that the jet was penetrating 'fresh' sludge. Gas releases returned to prior values after the first tank sweep using the shifted azimuths, indicating that most of the sludge in the scallops had been excavated. The following sections describe how these instruments function and summarize their development histories.

\subsection{Principles of Operation}

The principles of operation of the ball rheometer and VFI are discussed in detail in Sections 3 and 4, respectively. This section gives a brief summary of how each device is used as a basis for discussing the development history; overall results are in Section 2.

\subsubsection{Ball Rheometer Operation}

The ball rheometer is based upon classical "falling ball rheometry," where the time it takes a ball-shaped object to fall through the fluid a known distance is related to the fluid's rheology. The ball rheometer raises or lowers a dense ball of $9.1 \mathrm{~cm}$ (3.6-in.) outer diameter (OD) and weighing $71 \mathrm{~N}(16 \mathrm{lb})$ through the waste on a tether, recording load, position, and velocity of the ball as raw test data. Besides being necessary to retrieve the ball, the tether allows many different ball velocities to be used, providing data over a much wider range than would be possible under gravity alone. Also, measuring the load while the ball is stationary provides a very accurate density measurement in fluids with negligible strength.

The tank waste sludges and slurries are generally non-Newtonian in that they possess a yield strength and their shear stress does not increase linearly with shear rate. Many different models have been proposed to predict the various kinds of non-Newtonian behavior. Finding the proper fluid model for relating shear stress to strain rate and fitting it to the actual load on the ball over a range of velocities may be more challenging than obtaining the initial load-versus-velocity data.

Pulling/lowering the ball at different speeds provides data that can be used to develop nonsingular simultaneous fluid equations, from which a basic non-Newtonian fluid model can be derived. Mathematical modeling, lab testing, and iterative methods are essential to ball rheometer data reduction. The intricacies of ball rheometry as applied to waste Tank 241-SY-101 and similar tanks are summarized in Section 3 and discussed by Shepard et al. (1995) in more detail.

The data available, in addition to a fluid model (relates shear stress to shear rate), are fluid density and general information on tank layering and waste condition. These data, with the gas 
content obtained from the VFI, can be used to determine how the tank waste traps gas, how much can be trapped, and where it is trapped. The rheology data will also be helpful in pump sizing and nozzle design required to mobilize tank wastes for future retrieval programs.

\subsubsection{Void Fraction Instrument Operation}

The VFI measures the fraction of the volume of a sample that is occupied by free gas as opposed to dissolved or absorbed gas. It performs this measurement by capturing a waste sample in a gas-tight chamber and compressing it with nitrogen gas. The ideal gas law gives the free gas fraction in the original sample based on precisely measured initial and final pressures and temperatures of the system. Errors associated with non-ideal gas behavior and solubility effects are minimized by using a sufficiently high pressure.

The void measuring system consists of three known volumes: 1) a gas source volume initially charged with nitrogen up to $3.45 \mathrm{MPa}(500 \mathrm{psia})$, 2) the volume of the line connecting the source volume with the sample chamber, and 3) the sample chamber of known size and optimal geometry to capture a waste sample mounted on a moveable arm. Each of these volumes was established precisely in WHC's 306E laboratory, including the effects of vessel expansion under pressure. Pressures and temperatures are measured directly in the source volume and at several locations in the $18.3-\mathrm{m}(60-\mathrm{ft})$ connecting line. The temperature of the waste in the sample

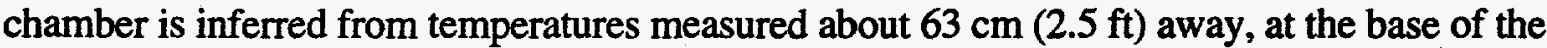
rotating arm.

During testing, the sample chamber is lowered to the first measurement location and allowed to come to thermal equilibrium, then closed to capture a sample; and the waste is compressed by opening a valve in the line from the source volume. While equilibrium is achieved and slightly thereafter, as evidenced by a constant source and line pressure, all temperatures and pressures are recorded, and the void fraction is calculated. Then the sample chamber is opened and moved to the next measurement location. Lowering the chamber with the cover open replaces the previous sample with fresh waste.

Unlike the ball rheometer, the VFI provides its intended void measurements in real time without requiring extensive data reduction effort after the test. However, the pressurization history must be inspected for various anomalies. For example, the sample chamber may have leaked due to grit under the O-ring seals or a portion of a previous waste sample may have adhered to the chamber to contaminate the next reading.

\subsection{Summary of the Instrument Development Program}

The VFI and ball rheometer were identified late in FY 1993 as instruments that could be used 1) to prove SY-101 was indeed in a mitigated condition and 2) to determine which of several tanks on the FGWL might require mitigation. Mitigation by mixer pump operation was assumed required for planning purposes, but the high projected cost made it imperative to determine which tanks really needed such equipment. Accordingly, the VFI and ball rheometer projects were initiated in October 1993. 
The projects teamed key contributors from Westinghouse Hanford Company (WHC), Pacific Northwest Laboratory (PNL)(a) and Los Alamos National Laboratory (LANL) to install and operate full-scale devices in Tank 241-SY-101 in one year. WHC led the overall project; LANL staff prepared the formal safety assessment (Sullivan 1995) and assisted with the technology development and application of technology to these two instruments. PNL staff led prototype testing, assisted in the technology development and application, wrote the test plans, and have performed all data reduction from the field testing.

The true scope of these developmental projects was larger than was initially thought. About 90 mechanical drawings and 70 electrical drawings were ultimately required to adequately detail the ball rheometer assembly and its control console and the VFI assembly with all its upper pneumatic systems. This was about twice the initial estimate. For example, two electric motors coupled by a double input worm gear box and clutches were deemed necessary to cover the speed ranges required for the ball rheometer. Also, the safety bases being developed in parallel with the equipment comprised well over 100 pages and created several iterations in design thought process during the course of the project. Nevertheless, the development team persevered, and both devices met the original aggressive 12-month schedule.

The ball rheometer project plan was issued in October 1993, and the project was fully under way in November of that year. It was bolted to Tank 241-SY-101's riser 4A in August 1994 and was first operated in September 1994, although problems with the water lance delayed actual testing in waste until March 1995. The project plan for the VFI was issued in December 1993 and was fully resource-loaded by early February 1994. It was shipped to the SY-101 tank farm in November 1994 and tested in riser 11B on December 19, 1994.

\subsubsection{Ball Rheometer Development and Testing}

Early discussions at LANL and PNL of how to best obtain rheological information identified a falling ball concept as the front-runner for in situ application. Several modes of ball operation were desired in the beginning: constant velocity, tension, density, and calibration. Constant tension proved too challenging to complete given the aggressive schedule and unknown tank waste drag data. The computer was unable to feed back quickly enough to control constant tension.

The ball rheometer system was designed to measure the properties of sludge typical of the nonconvective layer in Tank 241-SY-101 prior to mixing. The Ball Rheometer System Design Description, WHC-SD-WM-SDD-043, discusses in detail all design information and references all other design documents pertaining to the ball rheometer. A 71-N (16-lb) tungsten alloy ball was selected for the maximum-density material compatible with the waste. The ball was tethered with a polypropylene-coated steel cable for easy decontamination. The cable take-up spool was designed for one wrap of cable to ensure constant velocity and positional accuracy.

(a) Pacific Northwest Laboratory is operated by Battelle Memorial Institute for the U.S. Department of Energy under Contract DE-AC06-76RLO 1830. 
Acceptance testing of the ball rheometer in the WHC $306 \mathrm{E}$ facility concluded successfully in August 1994. The ball rheometer was bolted to riser 4A on SY-101 in August 1994 and was first operated in September 1994. The first test showed the ball passed through the riser with no interference, and the cable hung in the center of the riser after the ball entered the dome space. However, the ball would not penetrate the waste crust. Several attempts were made, with field approval, to repeatedly raise/lower the ball while adding water in an attempt to erode a hole through the crust. But only about $19-\mathrm{cm}(7.5$-in.) penetration was achieved.

The ball rheometer was then removed, and a hole was water-lanced through the crust. After water lancing, the required 400 to $700 \mathrm{scfm}$ tank ventilation flow required by the safety basis could not be achieved or maintained long enough to perform testing because bad weather and high humidity restricted flow through the HEPA filters. Ten days after lancing, weather permitted a test with the ball rheometer, but the ball still could not penetrate the crust. It was believed that the crust had re-crystallized or the lance did not create a large enough hole.

The ventilation HEPA filters were changed in early December, eliminating further delays due to low ventilation flow rate. But the ball rheometer could not be tested until modifications to the water lance were completed. The water lance was fitted with a special fixture to ensure that it opened at least a 9.1-cm (3.6-in.) inner-diameter (ID) hole through the tank crust. Riser impact protection was added to the lance to address a safety concern. All lance modifications had to be done in the field, because the lance was contaminated. On March 20,1994, the lance was run successfully during the day shift. Ball rheometer tests started about $9 \mathrm{pm}$ that night and were conducted around the clock until 8 am March 21.

\subsubsection{Void Fraction Instrument Development}

Initial investigations indicated a compressibility technique was the simplest and quickest way to get direct in situ void measurement. Compressing the waste with a moving mechanical piston was deemed too complex and unreliable, and liquid injection was discarded because it would alter the waste volume by dissolving some of the solids and releasing dissolved gas. Pressurizing with nitrogen gas was finally selected.

To investigate feasibility, a scale model of the concept was built and tested at PNL. Stainless-on-stainless galling was a problem in the early PNL tests, which guided WHC to hard chrome-plate sliding surfaces. The scale model helped to refine optimal volumes and thermodynamic equilibration times and to identify general hardware problems. Questions were raised about potential errors due to non-ideal gas behavior and dissolution of ammonia with increasing pressure. It was finally proved that compressing the gas in the sample to a sufficiently small volume virtually eliminated the effect of these errors.

One question was apparent to all members of the team: how does insertion of the VFI affect local gas concentration? The disturbance of inserting the VFI could cause some of the gas to escape, thus reducing the amount measured. LANL performed tests with neutrally buoyant particles of various sizes and concluded that the amount of gas captured by the sample chamber was within $0.5 \%$ absolute void of the undisturbed material. 
During acceptance testing of the VFI in the WHC 306E facility, one of the many challenges faced was keeping the O-ring seals in place while the sample chamber opened under pressure. High-speed video equipment was brought in to help diagnose the phenomena of "flying O-rings." Vent holes were drilled in the sample chamber cover to prevent $O$-ring loss under worst-case conditions. Final system testing concluding successfully in September 1994.

With the test reports issued and the fabrication packages closed, the equipment was "green tagged" (accepted for plant service by project QA) and shipped to the SY-101 tank farm in November 1994. A comprehensive engineering document, Void Fraction Instrument System Design Description, WHC-SD-WM-SDD-043, was published, discussing in detail all design information and referencing all other design documents pertaining to the VFI.

The VFI was first run in riser 11B in SY-101 on December 21, 1994. Unlike the ball rheometer, the VFI sank easily through the crust layer. The load registered on the crane dynamometer decreased about $890 \mathrm{~N}(200 \mathrm{lb})$ during the VFI's passage through the crust. While nearing the tank floor, the crane crew observed the dynamometer readout again decreasing, eventually indicating that the sludge was supporting about one third of the $6.23-\mathrm{kN}(1400-\mathrm{lb})$ load of the VFI. At the lowest depth of the second traverse, one measurement failed due to leaking O-rings. Posttest field inspection revealed that the $\mathrm{O}$-rings and sample chamber area were in excellent condition. Since no dents, cuts, or other abrasions were apparent, we concluded that the leaking O-rings were caused by grit stuck in the sealing area.

During these tests, crane dynamometer information was immediately useful to determine crust strength and sludge location and relative strength. The VFI system has been modified accordingly to record dynamometer information at $15 \mathrm{~Hz}$ when the VFI is moving vertically. Also, in future tests, the line pressure and the lower resistant temperature device (RTD) temperature values will be recorded while the VFI is being raised through the waste. 


\subsection{Summary of Results}

Operation of the void fraction instrument (VFI) and ball rheometer in Tank 241-SY-101 provided the first direct assay of the waste condition in the tank after more than a year of mixer pump operation. Without these instruments, only the two thermocouple trees in risers $17 \mathrm{~B}$ and $17 \mathrm{C}$ provided any detailed information about the character of the waste layers and their depth. There was no way to measure the gas content or the rheology of the waste. While mitigation of flammable gas releases from 241-SY-101 is not in question, we still needed to estimate the amount of gas remaining in the waste, its location, and the effects of mixer pump operation on the waste. The test results therefore add considerably to our knowledge of the long-term effects of mixing and allow us to quantify the volume of stored gas more accurately.

This section presents an overall view of the test results as they pertain to tank conditions. We begin by describing what we were able to determine from the thermocouple data prior to ball rheometer and VFI testing. Each testing program is then summarized in turn with the most pertinent results. Finally, all this information is combined to form the final estimates of waste configuration, condition and gas content we have been seeking. Sections 3 and 4 describe the actual performance of each device.

\subsection{Pre-Test Waste Condition}

Except for the crust at the top and a thin layer of sludge on the bottom, the waste into which the VFI and ball rheometer were deployed was well-mixed as a result of more than one year of mixer pump operation, especially the consistent thrice-weekly excavations performed since September 1994. Compared with conditions in unmitigated tanks, the mixed waste in Tank 241SY-101 was expected to have much less gas, very little nonconvective sludge, and, in general, fairly uniform properties from just below the crust almost to the bottom.

These conditions were inferred from temperature profiles and transient thermocouple response to pump operation indicated by the two MITs in risers $17 \mathrm{~B}$ and 17C. These trees are on approximately the 97- and 208-degree pump azimuths, 8.6 and $9.3 \mathrm{~m}$ (28.2 and $30.5 \mathrm{ft}$ ) from the pump, respectively (see Figure 2.1). Thermocouples measure temperatures at 22 locations along the MIT's length extending to within four inches of the tank bottom. A 'validation probe' is also run in each MT occasionally, taking readings every $10.2 \mathrm{~cm}$ (4 in.), beginning $20.4 \mathrm{~cm}$ (8 in.) above the bottom. The lowest four thermocouples, positioned 10.2, 20.4,71.1, and $132.1 \mathrm{~cm}$ $(4,16,28$, and 52 in.) above the tank bottom, respectively, are of most interest. The locations of MITs and other important instruments in the tank are shown in Figure 2.1.

The vertical temperature profiles defined by several of the latest MIT validation probe readings at the MITs in risers $17 \mathrm{C}$ and 17B, shown in Figures 2.2 and 2.3, respectively, reveal four waste layers: a heat-generating nonconvective layer on the bottom evidenced by a parabolic temperature profile, two distinct convective layers with a uniform temperature profile, and a solid 


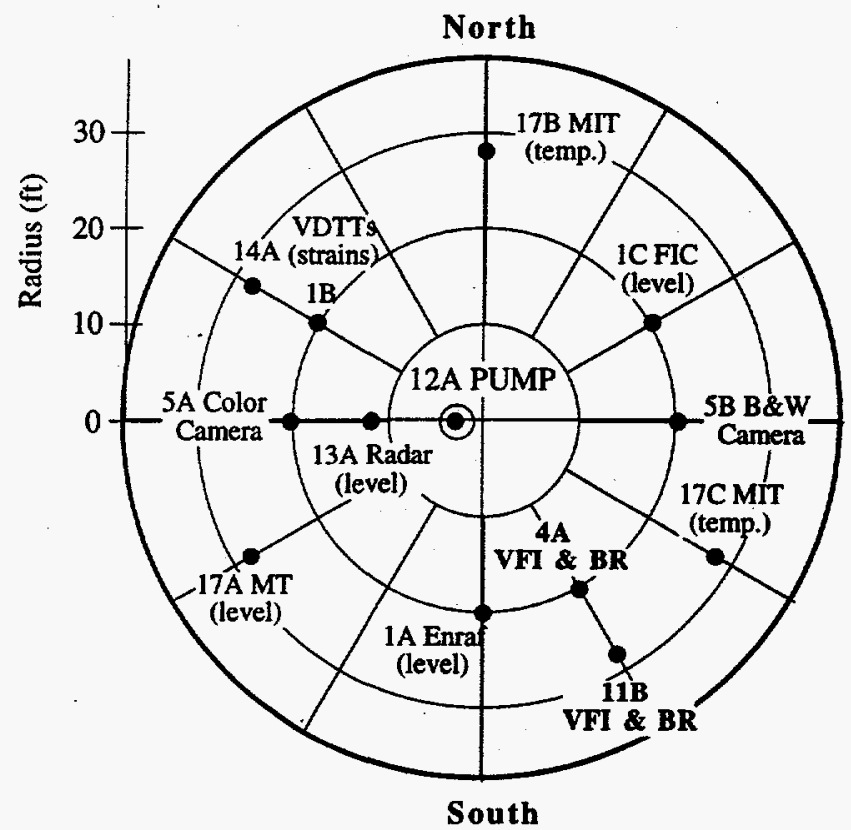

Figure 2.1. Tank 241-SY-101 Plan View

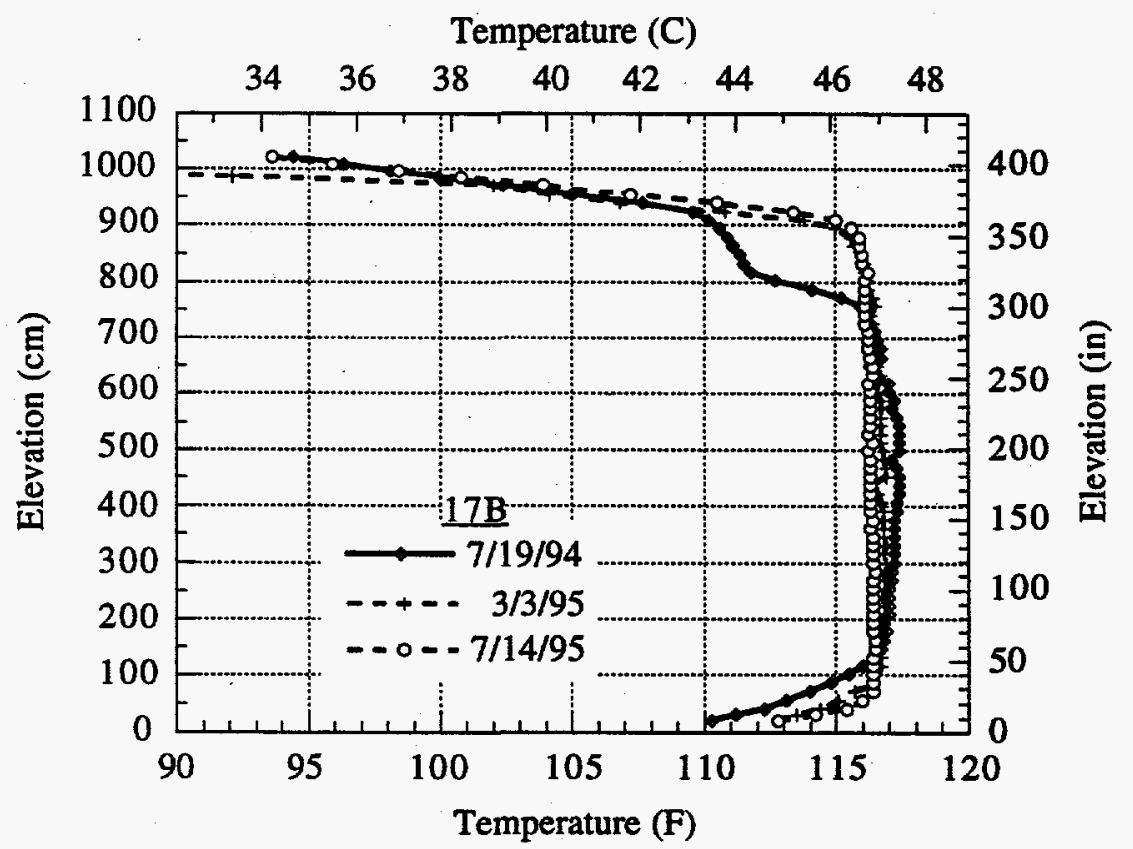

Figure 2.2. Temperature Profile from the $17 \mathrm{C}$ MIT Validation Probe 


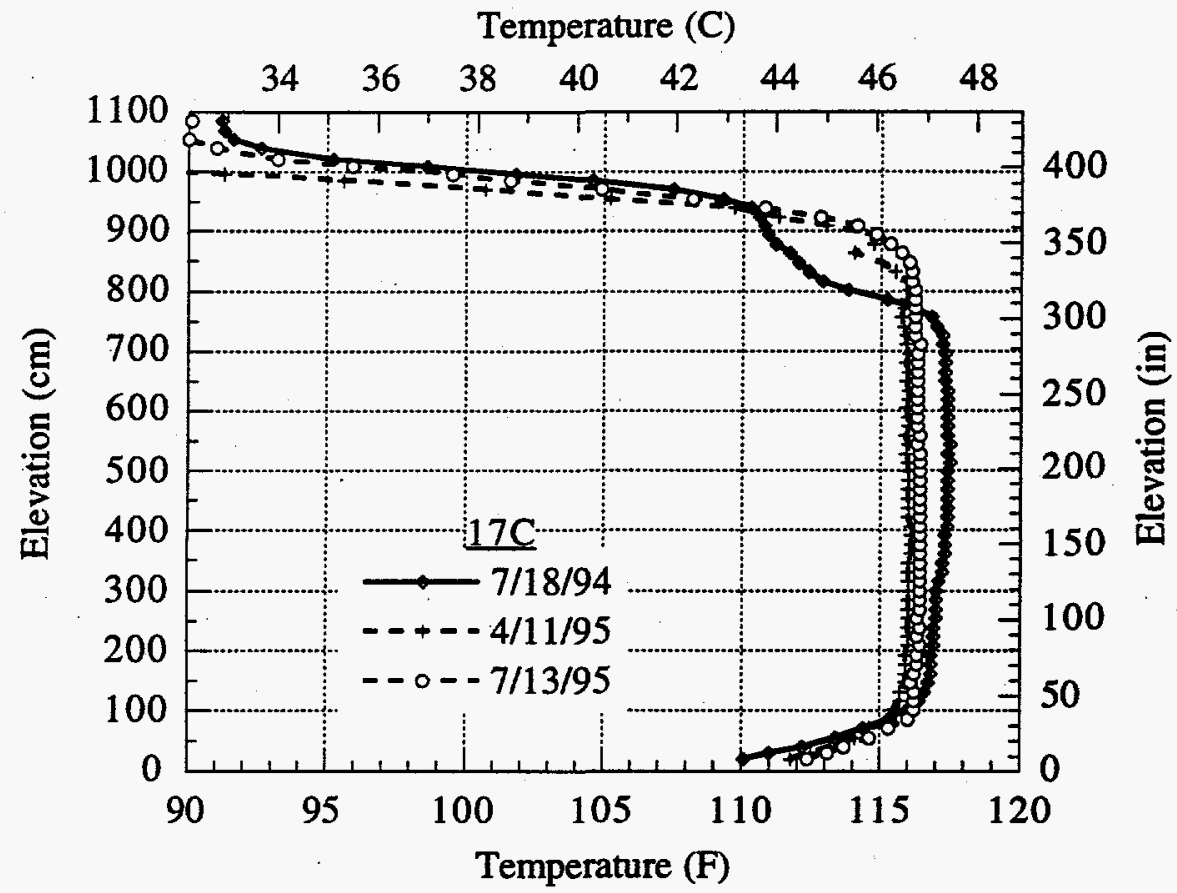

Figure 2.3. Temperature Profiles from the 17B MIT Validation Probe

crust on top with a linear temperature profile. Based on transient response of the temperature profile to the pump jet, the nonconvective layer actually consists of two separate layers of settled solids and sludge. Table 2.1 lists the five layers from top to bottom.

Table 2.1. Waste Layering in Tank 241-SY-101

\begin{tabular}{||c|c|l||}
\hline \multicolumn{1}{|c|}{ Layer } & $\begin{array}{c}\text { Approx. } \\
\text { Thickness } \\
(\mathrm{cm})\end{array}$ & \multicolumn{1}{|c|}{ Character } \\
\hline Crust & 102 & $\begin{array}{l}\text { Porous solids floating on the liquid. Essentially } \\
\text { no physical changes in over 12 months. }\end{array}$ \\
\hline Upper convective & $152-0$ & $\begin{array}{l}\text { Mostly liquid. Forms only during periods of } \\
\text { reduced mixing. }\end{array}$ \\
\hline Mobile slurry & $673-874$ & High fraction of suspended solids. Well mixed. \\
\hline Loosely settled solids & $76-0$ & $\begin{array}{l}\text { Heavier, larger particles that settle out of slurry. } \\
\text { Readily dispersed by jet, non-uniform depth. }\end{array}$ \\
\hline Undisturbed sludge & $13-41$ & Eroding slowly, non-uniform depth. \\
\hline
\end{tabular}


The crust layer has remained almost totally undisturbed and unchanged since early November 1993, when a gas release caused surface motion for the last time.(a) Comparing MIT validation probe temperature profiles from July 1994 through April 1995 in Figures 2.2 and 2.3 show that its thickness of $102 \pm 10 \mathrm{~cm}(40 \pm 4 \mathrm{in}$.) at $17 \mathrm{~B}$ and $76 \pm 10 \mathrm{~cm}(30 \pm 4 \mathrm{in}$.) at $17 \mathrm{C}$ has not changed measurably.

Below the crust, an upper convective layer forms as solids settle out during periods of reduced mixing. Aggressive pumping eliminates this layer by mixing it with the slurry below. This predominantly liquid layer is visible in the July 1994 validation probe profiles in Figure 2.3 but not in the later ones after the regular high-speed excavation runs had begun. A similar upper convective layer was also evident following natural rollovers and the larger pump-induced gas releases prior to high- speed testing (Allemann et al. 1994), and during the 'regrowth' phase of Full-Scale testing (Stewart et al. 1994). We did not expect this layer to exist during VFI and ball rheometer deployment.

The most extensive layer is a mobile slurry bearing most of the solid material in a suspension that is maintained by mixing. The temperature profiles for July 1994 in Figures 2.2 and 2.3 show the top of the slurry layer contracted to about $760 \mathrm{~cm}$ (300 in.) after a relatively inactive period, while the later profiles show that regular excavation runs have expanded the slurry all the way to the crust. A fair estimate can be made of the material density in this layer, but we were unable to predict the viscosity or void fraction. However, both were expected to be low since the region is apparently dominated by convection.

The nonconvective, loosely settled layer evidently forms when the larger and/or heavier solid particles settle out of the slurry above within a few days of the last pump run. Its upper boundary can be estimated by the level where the transition from parabolic (nonconvective) to uniform (convective) temperature profile occurs a few days after a pump run. The July and October 1994 validation probe profiles in Figure 2.3 show the boundary between the 100- and 150-cm (40- and 60-in.) levels. The March and April 1995 profiles show a 76-cm (30-in boundary. Although this material is sufficiently dense to suppress convection, a five-minute pump bump resuspends the entire layer even after a month of settling. There is no evidence that the settled material gains any appreciable yield strength.

The elevation of the top of the undisturbed sludge layer is estimated by observing the sudden increase in thermocouple readings during a pump run when a thermocouple is suddenly exposed to hotter fluid as the pump jet disturbs previously settled material. The thermocouple response at the 17B MIT indicates that the top of the undisturbed sludge is less than $40 \mathrm{~cm}(16 \mathrm{in}$.) above the tank bottom and probably less than $15 \mathrm{~cm}(6 \mathrm{in}$.). The thermocouples on the $17 \mathrm{C}$ MIT also show that the bottom sludge is less than $40 \mathrm{~cm}(16 \mathrm{in}$.) deep at that location and probably

(a) Stewart, C.W., Changes In 241-SY-101 Waste Surface Between 12/9/93 And 10/12/94, Letter report PNL-MIT-121494, Pacific Northwest Laboratory, Richland, Washington. 
closer to $20-30 \mathrm{~cm}(8-12 \mathrm{in}$.) at maximum.(a) Although the sludge depth should be least where it is directly in line with the jet, there is evidence that the sludge is not much deeper between angles away from its direct impact. The transient temperature response at $17 \mathrm{~B}$ when the pump is aimed at different azimuths shows that the jet is able to move the waste below $70 \mathrm{~cm}(28 \mathrm{in}$.) over a 60 degree sector following its passage.

These inferences from thermocouple indications give us a qualitative description of the state of the waste. But there remains considerable uncertainty as to the volume of waste that can retain gas and how much gas is actually still stored. Neither can we estimate the properties of the waste (except for density) with the information at hand. The VFI provided vital data on gas content and location, and the ball rheometer actually measured waste physical properties. The results from the two instruments taken together provide a quantitative picture of the effects of mixer pump operation on the waste and a reasonably accurate estimate of stored gas volume and location. The balance of this section summarizes these results and our overall interpretation.

\subsection{Data from the Void Fraction Instrument}

The VFI was first deployed in riser 11B in Tank 241-SY-101 on December 21, 1994, and a second time in riser 4A on January 17,1995 . Riser $11 \mathrm{~B}$ is at the $8.5-\mathrm{m}$ (28-ft) radius from the

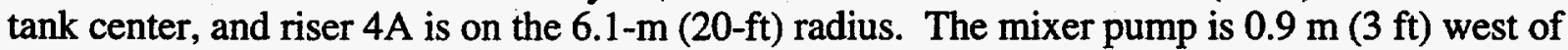
the tank center, so the distance from the pump to $11 \mathrm{~B}$ is $9 \mathrm{~m}(29.6 \mathrm{ft})$ and to $4 \mathrm{~A}$ is $6.6 \mathrm{~m}(21.9 \mathrm{ft})$. Since the sample chamber is at the end of a $762-\mathrm{cm}(2.5-\mathrm{ft})$ arm that can be turned toward or away from the pump (or in any other direction), minimum and maximum distances from the pump for a void measurement are 5.9 and $7.4 \mathrm{~m}(19.4$ and $24.4 \mathrm{ft})$ in $4 \mathrm{~A}$ and 8.3 and $9.8 \mathrm{~m}(27.1$ and $32.1 \mathrm{ft})$ in $11 \mathrm{~B}$.

Two vertical traverses were accomplished in riser 11B on December 21. On the first traverse, with the arm aimed inward toward the pump, the VFI measured zero void fraction from just below the crust to about $107 \mathrm{~cm}$ (42 in.) off the bottom. The void fraction at $43 \mathrm{~cm}(17 \mathrm{in}$.) was about $5 \%$. As the arm was lowered below $43-\mathrm{cm}$ the sludge began to support the arm, and the crane began to unload-it actually went to nearly zero load at $20 \mathrm{~cm}$ ( $8 \mathrm{in}$.). The arm was then raised slightly to reload the crane, and two measurements were taken at $25 \mathrm{~cm}$ (10 in.), showing $10-12 \%$ void fraction.

After completing the first traverse, the VFI was raised back into the dome space in view of the camera for a visual inspection. Then it was turned $180^{\circ}$ to orient the arm toward the tank wall and lowered again for the second traverse. At this orientation, with the arm aimed away from the pump, the void fraction was about $2 \%$ at $107 \mathrm{~cm}$ (42 in.) off the tank bottom and $3 \%$ at $76 \mathrm{~cm}$ (30 in.). At approximately $60 \mathrm{~cm}(2 \mathrm{ft})$, the crane began to unload rapidly again, indicating the presence of heavy sludge. A void measurement at this level failed due to leaking O-rings, and the test ended.

(a) Calculations in Stewart, C.W., Assessment of Bottom Sludge Depth in Tank 241-SY-101, Rev. 1, letter report PNL-MIT-020795, indicated the sludge depth was between 12 and $15 \mathrm{~cm}$ (5 and 6 in.) with a temperature change of less than $0.6^{\circ} \mathrm{C}\left(1^{\circ} \mathrm{F}\right)$ at $\mathrm{TC} \# 1$ on $17 \mathrm{~B}$. 
The second VFI deployment in 241-SY-101 was performed through riser 4A on January 17. During the first traverse with the sample chamber oriented toward the pump, the VFI measured zero void fraction down to $91 \mathrm{~cm}$ ( $3 \mathrm{ft}$ ) from the bottom, as it did on the first deployment. The void fraction at $33 \mathrm{~cm}$ ( $13 \mathrm{in}$.) was $9.5 \%$. There was no unloading of the crane on this or any of the succeeding traverses in this deployment. On the second traverse, with the sample

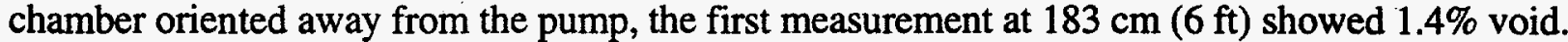

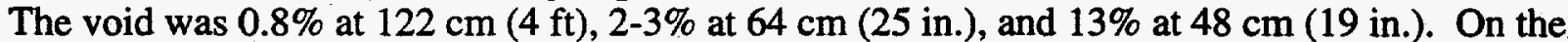
third, and last, traverse, with the arm ninety degrees from the first two, the void was $0.3 \%$ at 91 $\mathrm{cm}(3 \mathrm{ft})$ and $7-8 \%$ at $41 \mathrm{~cm}(16 \mathrm{in}$.). The fourth traverse was canceled because of a low battery in the crane dynamometer.

All of the above void fraction measurements are plotted in Figure 2.4. Even though the data points are separated by up to $4 \mathrm{~m}(13 \mathrm{ft})$, the trend of increasing void fraction with depth is remarkably uniform. The curve fit represents all data except the two outliers from the second traverse in riser $4 \mathrm{~A}$. Though not shown on the figure, separate curve fits to the data from each deployment are essentially the same.

The VFI data are consistent with the waste configuration inferred from temperature profiles. The highest void fractions below $61 \mathrm{~cm}$ (24 in.) represent the undisturbed sludge, while

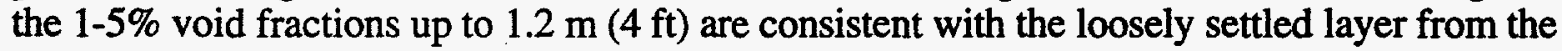
temperature profiles. The average void fraction of this layer calculated by integrating the curve fit between $25 \mathrm{~cm}(10 \mathrm{in}$.) and $1.2 \mathrm{~m}(4 \mathrm{ft})$ is just over $3 \%$.

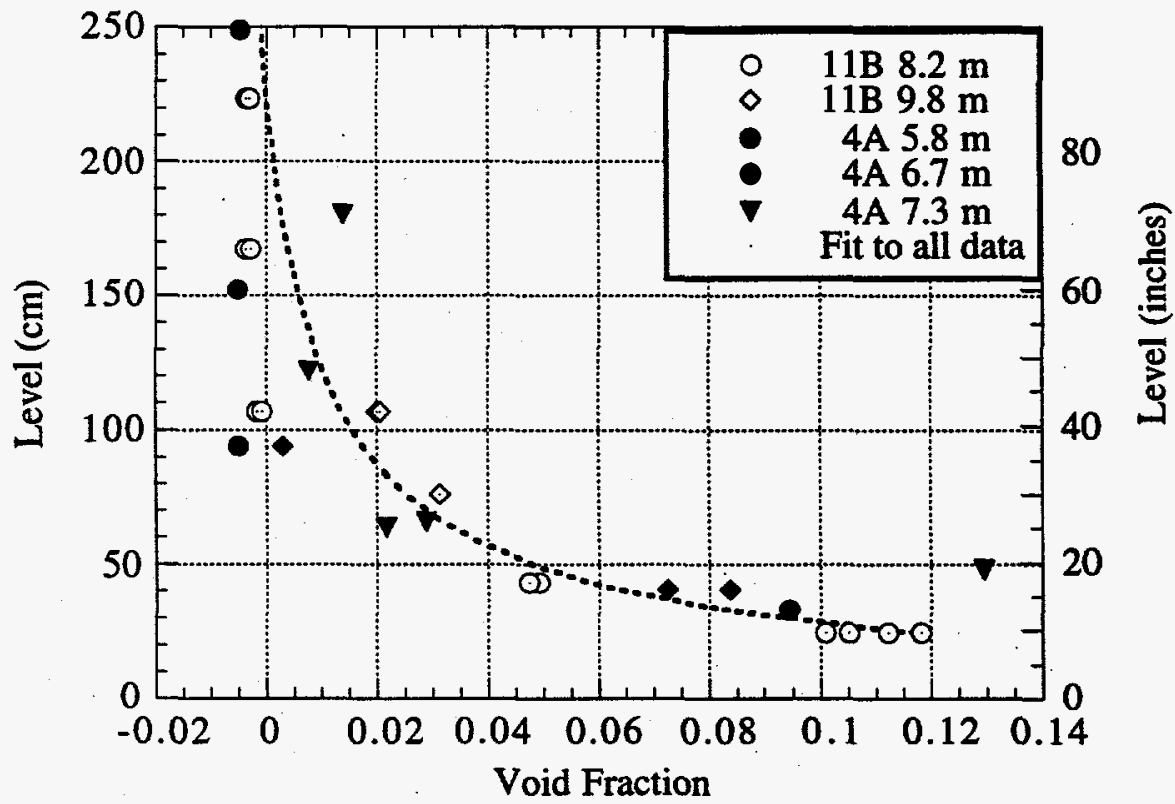

Figure 2.4. Void Fraction Measurements 
There is evidence for the existence of 'scallops' of material between the chosen pump angles where the jet has not been directed. As seen in Figure 2.1, risers 4A and 11B are located away from the direct impact of the jet between nominal pump azimuths. Therefore, while the thermocouple responses at the 17B and 17C MITs indicate a sludge depth of 10-30 cm (4-12 in.) in line with the pump, the void profile in Figure 2.4 implies a depth of $25-40 \mathrm{~cm}(10-16 \mathrm{in}$.) or greater at about the same radius. The crane unloading observations indicate heavy sludge as high as $60 \mathrm{~cm}(24 \mathrm{in}$.) off the bottom.

On the other hand, the crane unloading might also indicate a local obstruction not representative of a typical scallop. Since the crane unloaded at $68 \mathrm{~cm}(24 \mathrm{in}$.) with the arm directed away from the pump, and at only $25 \mathrm{~cm}$ (10 in.) with the arm inward, the change in height of the highstrength material or obstruction must be quite abrupt.

\subsection{Results of the Ball Rheometer Tests}

The ball rheometer was deployed in the same two risers as the VFI, but three months later, due to problems in penetrating the crust layer, as discussed in Section 1.3. The ball was lowered through riser 4A March 27 and through riser 11B on April 5, 1995. Though the VFI had already penetrated the crust, the field engineers took no chances and cut a passage with the recently modified water lance each time. The ball passed through the free liquid level at riser $4 \mathrm{~A}$ at a distance of $718 \mathrm{~cm}$ (283 in.) below the 'zero' reference point in the housing.a The ball was seen on in-tank video to disappear from sight below the crust surface before load reduction indicated the liquid level. Since the ball diameter is $9.1 \mathrm{~cm}$ (3.6 in.), the liquid level is at least one radius or $4.6 \mathrm{~cm}$ (1.8 in.) below the crust surface. There was no indication that crust material hindered the ball as it passed through.

Once below the crust, the ball was lowered at a constant $2 \mathrm{~cm} / \mathrm{s}$ until it was supported by either heavy sludge or the tank bottom. The measured drag on the ball was minimal until it began increasing over about the last $60 \mathrm{~cm}$ ( $24 \mathrm{in}$.) of travel. The ball became fully supported at a distance of $1,727 \mathrm{~cm} \mathrm{(680} \mathrm{in.)} \mathrm{below} \mathrm{reference,} \mathrm{which} \mathrm{is} 1,009 \mathrm{~cm}$ (397 in.) below the indicated liquid level. Adding one ball radius for the lower surface and one more for the crust surface makes the minimum distance between the crust surface and the point the ball came to rest $1018 \mathrm{~cm}(400.8$ in.). The nearest waste surface level measurement from the Enraf gauge approximately $61 \mathrm{~m} \mathrm{(20}$ $\mathrm{ft}$ ) away typically reads $1024 \mathrm{~cm}$ (403 inches). Therefore it is quite probable that the ball actually reached the tank bottom or within one ball diameter $(9.2 \mathrm{~cm})$ of it.

In the next test, one week later, the liquid level at riser $11 \mathrm{~B}$ registered $720 \mathrm{~cm}(283.5 \mathrm{in}$.) below the reference point. As before, the ball disappeared below the crust before the load decreased at the liquid level, and there was minimal drag on the ball until it reached about $30 \mathrm{~cm}$ (12 in.) from where it became supported at $1656 \mathrm{~cm}$ (652 in.). Adding one ball diameter to the difference as above yields a minimum distance from the crust surface to the stopping point of

(a) Ball position is measured to the center of the ball. Therefore one radius $(4.6 \mathrm{~cm}$ or $1.8 \mathrm{in}$.) must be added to calculate the elevation of a surface supporting the ball. The 'zero' position is about $1730 \mathrm{~cm}$ above the tank bottom. 
$945 \mathrm{~cm}$ ( $372 \mathrm{in}$.). If the crust surface elevation is $1024 \mathrm{~cm}$ (403 in.) as given by the nearby Enraf level gauge, the ball stopped $79 \mathrm{~cm}$ (31 in.) above the tank bottom. This is approximately the same level where the VFI began unloading, though it was able to penetrate farther, to about $61 \mathrm{~cm}$ ( 24 in.), by virtue of its greater weight.

The viscosity of the mixed slurry was actually lower than the ball rheometer was designed to measure. In fact, the cumulative drag on the tether cable was several times greater than the drag on the ball. Nevertheless, the mixed slurry was found to be a non-Newtonian, shear thinning fluid. The best fit to the data gives a viscosity of about 10 Poise with an uncertainty of about a factor of two. The data are plotted in Figure 2.5. The material near the bottom that the ball was able to pass through before stopping showed shear thickening behavior with a very small yield strength of about $20 \mathrm{~Pa}(0.004 \mathrm{psi})$ and an average viscosity of approximately 200 Poise. The yield strength profile is plotted in Figure 2.6 and a representative rheogram is shown in Figure 2.7.

The ball rheometer also obtained density readings derived from the buoyant force on the ball (corrected for submerged cable volume). The density profiles for the runs in 4A and 11B are shown in Figure 2.8. The test in riser 4A was run four days after a pump run while the one is 11B was only one day after. The difference in the density profiles is a clear result of solids settling over several days. Even though the yield strength of the material near the bottom was very low, it may have partially supported the ball to give a high apparent density on the last two points in riser 4A.

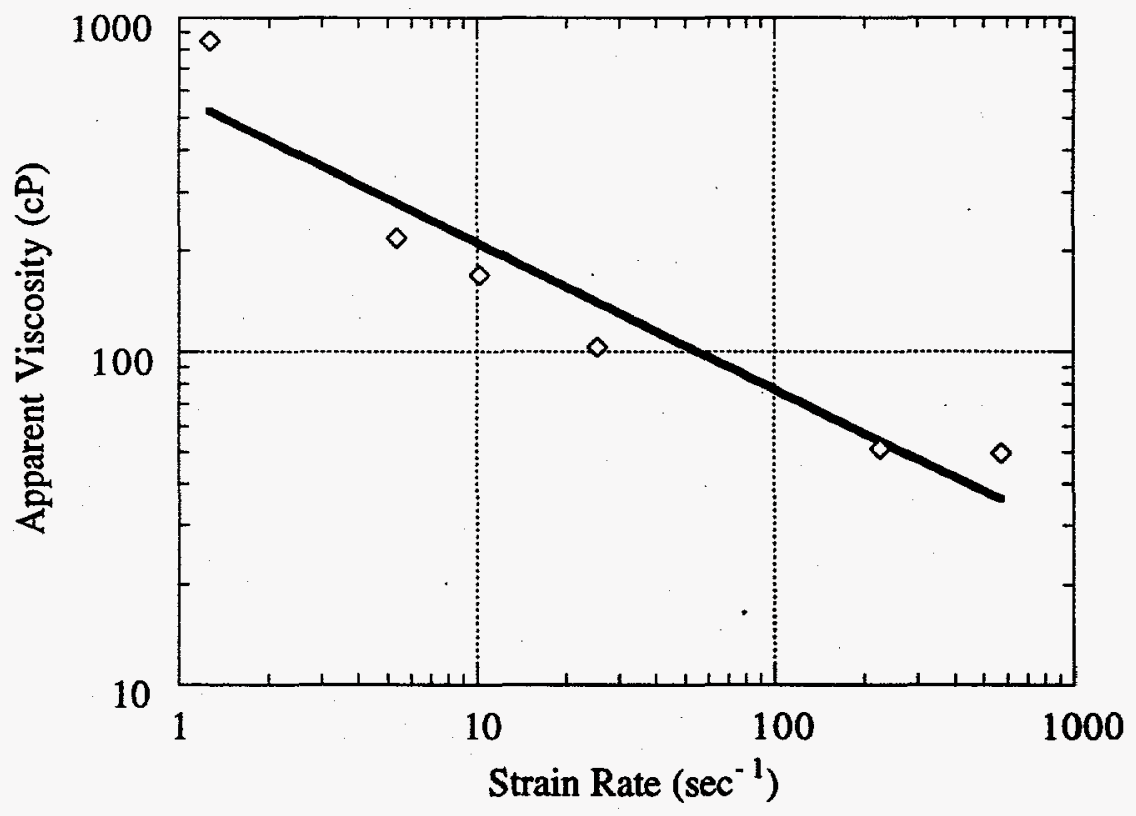

Figure 2.5. Apparent Viscosity of 241-SY-101 Mixed Slurry 


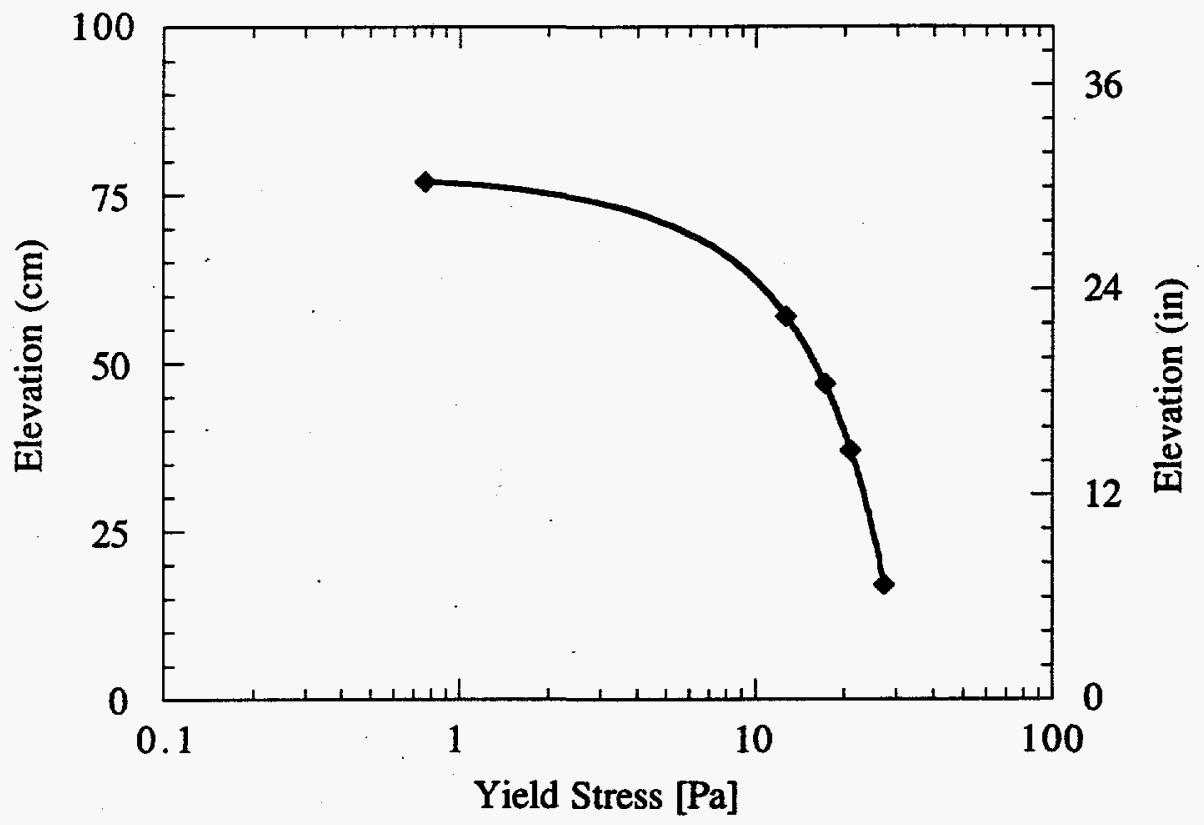

Figure 2.6. Yield Stress of the Loosely Settled Layer in 241-SY-101

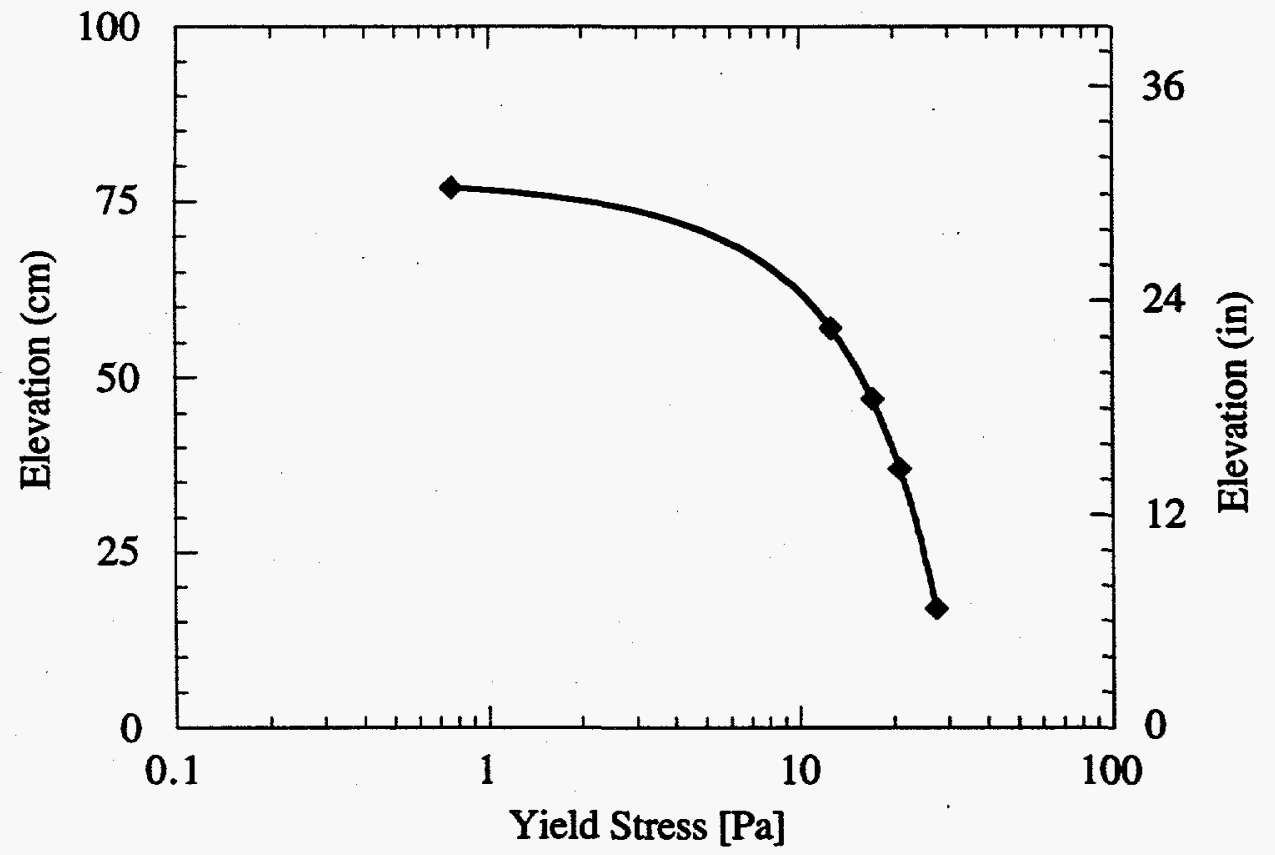

Figure 2.7. Rheogram of the Loosely Settled Layer in 241-SY-101 


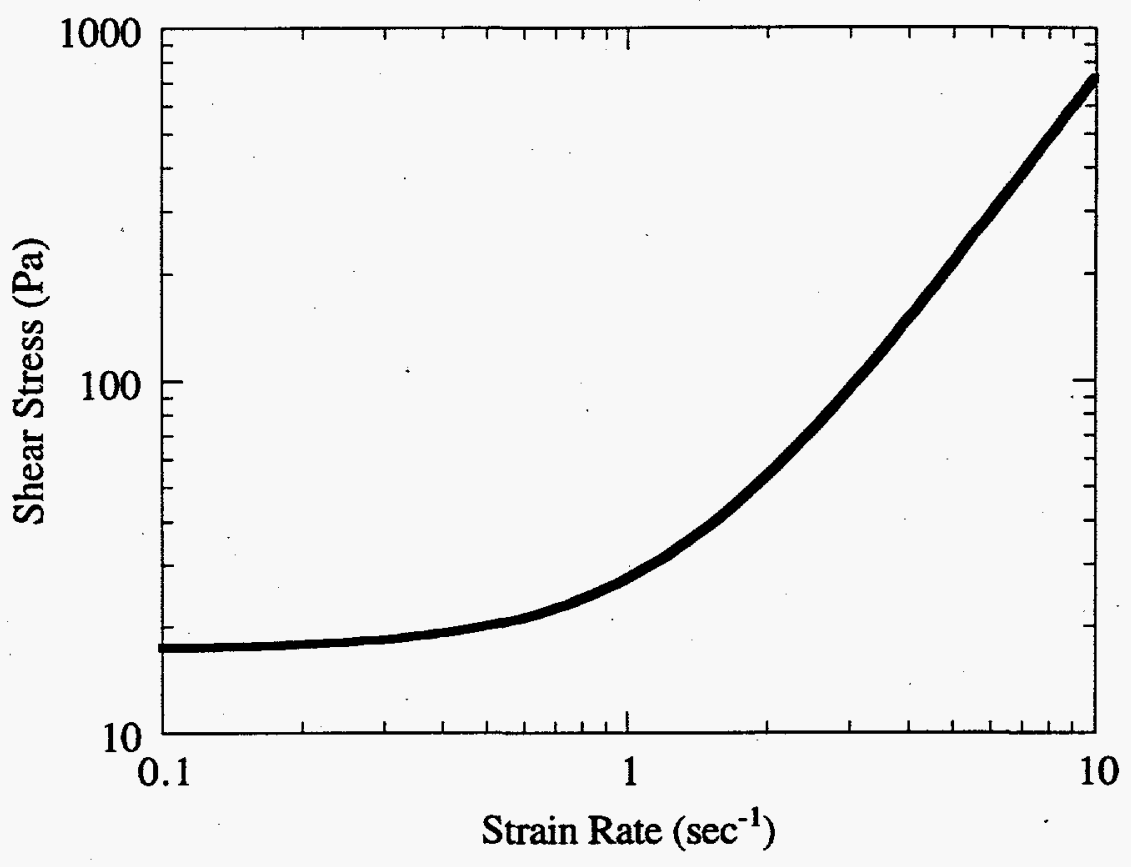

Figure 2.8. Density Profiles from the Ball Rheometer

\subsection{Interpretation of Results}

These data allow us to estimate the volume of sludge remaining on the bottom and the total volume of gas contained therein. The rest of this section addresses these two issues.

The VFI, ball rheometer, and two MITs provide a direct measure of sludge depth at seven locations in four risers (two MITs, two rheometer tests and five VFI orientations). The locations are generally in the northeast third of the tank spread over a sector of $138^{\circ}$ (about the pump column) and distances from about 6.7 to $9.7 \mathrm{~m}$ ( 22 to $32 \mathrm{ft}$ ) from the pump. These data are summarized in Table 2.2 .

With data at so few locations, constructing a plausible geometry for the sludge layer is a truly daunting task involving much uncertainty. The problem is estimating the three-dimensional geometry of sludge using the information at hand. To do this, various models can be derived from Table 2.2 that qualitatively reflect jet effects on sludge geometry. It is not possible to do formal analyses of exact dimensions now due to the paucity of data on which to base them.

The volumes calculated for the sludge and loosely settled layers by the various geometry models are similar. A representative prediction of sludge volume is $181 \pm 70 \mathrm{~m}^{3}(6,400 \pm 1,400$ $\mathrm{ft}^{3}$ ) with a loosely settled layer of $192 \pm 85 \mathrm{~m}^{3}\left(6,800 \pm 3,000 \mathrm{ft}^{3}\right)$ (Brewster et al. 1995). 
Table 2.2. Sludge Depth Data from MITs, VFI, and Ball Rheometer

\begin{tabular}{|c|c|c|c|}
\hline $\begin{array}{l}\text { Location } \\
\text { (riser/azimuth/radius*) }\end{array}$ & $\begin{array}{l}\text { Sludge } \\
\text { Depth } \\
(\mathrm{cm})\end{array}$ & $\begin{array}{l}\text { Date (no. } \\
\text { excavation } \\
\text { runs) }\end{array}$ & Method of Estimation \\
\hline $4 \mathrm{~A}-233^{\circ}-19.4,7.4$ & $<33$ & $1 / 17 / 95$ & VFI - no crane unloading \\
\hline $4 \mathrm{~A}-233^{\circ}-6.7$ & 0 & $3 / 28 / 95$ & Ball penetration to tank bottom. \\
\hline $17 \mathrm{~B}-97^{\circ}-8.6$ & $<41$ & $4 / 13 / 94(4)$ & Temp. jump at TC \#2 \\
\hline $17 \mathrm{~B}-97^{\circ}-8.6$ & $13-15$ & $12 / 16 / 94(12)$ & Conduction calc. for TC \#1 and 2 \\
\hline $17 \mathrm{~B}-97^{\circ}-8.6$ & -10 & $4 / 4 / 95(22)$ & Strong conduction response at $\mathrm{TC} \# 1$ \\
\hline $17 \mathrm{C}-208^{\circ}-9.3$ & $<41$ & $12 / 7 / 94(13)$ & Temp. jump at TC \#2. \\
\hline $17 C-208^{\circ}-9.3$ & $>10$ & $5 / 1 / 95(23)$ & No response at $\mathrm{TC} \# 1$ \\
\hline $11 \mathrm{~B}-235^{\circ}-8.3$ & $20-25$ & $12 / 21 / 94$ & VFI - crane unloading \\
\hline $11 \mathrm{~B}-235^{\circ}-9.8$ & $60-76$ & $12 / 21 / 94$ & VFI - crane unloading \\
\hline $11 \mathrm{~B}-235^{\circ}-9.0$ & 76 & $4 / 5 / 95$ & Ball supported \\
\hline
\end{tabular}

Knowing the volume of each waste layer allows us to calculate the associated gas volume once we assign a void fraction. We need to compute the gas volume in four layers: the bottom sludge, the loosely settled layer, the mixed slurry, and the crust.

The VFI measured from 8-12\% void at the lowest locations, so we can assign a value of \pm $2 \%$ to the uncertainty in the void fraction due to location and interpretation of results in the sludge. The uncertainty in the void measurement itself is $\pm 2 \%$ by design, (a) although the actual error is estimated in Section 4 to be less than $1 \%$. Assuming the former, the total void fraction and uncertainty in the sludge is $10 \pm 3 \%$. The loosely settled layer above the sludge measured $2-5 \%$ void. We shall assume a combined $2 \%$ uncertainty to give the void fraction of this layer as $3.5 \pm 2 \%$.

Given these void fractions and volumes of the two lowest layers, the gas volume of the combined sludge and loosely settled layers is $68 \pm 28 \mathrm{~m}^{3}(2,400 \pm 1,000 \mathrm{SCF})$ at one atmosphere (atm). One can also assume that the material that supported the VFI and ball under riser 11B was only a local obstruction and that the void fraction profile given in Figure 2.2 applies everywhere. Integrating this void profile assuming a uniform $11 \%$ void below $25 \mathrm{~cm}$ (10 in.) yields a gas volume of $59 \pm 22 \mathrm{~m}^{3}(2,100 \pm 780 \mathrm{SCF})$ at STP.

(a) Alzheimer et al. 1994. Void Fraction Measurement Device Theory of Operations. Letter report MIT-061794, Pacific Northwest Laboratory, Richland, Washington. 
The VFI typically measured zero void fraction in the convective slurry. Although this is consistent with the relatively fast rise times of even very small bubbles and bubble-particle systems, the uncertainty in the VFI zero measurement might allow up to $1 \pm 0.5 \%$ void fraction in the slurry. Subtracting the volume of the sludge and loosely settled layers from the total non-crust waste volume (allowing $\pm 10 \mathrm{~cm}$ [4 in.] uncertainty in crust thickness) yields a total slurry volume of $3,400 \pm 100 \mathrm{~m}^{3}\left(120,000 \pm 3,500 \mathrm{ft}^{3}\right)$. At a $1 \pm 0.5 \%$ void, this volume would contain $33 \pm 28$ $\mathrm{m}^{3}(1,150 \pm 1,000 \mathrm{SCF})$ of gas at STP assuming it is stored at $1.7 \mathrm{~atm}$.

Since all gas released from the waste must eventually pass through the crust, this layer must of necessity contain some gas. In fact, since the solid material composing the crust is more dense than the surrounding liquid, it must have a significant gas content in order to float. This is estimated at $102 \pm 34 \mathrm{~m}^{3}$ at STP $(3,600 \pm 1,200 \mathrm{SCF})$ (25\% void fraction) using a reasonable estimate for crust properties and their uncertainty (Brewster et al. 1995). The pressure of this gas volume is considered to be $1 \mathrm{~atm}$.

Adding up the stored gas volumes in each of the four layers yields a total of $203 \pm 53 \mathrm{~m}^{3}$ $(7,200 \pm 1,800 \mathrm{SCF})$ of gas at $1 \mathrm{~atm}$. Individual contributions are summarized in Table 2.3. Given the current waste level of $1016 \mathrm{~cm}$ (400 in.), the degassed waste level would be $978 \mathrm{~cm}$ (385 in.). This matches the level estimated from large historic gas release events (LANL 1995).

The data and observations from the two MITs, the VFI, and the ball rheometer lead to the following general conclusions about the current character of the waste in Tank 241-SY-101:

Table 2.3. Volume of Gas Stored in Waste Layers

\begin{tabular}{||l|c|c|c|c||}
\hline Waste Layer & $\begin{array}{c}\text { Layer Volume } \\
\left(\mathrm{m}^{3}\right) /\left(\mathrm{ft}^{3}\right)\end{array}$ & Void (\%) & $\begin{array}{c}\text { Pressure } \\
(\mathrm{atm})\end{array}$ & $\begin{array}{c}\text { Gas Volume } \\
\left(\mathrm{m}^{3} \text { at STP) }(\mathrm{SCF})\right.\end{array}$ \\
\hline \hline Crust & $\begin{array}{c}416 \pm 42 \\
(14,700 \pm 1,470)\end{array}$ & $25 \pm 8$ & 1.0 & $\begin{array}{c}102 \pm 34 \\
(3,600 \pm 1,200)\end{array}$ \\
\hline Mixed Slurry & $\begin{array}{c}3,400 \pm 100 \\
(120,000 \pm 3,500)\end{array}$ & $1 \pm 0.5$ & 1.7 & $\begin{array}{c}34 \pm 28 \\
(1,200 \pm 1,000)\end{array}$ \\
\hline Loosely Settled & $\begin{array}{c}192 \pm 85 \\
(6,800 \pm 3,000)\end{array}$ & $3.5 \pm 2$ & 2.4 & $\begin{array}{c}17 \pm 17 \\
(600 \pm 600)\end{array}$ \\
\hline Sludge & $\begin{array}{c}181 \pm 40 \\
(6,400 \pm 1,400)\end{array}$ & $10 \pm 3$ & 2.5 & $\begin{array}{c}51 \pm 23 \\
(1,800 \pm 800)\end{array}$ \\
\hline Total (or Avg.) & $\begin{array}{c}4,188 \\
(147,900)\end{array}$ & $4.9 \pm 1.2$ & $1.3(\mathrm{a})$ & $\begin{array}{c}204 \pm 53(\mathrm{~b}) \\
(7,200 \pm 1,800)\end{array}$ \\
\hline \hline (a) Pressure calculated to give equivalent compressibility. \\
(b) Uncertainties combined as rms.
\end{tabular}


- The solids are well-mixed by the current mixer pump, as evidenced by the nearly uniform temperature, void fraction, and viscosity, from just below the crust to within less than a meter of the tank bottom.

- The vertical temperature profile indicates that heavier solids settle out of the mixed slurry into a layer $\sim 50 \mathrm{~cm}$ deep between pump runs. This loosely settled layer has a small yield strength $(-25 \mathrm{~Pa})$ and a viscosity 200 Poise and exhibits shear thickening behavior.

- The mixed slurry has no measurable yield strength and a shearthinning viscosity of about 6 Poise at a shear rate of about $1 \mathrm{sec}^{-1}$.

- The mixed slurry contains less than $1 \%$ void based on the uncertainty of the VFI from lab test results. The lowest $10-30 \mathrm{~cm}$ of sludge contain $10-12 \%$ void, and the approximately one-meter-deep loosely settled layer above averages $2.5 \%$ void.

- There is relatively little undisturbed sludge left on the tank bottom. Only the data from riser 11B indicates a sludge depth of more than a few centimeters of sludge and that is less than a meter.

These results confirm that the mixer pump in 241-SY-101 has performed the job it was installed to do: thoroughly mix the waste to release stored gas and prevent future gas accumulation. Uncertainty is still large due to the limited number of measurements, but the information supplied by the VFI and ball rheometer has filled a great gap in our quantitative knowledge of the waste condition. The success of their respective deployment campaigns gives confidence that we will also obtain valuable data from the next tanks scheduled for inspection.

The balance of this report presents the data, data reduction methods, operating procedures, and uncertainty analysis in full detail. 


\subsection{Rheological Properties}

This section describes the ball rheometer system, test procedures, data reduction methods, uncertainty analysis, and the rheological properties found in Tank 241-SY-101. Most of the waste is a non-Newtonian mixed slurry with relatively low viscosity and negligible yield strength. Only the last meter of waste on the tank bottom exhibited a measurable yield strength. Selected raw data are given in Appendix A.

\subsection{System Description}

The ball rheometer consists of a 9.12-cm-diameter tungsten alloy ball tethered to a steel cable that is wound onto a spool or drum. The basic components are shown in Figure 3.1. The cable runs from the spool, through a guide, then over a pulley, and finally to the ball, where it is attached by a swaged fitting located on the top of the ball. The spool operates much like the familiar level-wind spin-casting reels used by fishermen. The guide distributes the line across the width of the spool, and only a single layer of cable is needed on the spool. Instead of a crank handle to deploy or retrieve the line, these functions are performed with electric motors, clutches, reduction gears, and a driveline. The pulley rests on a load cell, which measures the tension in the cable plus the pulley weight and any friction in the pulley when it is in motion.

Four quantities are measured during the tests: the ball position, the ball velocity, the force at the load cell, and the elapsed time since the start of a test. Ball position is determined by monitoring an encoder attached to the cable spool. Ball velocity is measured with a tachometer located on each of the drive's electric motors. Ball velocity can be obtained more accurately from the position data and the internal clock. Two motors are used to operate the spool, one for highspeed applications ( 3 to $100 \mathrm{~cm} / \mathrm{s}$ ) and another for low-speed applications $(0.1$ to $3.0 \mathrm{~cm} / \mathrm{s})$. The linear velocity and location of the ball can be related to the tachometer and encoder readings because the spool diameter is known.

Complementing the hardware is a data acquisition system, which allows for controlling the ball and recording the data. The data acquisition system performs the test and stores the data. The ball position, velocity, and force measured by the load cell are recorded as a function of time, typically at a rate of $15 \mathrm{~Hz}$. The test is entirely controlled from a keyboard. The ball speed and direction, the distance through which the ball will move, and the data collection rate are all adjustable. In addition to rising- and falling-ball tests, static measurements can be obtained where the ball is stationary to determine fluid density.

Several load cells are available for use, ranging from $67-\mathrm{N}$ to $2,225-\mathrm{N}$ full-scale (15 to 500 lb). We primarily used a $445-\mathrm{N}$ load cell. The accuracy of the load cells is about $0.1 \%$ of fullscale, and it is best to use the smallest load cell possible consistent with the maximum loads achieved. Load cells can be changed in the field very easily. 


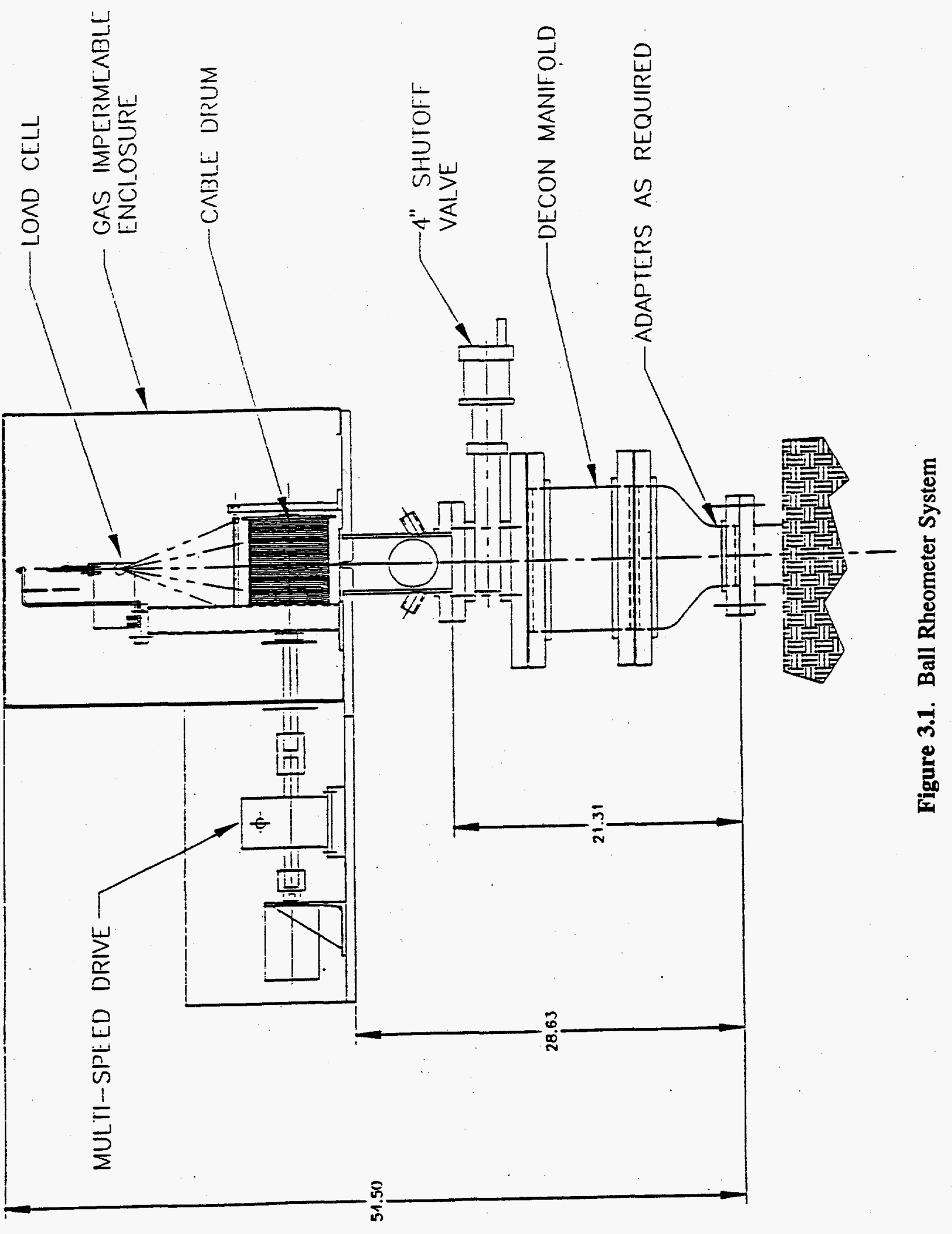




\subsection{Testing Procedure}

The ball rheometer was deployed on two separate occasions in Tank 241-SY-101. The first was in riser 4A on March 27 and 28, 1995, and the second was in riser 11B on April 5, 1995.

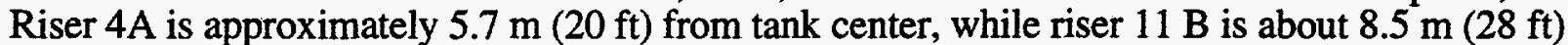
from tank center. Both risers are approximately $150^{\circ}$ clockwise from true north. Approximately 240 different tests were run in riser $4 \mathrm{~A}$, and 150 were performed in riser $11 \mathrm{~B}$. We will describe in general terms the measurements that were made and the reasons for them. Because the measurements in each riser were similar, no distinctions will be made as to specific risers in the discussion.

Prior to deployment of the ball rheometer, a water lance was operated to open an access hole in the crust through which the ball could traverse freely. The water lance creates a hole about $10 \mathrm{~cm}$ in diameter. The crust depth is estimated to be about $100 \mathrm{~cm}$. The water lancing procedure was performed several hours prior to the deployment of the ball rheometer; and in both cases, we had no difficulty lowering the ball into the waste through the hole created by the water lance.

The ball was first lowered through the 10-cm-diameter riser and into the tank dome space. After determining that the cable did not rub against the pipe opening, a short series of tests was performed in the dome space to determine pulley friction, raising and lowering the ball at several velocities. Pulley-friction measurements had been made previously in WHC labs but are always taken as a necessary part of the test procedure. Pulley friction is not constant under similar ball velocity and load conditions. The frictions measured in the first deployment were somewhat greater than those measured in the second. Pulley friction may be temperature-dependent, and it was significantly colder during the first deployment.

A static measurement (stationary ball) was obtained near the waste surface to determine the weight of the ball and deployed cable at the waste surface. This value must be subtracted from subsequent measured load values in the waste in order to determine density and drag force. After these initial measurements were completed, we began testing in the waste.

Starting with the ball at about $700 \mathrm{~cm}$ from the ball rheometer zero position, we lowered the ball for $100 \mathrm{~cm}$ at $1 \mathrm{~cm} / \mathrm{s}$. This test establishes the location of the waste liquid surface level. The load cell data for this event are shown in Figure 3.2. The load gradually decreases due to the buoyancy force of the waste on the ball as it enters the waste. At the midpoint of the change (about $718 \mathrm{~cm}$ ), the ball is half immersed in the liquid. This establishes the location of the fluid surface relative to the instrument zero and is the most useful reference for subsequent measurements in the waste.

With the ball $100 \mathrm{~cm}$ below the surface, we then probed the tank waste from top to bottom. This was done to get the only measurement possible on completely undisturbed waste and to see what to expect during subsequent detailed measurements. The ball was lowered at a low velocity (either 1 or $3 \mathrm{~cm} / \mathrm{s}$ ) to the bottom of the tank or as far as possible. After some other exploratory tests, the ball was returned to the starting location, $100 \mathrm{~cm}$ beneath the waste liquid surface.

The waste was then probed in $100-\mathrm{cm}$ increments from top to bottom. Within each increment, the ball was lowered and then raised for $100 \mathrm{~cm}$ at specific velocities $1.0,3.0,5.0$, and $10.0 \mathrm{~cm} / \mathrm{s}$. Then the ball was lowered $100 \mathrm{~cm}$ at $3.0 \mathrm{~cm} / \mathrm{s}$, and the sequence was repeated over the next $100 \mathrm{~cm}$ of waste fluid. Measurements were also obtained at $0.1 \mathrm{~cm} / \mathrm{s}$ in each $100-\mathrm{cm}$ section. However, this speed is too low to probe a $100-\mathrm{cm}$ interval in a practical time, so these tests were 


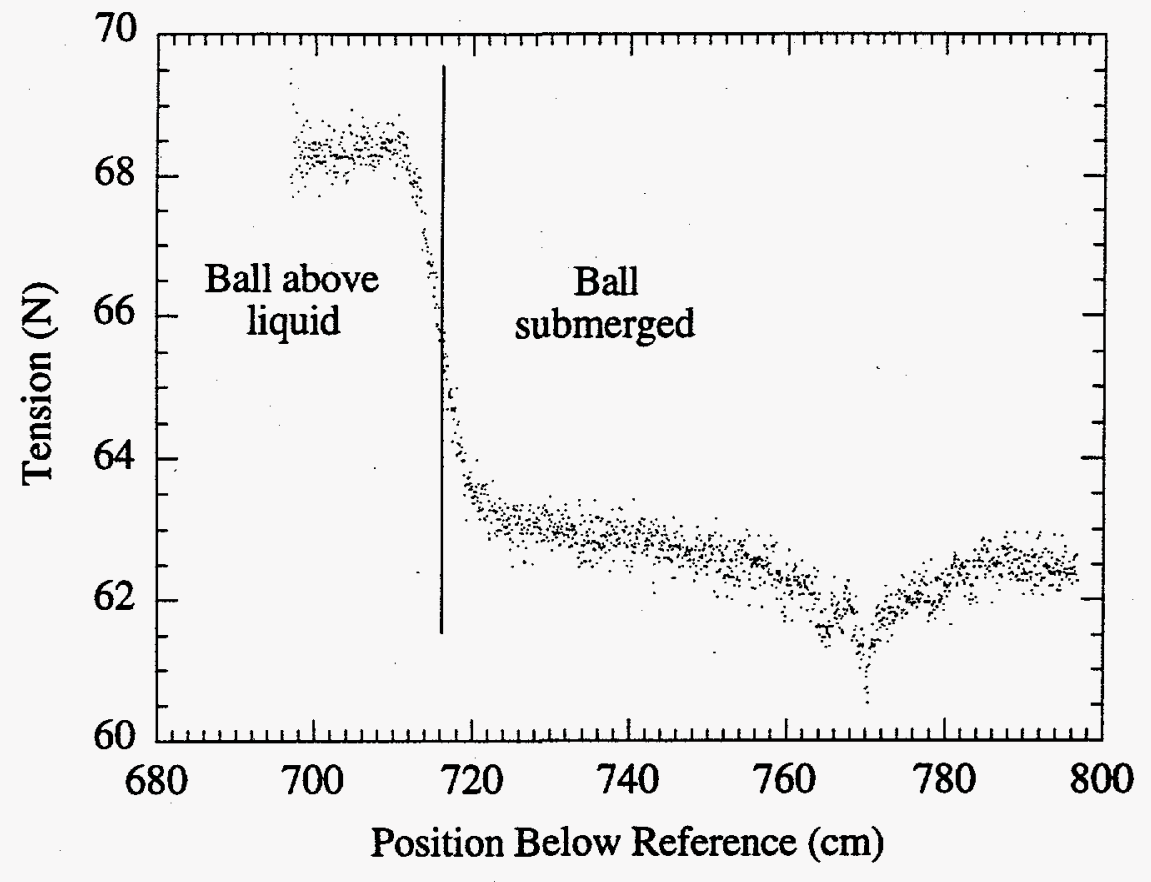

Figure 3.2. Cable Tension as Ball Passes the Liquid Level

run over 5-cm lengths (both falling and rising ball), which were at the beginning of the $100-\mathrm{cm}$ section. In any $100-\mathrm{cm}$ section, then, we obtained a minimum of two measurements at each velocity, one for a downward moving ball and one for an upward moving ball. Fluid density was also measured at the beginning of each $100-\mathrm{cm}$ section by measuring the apparent weight of the stationary ball.

After progressing $500 \mathrm{~cm}$ downward in the manner described, we performed high-speed tests by raising the ball over $400 \mathrm{~cm}$ at velocities of 50 and $100 \mathrm{~cm} / \mathrm{s}$. In addition, the data rate was increased to $100 \mathrm{~Hz}$ rather than the standard $15 \mathrm{~Hz}$. These data are useful when the viscous drag on the ball is small at the lower velocities, which was the case here. Another similar set of the high-speed data were acquired with the ball between 600 and $1000 \mathrm{~cm}$ from the waste liquid level. While performing the high-speed tests, additional stationary ball measurements were made to supplement the density information, and we obtained density measurements at points roughly 50 $\mathrm{cm}$ apart throughout the waste.

Tests on retrieving the ball from the bottom were fairly simple. Additional density measurements were performed as the ball was raised from the bottom. After the ball had been retrieved $450 \mathrm{~cm}$, it became necessary to activate the decontamination system so that no cable that had been in the waste was respooled without washing. Once the decontamination system was activated, the ball was retrieved into the rheometer enclosure at $2 \mathrm{~cm} / \mathrm{s}$ without stopping. 


\subsection{Analysis and Results}

The data analysis strategy for Tank 241-SY-101 waste rheology was devised in accordance with both the test procedure and the peculiarities of the data obtained at various depths. The tank waste can be stratified, and each stratum's rheology may differ considerably from the others. This limits the accuracy that can be obtained by measuring tension on the ball/cable system due to viscous and form drag as it passes through the layers.

\subsubsection{Data Reduction}

The load cell measures the total tension in the cable. To infer the density and the rheological characteristics of the waste from tension measurements, a proper accounting must be made of all the forces involved in the measurement. The procedure was to first measure the weight of the ball and cable in the tank dome space just above the fluid surface. This value is subtracted from tension measurements made in the waste. The contributions to the tension force measured by the load cell of the ball rheometer are due to the following effects: 1) pulley friction, $f ; 2$ ) ball weight, $W_{b}$; 3) ball buoyancy, $\left.B_{b} ; 4\right)$ cable weight, $\left.W_{c} ; 5\right)$ cable buoyancy, $\left.B_{c} ; 6\right)$ drag on the ball, $D_{b}$; and 7) drag on the cable, $D_{c}$. The magnitude of the tension will depend on whether the ball/cable system moves up or down. When the system moves up (rising ball) or down (falling ball), the load cell measures the tensions $T_{u}$ and $T_{d}$, respectively, given by

$$
\begin{aligned}
& T_{u}=W_{b}+W_{c}-B_{b}-B_{c}+D_{b}+D_{c}+f \\
& T_{d}=W_{b}+W_{c}-B_{b}-B_{c}-D_{b}-D_{c}-f
\end{aligned}
$$

Regardless of whether the ball/cable system traverses up or down, $T_{v}$ and $T_{d}$ are the difference in total cable tension measurements with the ball in the fluid at some depth and with the ball at the initial reference position just above the fluid surface.

There is no way to separate cable drag from ball drag a priori, and the sum is measured in the tests. To obtain drag force values, the fluid density as a function of depth must first be known; this can be determined from static or dynamic measurements of cable tension. Pulley friction also enters into the equation. Pulley friction was measured beforehand by performing tests in the dome space of the tank at several velocities. These data show that pulley friction is not constant. Pulley friction should be measured before beginning tests in the waste. Once the density is established as a function of depth, the buoyancy forces on the cable and ball can be accounted for. The weight per unit length of cable was accurately measured in the laboratory before deploying the ball rheometer. The uncertainty in the derived drag forces, which will be discussed below, is generally about $0.3 \mathrm{~N}$.

The drag force can also be determined by considering the difference between measurements at a constant velocity with the ball rising and falling. Solving for the combined ball and cable drag from Eq. (3.1), we obtain

$$
D_{b}+D_{c}=\frac{T_{u}-T_{d}}{2}-f
$$


with an uncertainty of $0.2 \mathrm{~N}$. Thus, the combined drag force at any velocity can be determined if the pulley friction is known for that velocity. The resulting reduced data, combined drag force as a function of velocity and depth into the waste, were used to determine fluid rheology which will be described in the next section.

\subsubsection{Rheology of the Mixed Fluid Region}

Data obtained from both risers are qualitatively similar. Both data sets show that most of the waste is very well mixed and of low viscosity. A settled layer is at the bottom of the tank. But there are some differences that should be noted. In riser $4 \mathrm{~A}$ the ball sank to very near the bottom of the tank, and the settled layer was about $60 \mathrm{~cm}$ in depth, sufficient to obtain rheological information about the layer. In riser $11 \mathrm{~B}$ the ball only sank to about $80 \mathrm{~cm}$ above tank bottom. The settled layer was too thin to allow rheological characterization; therefore, the rheological results presented here for the settled layer were obtained from only one riser. Data from about two ball diameters above the tank floor $(20 \mathrm{~cm})$ were not used for rheological analysis because tension measurements in this region are strongly influenced by the interaction of the ball with the tank bottom. In other words, tension data very close to the tank floor cannot be easily correlated with apparent viscosity obtained by pure drag on the ball/cable system.

The tension data obtained in riser 4A on March 28 showed two main regions of rheological behavior evidenced by a change in the difference between the upward and downward tensions, as shown in Figure 3.3. This change occurs at about $0.8 \mathrm{~m}$ from the floor, and the tension difference is approximately uniform from 0.8 to $10 \mathrm{~m}$. This indicates that the rheological behavior of the mixed slurry (which will be referred to as the mixed region) is uniform and that there is a spatial dependence on the rheological properties of the material in the settled layer (which will be referred to as the settled region) located about $9.4 \mathrm{~m}$ below the crust. In addition, the large difference in

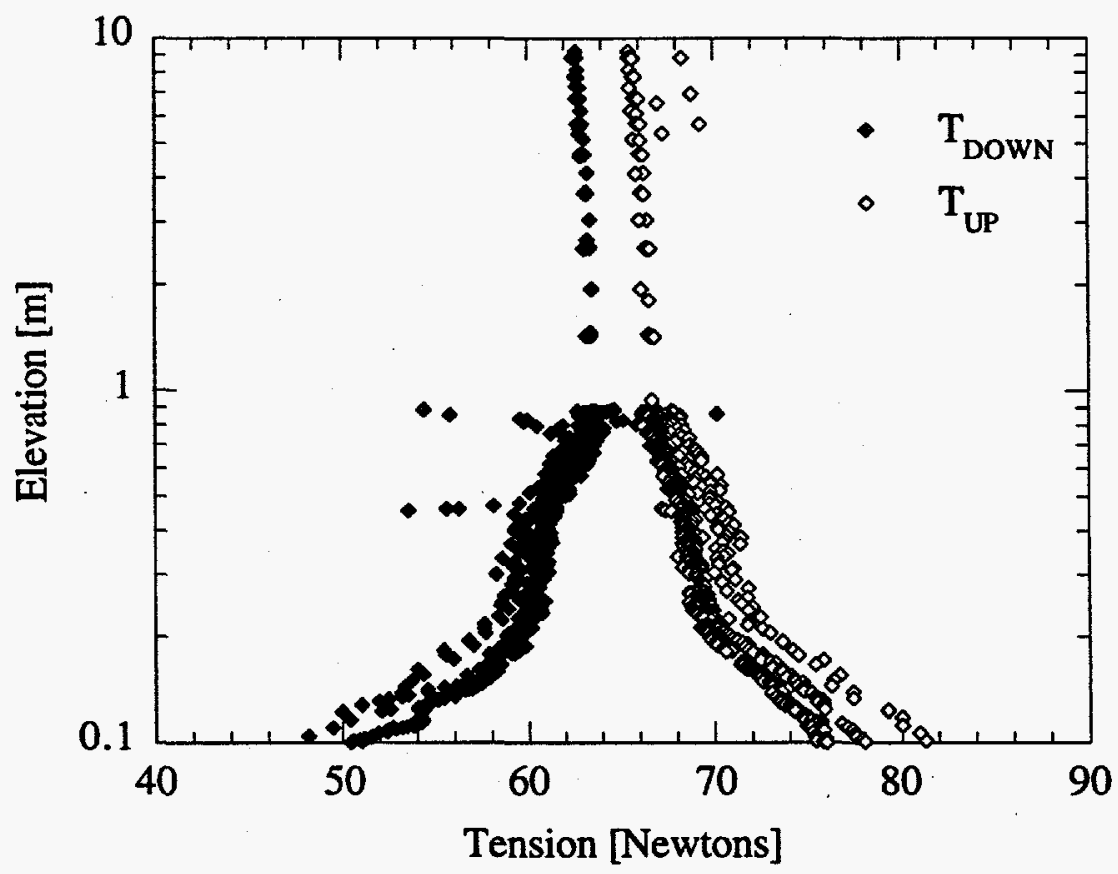

Figure 3.3. Tension Measurements for Downward and Upward Ball/Cable Motion 
the up and down tension measurements is indicative of a viscoplastic material in the settled region. Because of the presence of these distinct regions of rheological behavior, two different approaches were used to analyze the data.

In addition, the analysis strategy is based on the cyclical procedure in which the measurements were taken and on the evidence that the sludge is heavily stratified at the bottom. The data showed that in the mixed region the measured drag of the ball/cable system ranged from 0 to less than 0.3 Newton, which is on the same order as the minimum detectable force by the load cell, or 0.2 Newton. In the mixed region, the apparent viscosity of the fluid was low enough to make the drag due to the ball itself not detectable by the load cell.

Tension measurements were performed by lowering and raising the ball $1 \mathrm{~m}$ at a constant velocity from a reference position. Tension measurements were made in several 1-meter layers at various speeds with the first cycle at a depth of $1 \mathrm{~m}$ below the waste surface. In this manner, the entire depth occupied by the sludge was probed. Starting from a specified reference position, the velocity of the ball over a scanning cycle of tension measurements is $U$ (down) for a distance of 1 $\mathrm{m}$, then - $\mathrm{U}$ (up) for $1 \mathrm{~m}$ to the starting position. Tension measured while the ball is being lowered is $T_{d}$ and the tension while the ball is being raised is $T_{\mathfrak{u}}$.

Since the drag on the cable is proportional to its length, the measured forces are mostly due to the cable drag after the ball is a few meters below the crust. Over $70 \%$ of the total drag force is due to the cable with the ball moving $10 \mathrm{~cm} / \mathrm{s}$ in a fluid whose viscosity is $1000 \mathrm{cP}$ after about $3 \mathrm{~m}$ of cable has submerged.

Thus in the mixed region the apparent viscosity can be more easily inferred from the drag on the cable than the drag on the ball. Figure 3.4 shows the combined ball plus cable drag (as computed from Eq. 3.2) as a function of tank elevation in the mixed fluid region for several traversing velocities. The combined force increases with depth due to the larger contribution from the cable to the total tension measured by the load cell. The curve fits shown in Figure 3.4 show that the total drag force increases monotonically with depth for the measurements at different velocities. Figure 3.5 shows the combined shear stress of the ball and the cable in the mixed fluid region as a function of elevation for tension measurements $2 \mathrm{~m}$ below the crust. Even though the combined force is an increasing function of depth, the combined stress remains fairly constant in the mixed fluid region as shown in Figure 3.5 by the curve fit. The consequence of this observation is that the rheological characteristics in the mixed region are homogeneous.

Because the major contribution to drag in the mixed region is due to the cable, the first step in the analysis is to obtain an expression that relates the force on the cable as a function of the velocity at which it moves and other pertinent parameters. Since the tension measurements are performed in a cyclic manner over a layer $1 \mathrm{~m}$ deep, the particular expression for force on the cable must take this into account. Thus, an average force on the cable over the time it takes to move the system $1 \mathrm{~m}$ up or down in the sludge is needed to properly correlate the cable drag with the apparent viscosity. 


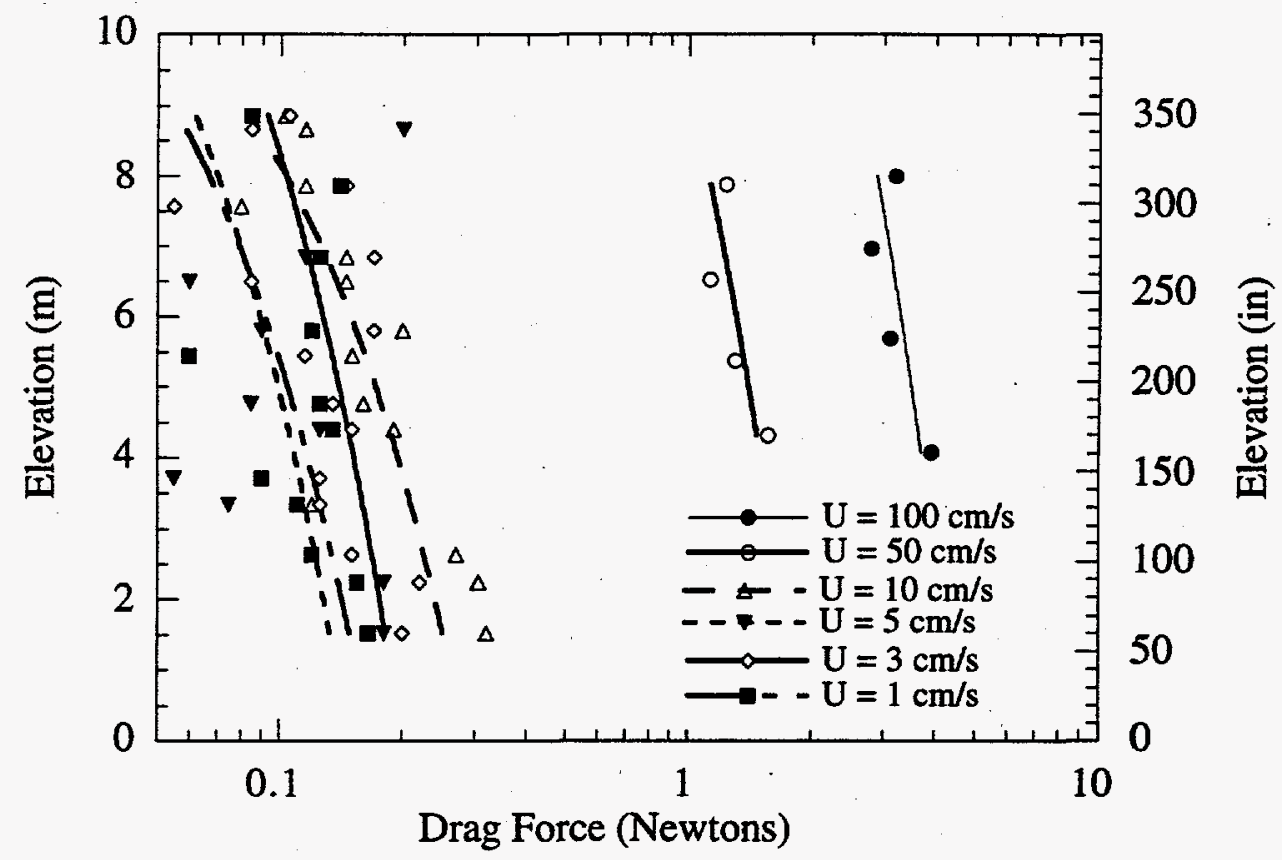

Figure 3.4. Combined Ball and Cable Drag Force Versus Elevation

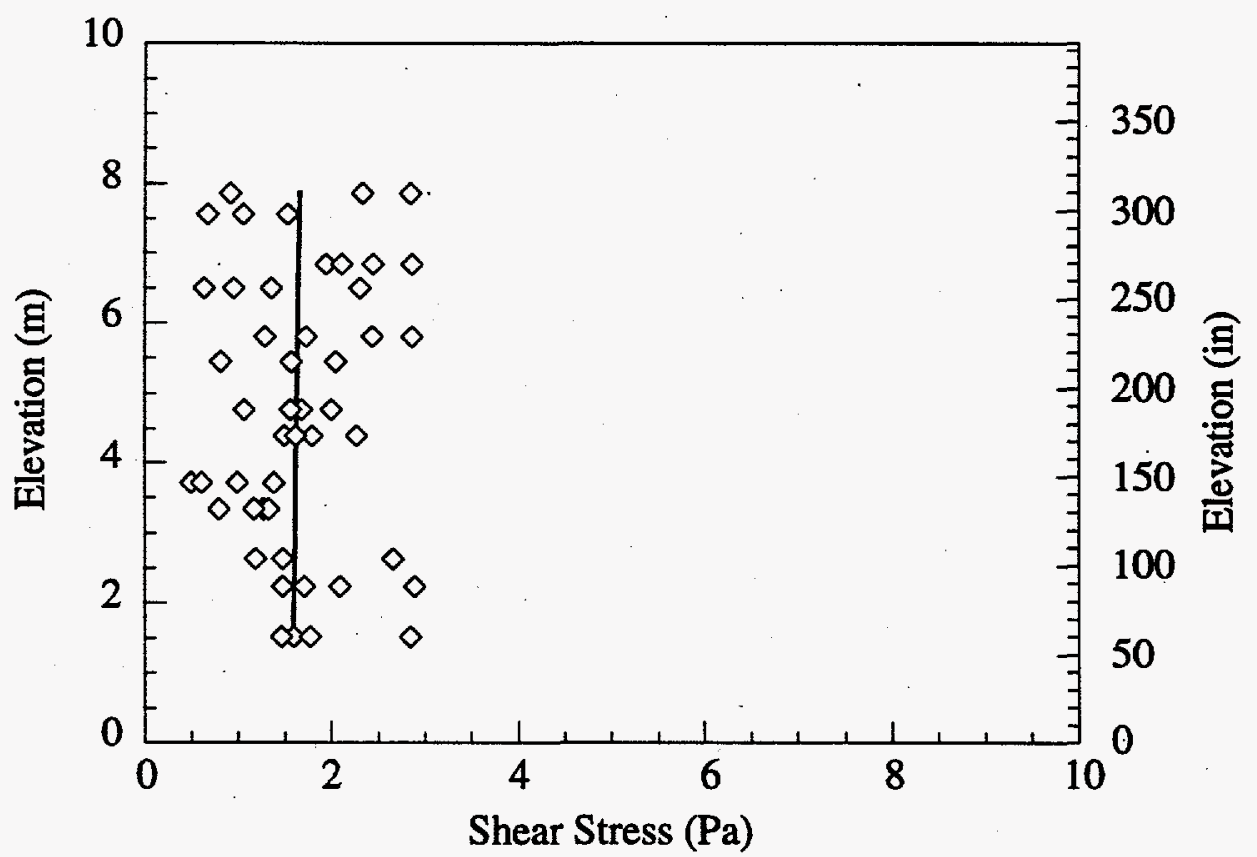

Figure 3.5. Shear Stress Variation in the Mixed Fluid Region 
A general correlation is obtained by relating dimensionless numbers involving the problem parameters. In this case, a Reynolds number, $\mathrm{Re}_{\mathrm{c}}$ based on the radius of the cable, and a timeaveraged cable drag coefficient, $\mathrm{C}_{\mathrm{Dc}}$, are defined as follows:

$$
\operatorname{Re}_{c}=\frac{\rho U R}{\mu_{\text {app }}}, \quad C_{D c}=\frac{2\langle\tau\rangle}{\rho U^{2}}
$$

where

$$
\begin{array}{lll}
\stackrel{\rho}{U} & = & \text { fluid density } \\
\mathrm{R} & = & \text { speed at which the ball/cable system is moving } \\
\mu_{\text {app }} & = & \text { cable radius } \\
\langle\tau & = & \text { apparent viscosity at a particular strain rate } \\
& = & \text { time-average shear stress on the cable }
\end{array}
$$

In the present case, the shear stress on the cable cannot be calculated from the steady-state solution of a cable moving at a constant velocity in a tank, because the time it would take the cable to induce a steady state velocity field is much greater than the time scale of the measurements. For the cable, a steady-state solution depends on the location of an outer boundary, in this case, the tank wall. The tank wall will not experience the effect of the cable until a long time has passed. For instance, in a fluid with a density of $1,600 \mathrm{~kg} / \mathrm{m}^{3}$, a viscosity of $1,000 \mathrm{cP}$ (which are in the range of properties found in the mixed fluid region in Tank 241-SY-101) it would take 2.44 hours for steady state to be reached if the tank diameter were $10 \mathrm{~m}$. However, this is not the case for the ball where a steady-state solution does not require knowledge of the location of the outer boundary as long as the wall is beyond 20 ball diameters from the ball (Panton 1984).

The expression for $\tau(t)$ is obtained by solving for the velocity field from the equations of motion for an impulsively started cable in a viscous fluid. An analytic solution can be found by considering a cable of infinite extent moving along its axis in an unbounded body of fluid. The momentum equation is

$$
\frac{\partial \mathrm{v}}{\partial \mathrm{t}}=\frac{\mu}{\rho} \frac{1}{\mathrm{r}} \frac{\partial}{\partial \mathrm{r}}\left(\mathrm{r} \frac{\partial \mathrm{v}}{\partial \mathrm{r}}\right)
$$

where $v$ is the axial component of the velocity in the fluid caused by the motion of the cable, $t$ is the time variable, and $r$ is the radial coordinate (perpendicular to the cable axis, see Figure 3.6). The initial and boundary conditions for an impulsively started cable are

$$
\begin{aligned}
& v(r, t=0)=0 \\
& v(r=R, t)=U \\
& v(r \rightarrow \infty, t)=0
\end{aligned}
$$




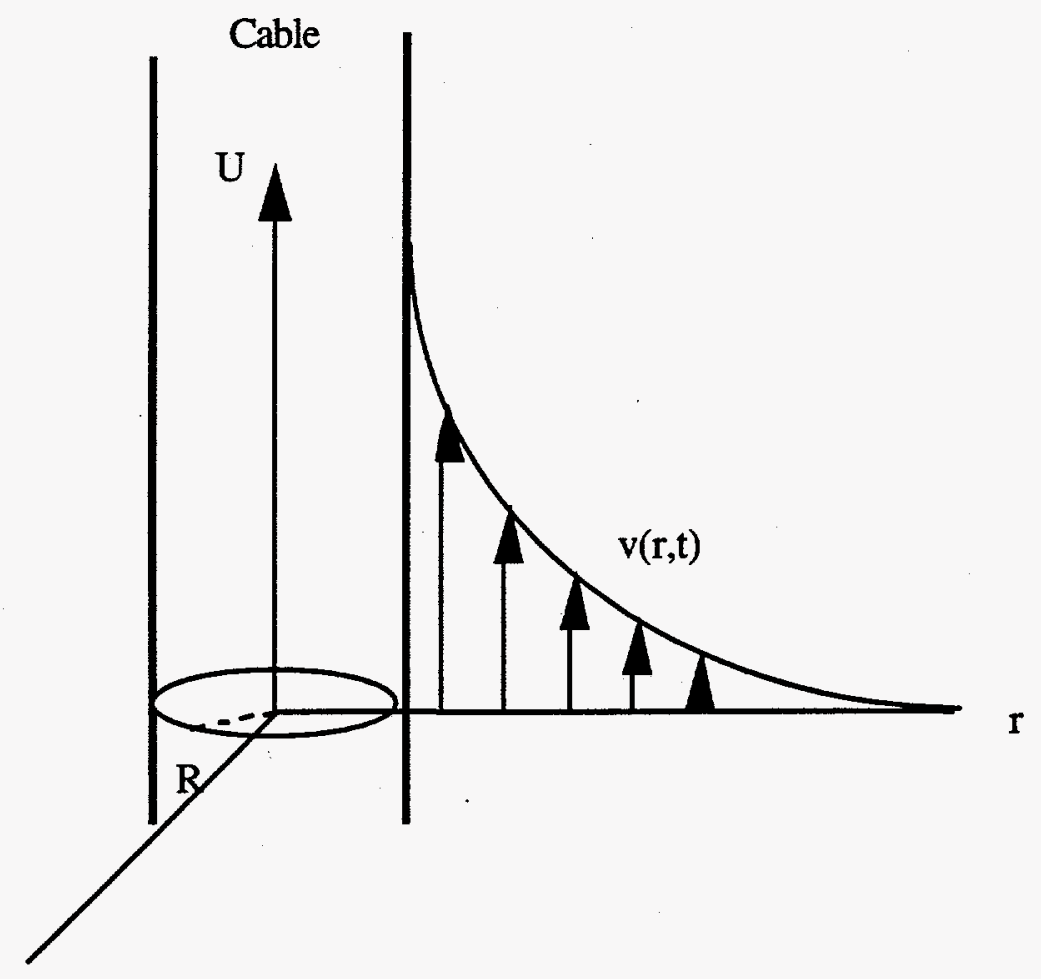

Figure 3.6. Velocity Field Induced by a Cable Moving Along Its Axis

The solution of Eq. (3.4) and the boundary conditions (3.5) yields

$$
v(r, t)=U \frac{E i\left(-\frac{\rho r^{2}}{4 \mu t}\right)}{\operatorname{Ei}\left(-\frac{\rho R^{2}}{4 \mu t}\right)}
$$

where $\mathrm{Ei}(-\mathrm{x})$ is the exponential integral function (Abramowitz and Stegun 1964). The shear stress at the cable as a function of time is

$$
\tau(\mathrm{t})=-\left.\mu \frac{\partial \mathrm{v}}{\partial \mathrm{r}}\right|_{\mathrm{r}=\mathrm{R}}=-\frac{2 \mu \mathrm{U}}{\mathrm{R}} \frac{\mathrm{e}^{-\frac{\rho \mathrm{R}^{2}}{4 \mu \mathrm{t}}}}{\mathrm{Ei}\left(-\frac{\rho \mathrm{R}^{2}}{4 \mu \mathrm{t}}\right)}
$$

A relationship between $\operatorname{Re}_{c}$ and $C_{D c}$ can be found by numerically integrating in time from zero to $T$ the shear stress over a range of viscosities and cable velocities for a given cable radius and fluid density. The cable has a radius of $1.5875 \mathrm{~mm}$, and we know that the average density of the sludge is $1600 \mathrm{~kg} / \mathrm{m}^{3}$. The following correlation was obtained after fitting the numerical results to a power function by the method of least squares: 


$$
C_{D c}=0.7031 \operatorname{Re}_{c}^{-0.83336}
$$

The above expression was computed by numerical integration in time over the period $\mathrm{T}$ (the time it takes for the ball/cable system to traverse $1 \mathrm{~m}$ ) for cable velocities from 0.01 to $1 \mathrm{~m} / \mathrm{s}$ and viscosities between 50 to $1000 \mathrm{cP}$.

The average force on the cable after the completion of an up/down cyclic measurement is

$$
\left\langle\mathrm{F}_{\mathrm{c}}\right\rangle=\pi R\langle\tau\rangle \int_{0}^{T}\left[\left(\mathrm{~L}_{\mathrm{r}}+\mathrm{Ut}\right)_{\mathrm{down}}+\left(\mathrm{L}_{\mathrm{r}}+1-\mathrm{Ut}\right)_{\mathrm{UP}}\right] d t=\pi \mathrm{RpU}^{2} \mathrm{C}_{\mathrm{Dc}}\left(\mathrm{L}_{\mathrm{r}}+\frac{1}{2}\right)
$$

where $L_{t}$ is the reference position from which the cyclic tension measurement is started. The drag coefficient on the ball is obtained form an experimental correlation reported by Chhabra (1993)

$$
C_{D b}=\left(2.25 \operatorname{Re}_{b}^{-0.31}+0.36 \operatorname{Re}_{b}^{0.06}\right)^{3.45}
$$

where $\mathrm{Re}_{\mathrm{b}}$ is the ball Reynolds number based on the ball diameter, $\mathrm{d}$, which, in the present case, is $9.144 \mathrm{~cm}$. This correlation has an uncertainty of less than $5 \%$ and is valid for Reynolds numbers between 0.01 and 300,000 . is The drag force on the ball, $F_{b}$, is

$$
\mathrm{F}_{\mathrm{b}}=\frac{1}{8} \pi \mathrm{d}^{2} \rho \mathrm{U}^{2} \mathrm{C}_{\mathrm{Db}}
$$

The above correlation is also applicable to pseudoplastic fluids by redefining the Reynolds number in terms of the power law parameters. Experiments have shown that for pseudoplastic fluids the standard correlation for Newtonian fluids is accurate within $30 \%$ (Chhabra 1993). The time dependence on the ball drag is negligible compared with that of the cable. Therefore, a timeaveraged ball drag over a $1-\mathrm{m}$ traverse will be equal to the steady-state value obtained from the above correlation. Thus the contribution to the drag force that is measured experimentally is

$$
\dot{F}=\left\langle F_{c}\right\rangle+F_{b}
$$

The ball drag can be separated from the cable drag by taking the derivative of the total force as a function of depth, because the main contribution to the drag force in the mixed region is due to the cable drag and the fluid in this region is fairly homogeneous. Therefore, the apparent viscosity can then be related to the measured drag force as a function of depth through the following equation:

$$
\mu_{\mathrm{app}}=\rho \mathrm{RU}\left(\frac{\frac{\mathrm{dF}}{\mathrm{dL}}}{0.7031 \pi \mathrm{R}_{\mathrm{r}} \mathrm{U}^{2}}\right)^{1.2}
$$


Note that, in this expression, the contribution from the ball drag has been completely eliminated because the derivative of $F_{b}$ with respect to $L_{r}$ is zero. There is a considerable amount of scatter in the drag-versus-depth data shown in Figure 3.4 that will also be reflected in the apparent viscosity values obtained with the previous equation. To bound the uncertainty in the viscosity measurements, the average as well as the maximum slopes of drag force as a function of depth are computed from the results shown in Figure 3.4.

If the fluid were Newtonian, the values of the apparent viscosity would be the same regardless of the velocity at which a particular tension measurement was carried out. However, tension measurements in the mixed fluid region exhibited different apparent viscosities at different measuring velocities. Specifically, the apparent viscosities decreased as the measuring velocities increased. This behavior is typical of pseudoplastic or shear-thinning fluids. A measure of the strain rate is given by the ratio between the measuring velocity to the cable radius. This ratio does not correspond to a true strain rate in the rheological sense. To obtain a true strain rate value consistent with the measurements, a time average of strain rates must be taken. Using the timedependent solution for the flow generated by the cable motion, we have

$$
\langle\dot{\gamma}\rangle=\frac{U}{R} \frac{1}{T} \int_{0}^{T}-2 \frac{e^{-\frac{\rho R^{2}}{4 \mu t}}}{E\left(-\frac{\rho R^{2}}{4 \mu t}\right)} d t
$$

The results obtained by numerical integration of the above expression for several values are least-squares fitted to yield the desired relationship for strain rate:

$$
\langle\dot{\gamma}\rangle=1.92 \frac{\mathrm{U}}{\mathrm{R}}\left[\log \left(\frac{4 \mu_{\mathrm{app}} \mathrm{T}}{\rho \mathrm{R}^{2}}\right)\right]^{-1.415}
$$

A region of apparent viscosities as a function of strain rate is obtained from the data in Figure 3.5 and the use of Eq. (3.11) and (3.13). The results of this analysis are shown in graphical form in Figure 3.7. The general trend observed in the rheological data is a consistent diminution of the apparent viscosity as a function of strain rate which is typical of pseudoplastic (shear thinning) fluids. This behavior is often described in terms of a power law model of the form

$$
\mu_{\text {app }}=\mathrm{K} \dot{\gamma}^{\mathrm{n}-1}
$$




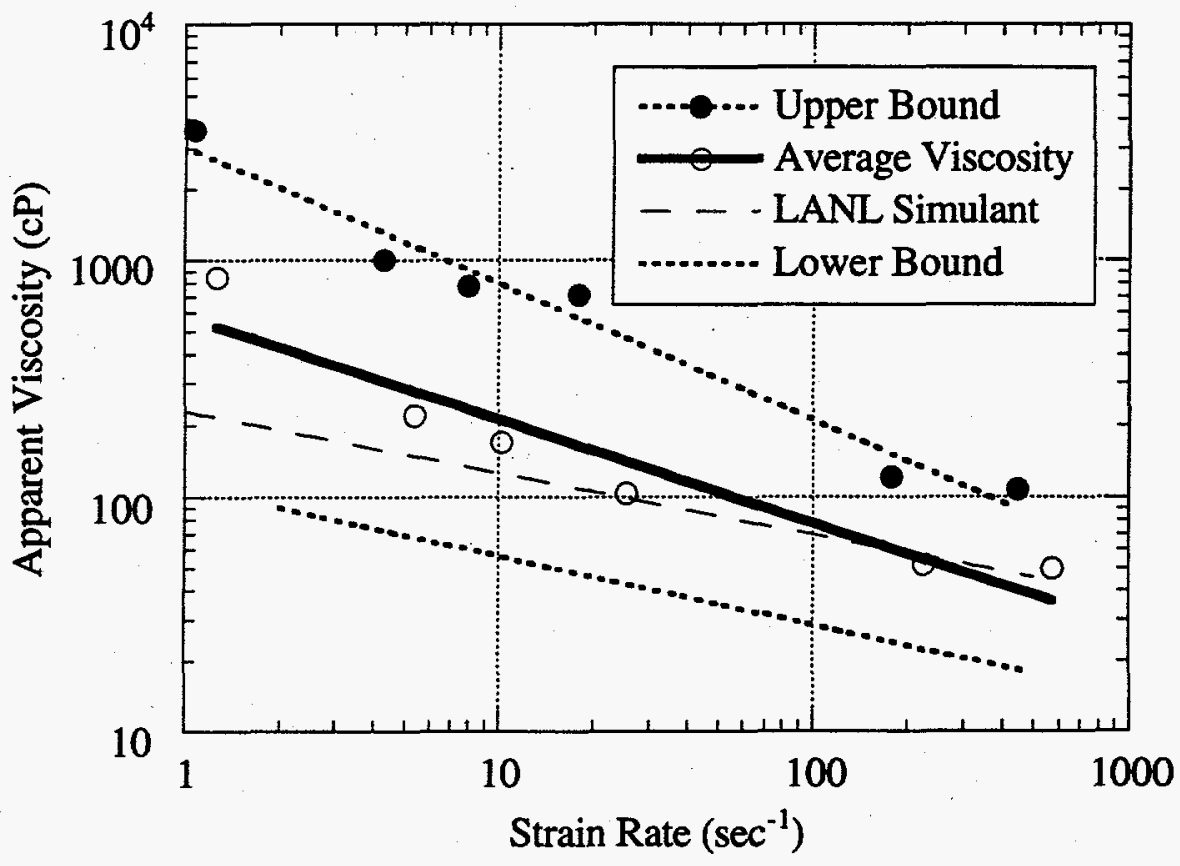

Figure 3.7. Region of Apparent Viscosities as a Function of Strain Rate

where $\mathrm{I}$ is the consistency factor and $\mathrm{n}$ is the behavior index. The power law parameters of the curves shown in Figure 3.7 are listed in Table 3.1. The lower bound on viscosity is obtained by a rotation of the upper bound fitted curve about the average viscosity curve. The curve obtained from viscosity measurements of the Los Alamos simulant (Shepard et al. 1995) compares favorably with the viscosities obtained from the ball rheometer data.

Table 3.1. Power Law Coefficients That Correspond to the Viscosity Curves in Figure 3.7

\begin{tabular}{|c|c|c|}
\hline Curve & K[Pa sn & $\mathbf{n}$ \\
\hline \hline Maximum & 3.027 & 0.420 \\
\hline Average & 0.578 & 0.563 \\
\hline Minimum & 0.110 & $0 / 705$ \\
\hline Simulant & 0.229 & 0.740 \\
\hline
\end{tabular}

\subsubsection{Rheology of the Settled Sludge Region}

The settled sludge region is adjacent to the tank floor and occupies a depth of about $0.5 \mathrm{~m}$. The major contribution to the drag in this region is due to the ball. In terms of the tension measurements the combined ball and cable drag force $F_{2}$ is 


$$
F_{2}=D_{b 2}+D_{c 2}=\frac{T_{u}-T_{d}}{2}-f-D_{c 1}
$$

where $D_{b 2}$ is the ball drag caused by the settled sludge, $D_{c 2}$ is the cable drag in the settled region, and $D_{c 1}$ is the cable drag in the mixed region, which was estimated in Section 2 . In this region data were taken at three different velocities $(1,3$, and $10 \mathrm{~cm} / \mathrm{s})$. Figure 3.8 shows $F_{2}$ as a function of depth for several measuring velocities.

A linear regression analysis of the data shown in Figure 3.8 yields

$$
\begin{aligned}
& -\mathrm{F}_{2}=-70.551+7.5877 \mathrm{~L} \text { at } \mathrm{U}=10 \mathrm{~cm} / \mathrm{s} \\
& -\mathrm{F}_{2}=-58.544+6.2352 \mathrm{~L} \text { at } \mathrm{U}=3 \mathrm{~cm} / \mathrm{s} \\
& --\mathrm{F}_{2}=-55.08+5.866 \mathrm{~L} \text { at } \mathrm{U}=1 \mathrm{~cm} / \mathrm{s}
\end{aligned}
$$

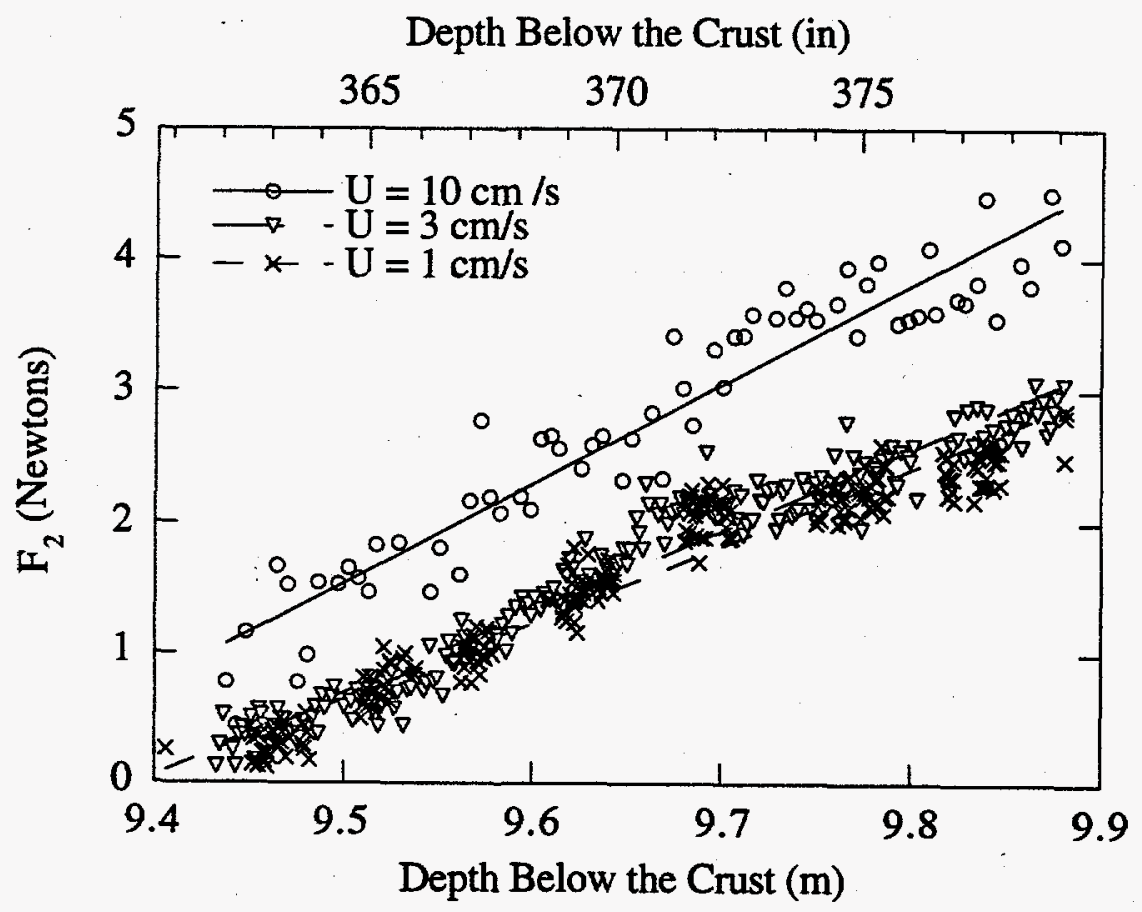

Figure 3.8. Combined Ball and Cable Drag Force in the Settled Region 
Figure 3.9 shows the combined average shear stress of the ball and cable drag in the settled region when the ball is moving at $10 \mathrm{~cm} / \mathrm{sec}$. Tension data for this region show that the sludge layer at the bottom is stratified because the shear stress varies with elevation. Therefore, the rheological characteristics are position-dependent. Equating $F_{c}$ to $D_{c 2}$ and $F_{b}$ to $D_{b 2}$ and substituting equations (3.8) and (3.10) into (3.14) yields

$$
\frac{F_{2}}{\pi \rho U^{2}}=\frac{d^{2}}{8}\left(2.25 \operatorname{Re}_{b}^{-0.31}+0.36 \operatorname{Re}_{b}^{0.06}\right)^{3.45}+0.7031 R(L-9.4) \operatorname{Re}_{c}^{-0.83336}
$$

For a fixed depth $\mathrm{L}$, the apparent viscosity is found by substituting equations (3.15) into (3.16) and then solving for $\mu$. In this shallow region, the effect of the ball dominates the contribution to the total drag. Once the apparent viscosities have been found, the effect of the ball can be isolated by computing the fractional contribution, $\mathrm{H}$, of the ball to the total drag.

$$
H=\frac{D_{b 2}}{D_{b 2}+D_{c 2}}
$$
meters)

The function $\mathrm{H}$ can be represented as a third-order polynomial in terms of the depth $\mathrm{L}$ (in

$$
H=669.86-199.94 L+19.95 L^{2}-0.665 L^{3}
$$

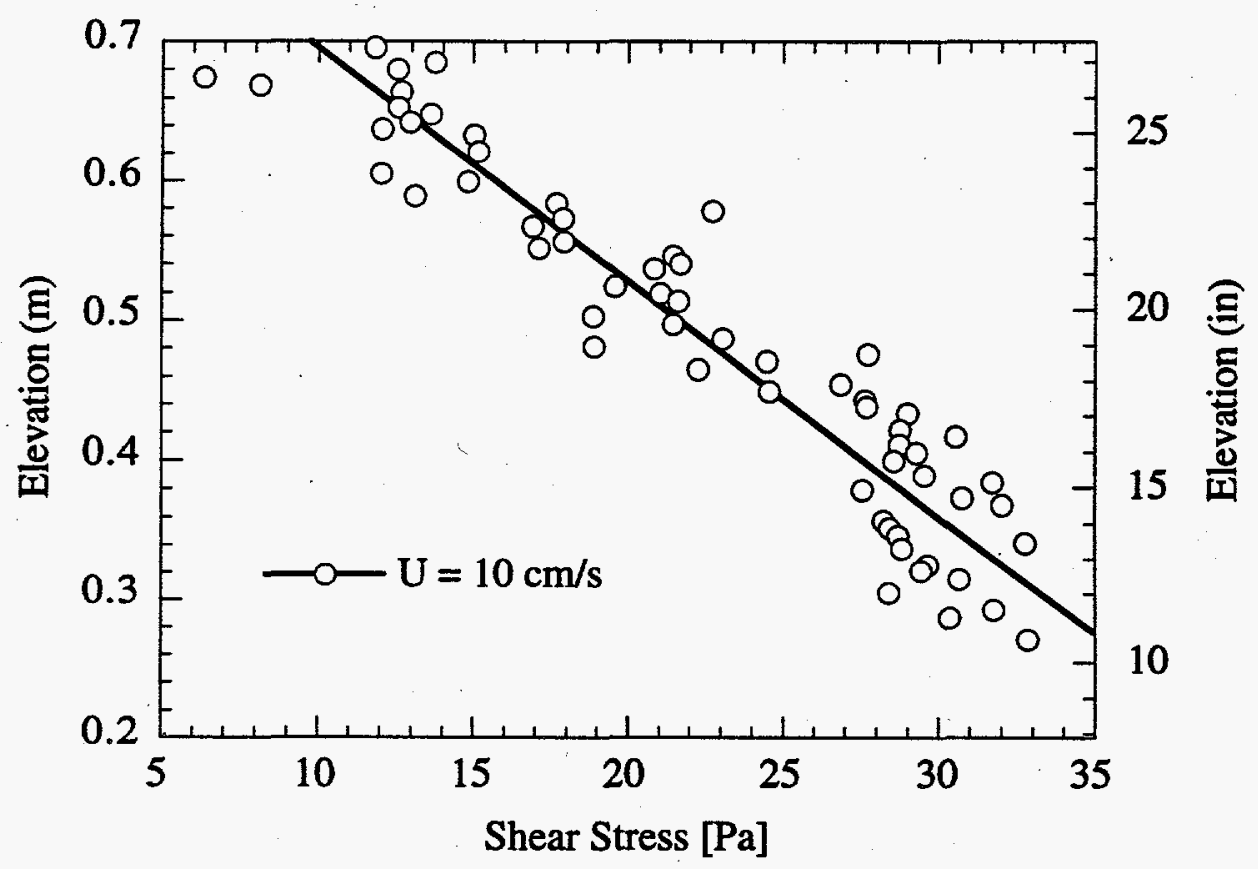

Figure 3.9. Shear Stresses in the Settled Region 
Therefore, the ball drag contributions as a function of depth are obtained by multiplying equations (3.16) and (3.17). From these results, the yield stress, $\tau_{\mathrm{o}}$, the consistency factor, $\mathrm{K}$, and the behavior index, $\mathrm{n}$, can be found by using a drag coefficient as a function of Reynolds number correlation for viscoplastic materials. It has been reported in the literature (Chhabra 1993) that, for viscoplastic materials at low Reynolds number,

$$
C_{D b}=\frac{24}{\operatorname{Re}_{\mathrm{Gb}}}, \quad \operatorname{Re}_{\mathrm{Gb}}=\frac{\rho \mathrm{U}^{2}}{\tau_{\mathrm{o}}+\mathrm{K}\left(\frac{\mathrm{U}}{\mathrm{d}}\right)^{\mathrm{n}}}
$$

where $\mathrm{Re}_{\mathrm{Gb}}$ is the generalized Reynolds number for viscoplastic fluids. The above correlation was also verified with the ball rheometer model apparatus for the 241-SY-101 simulant prepared at PNL and with a bentonite/clay/water mixture. The experimental correlations obtained with the ball rheometer model in both the waste simulant and Bentonite were

$$
\begin{gathered}
C_{\mathrm{Db}}=\frac{25.3}{\operatorname{Re}_{\mathrm{Gb}}^{1.03}} \quad(241-\mathrm{SY}-101 \text { Simulant) } \\
\mathrm{C}_{\mathrm{Db}}=\frac{22.3}{\operatorname{Re}_{\mathrm{Gb}}^{1.00}} \quad \text { (Bentonite) }
\end{gathered}
$$

The viscoplastic parameters are computed as a function of depth by solving three nonlinear equations obtained from equation (3.18) using the previously computed values for ball drag at three different measuring velocities. At a fixed depth, $\mathrm{L}$, the behavior index $\mathrm{n}$ is found by solving

$$
\frac{\left(\frac{U_{1}}{d}\right)^{n}-\left(\frac{U_{2}}{d}\right)^{n}}{\left(\frac{U_{2}}{d}\right)^{n}-\left(\frac{U_{3}}{d}\right)^{n}}=\frac{D_{1}(L)-D_{2}(L)}{D_{2}(L)-D_{3}(L)}
$$

where $D_{i}(L)$ denotes the ball drag at the measuring velocity, $U_{i}$. Having found $n, K$ is obtained from

$$
K=\frac{D_{1}(L)-D_{2}(L)}{3 \pi d^{2}\left[\left(\frac{U_{1}}{d}\right)^{n}-\left(\frac{U_{2}}{d}\right)^{n}\right]}
$$

and with $\mathbf{n}$ and $K$, the yield stress is calculated from 


$$
\tau_{\mathrm{o}}=\frac{\mathrm{D}_{1}(\mathrm{~L})}{3 \pi \mathrm{d}^{2}}-\mathrm{K}\left(\frac{\mathrm{U}_{1}}{\mathrm{~d}}\right)^{\mathrm{n}}
$$

The spatial variation of the consistency factor and the behavior index is shown in Figure 3.10 and that of the yield stress in Figure 3.11. Notice that the behavior index is greater than unity, thus the settled sludge exhibits shear thickening or dilatant behavior. This fluid behavior is not as common as shear thinning, and it has been observed in concentrated suspensions in which the suspending particles have irregular shapes. There is a range of strain rates for which the apparent viscosity of the material in the bottom sludge layer will increase as the shear force increases.

\subsubsection{Density}

The fluid density is obtained from

$$
\rho=\frac{B_{b}}{V g}
$$

where $\mathrm{V}$ is the ball volume and $\mathrm{g}$ is the gravitational constant. For static measurements, the buoyancy force on the ball is given by

$$
B_{b}=W_{b}+W_{c}-B_{c}-T_{s}
$$

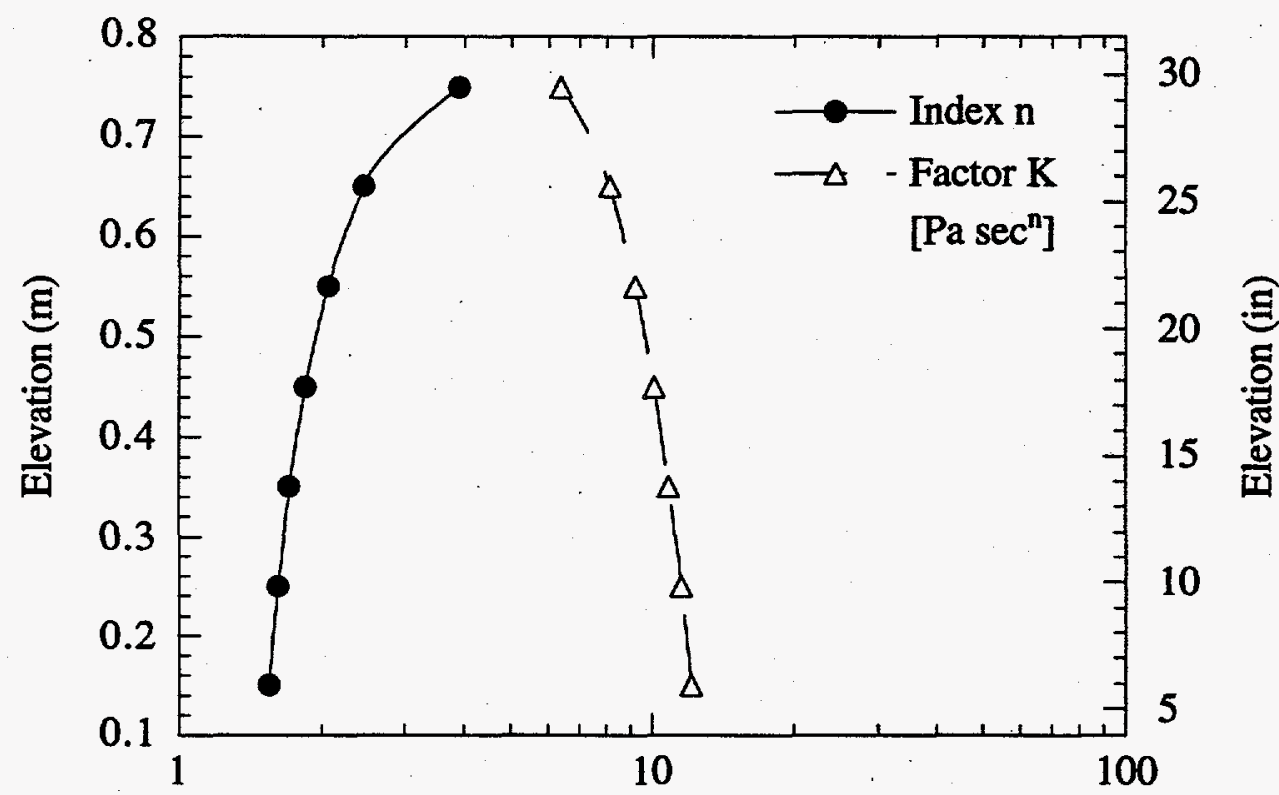

Figure 3.10. Parameters $\mathrm{K}$ and $\mathrm{N}$ Versus Elevation in the Settled Region 


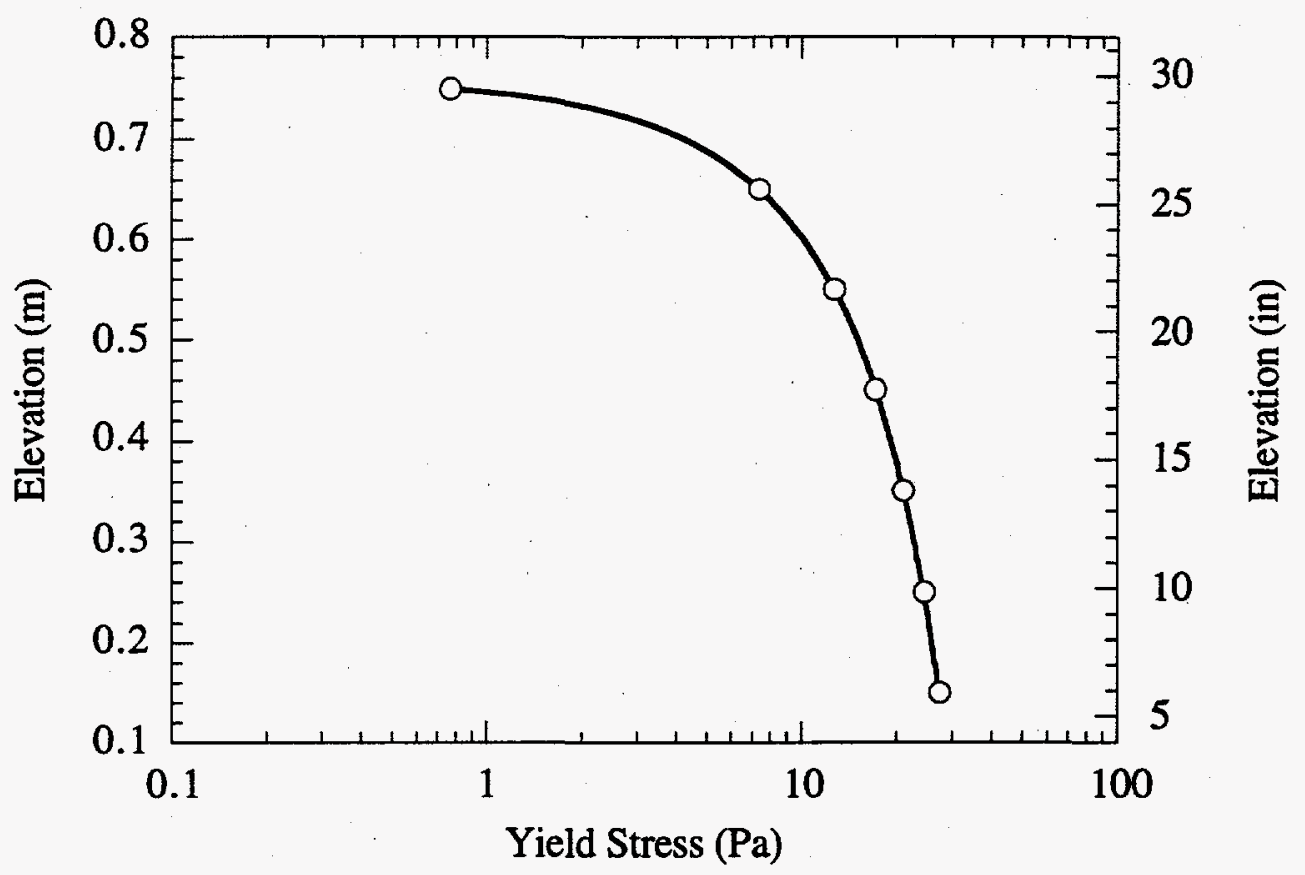

Figure 3.11. Yield Stress Versus Elevation in the Settled Region

where $T_{s}$ is the measured tension under static conditions. The total tension in the cable is measured when the ball is at rest in the fluid, and this value is subtracted from the reference tension measurement. Small corrections are applied to account for the weight of additional cable and the buoyancy force acting on this cable. Uncertainty in the density values is about $3 \%$. In addition, there may be a systematic uncertainty of another $4 \%$, which will be discussed below.

The density can also be determined from dynamic measurements. The dynamic method has great utility in the settled layer near the bottom of the tank, where very few static measurements were obtained and the effects of the yield stress of the material on the measurements are unknown. With dynamic measurements, such effects should cancel out. Adding Eq. (3.1) and the solving for the buoyancy on the ball we obtain

$$
B_{b}=W_{b}+W_{c}-B_{c}-\frac{T_{u}+T_{d}}{2}
$$

Note that the dynamic forces, such as drag, and the pulley friction vanish with the static method.

The densities determined by dynamic measurement were found to be in agreement with those obtained using static measurements, at least in the well-mixed regions of the fluid, which exhibited no measurable yield strength. The static density profiles from testing in both risers are shown in Figure 3.12 and the dynamic density from the riser 4A test is displayed in Figure 3.13. We believe that the density profiles are different for the two tests because of solids settling out 


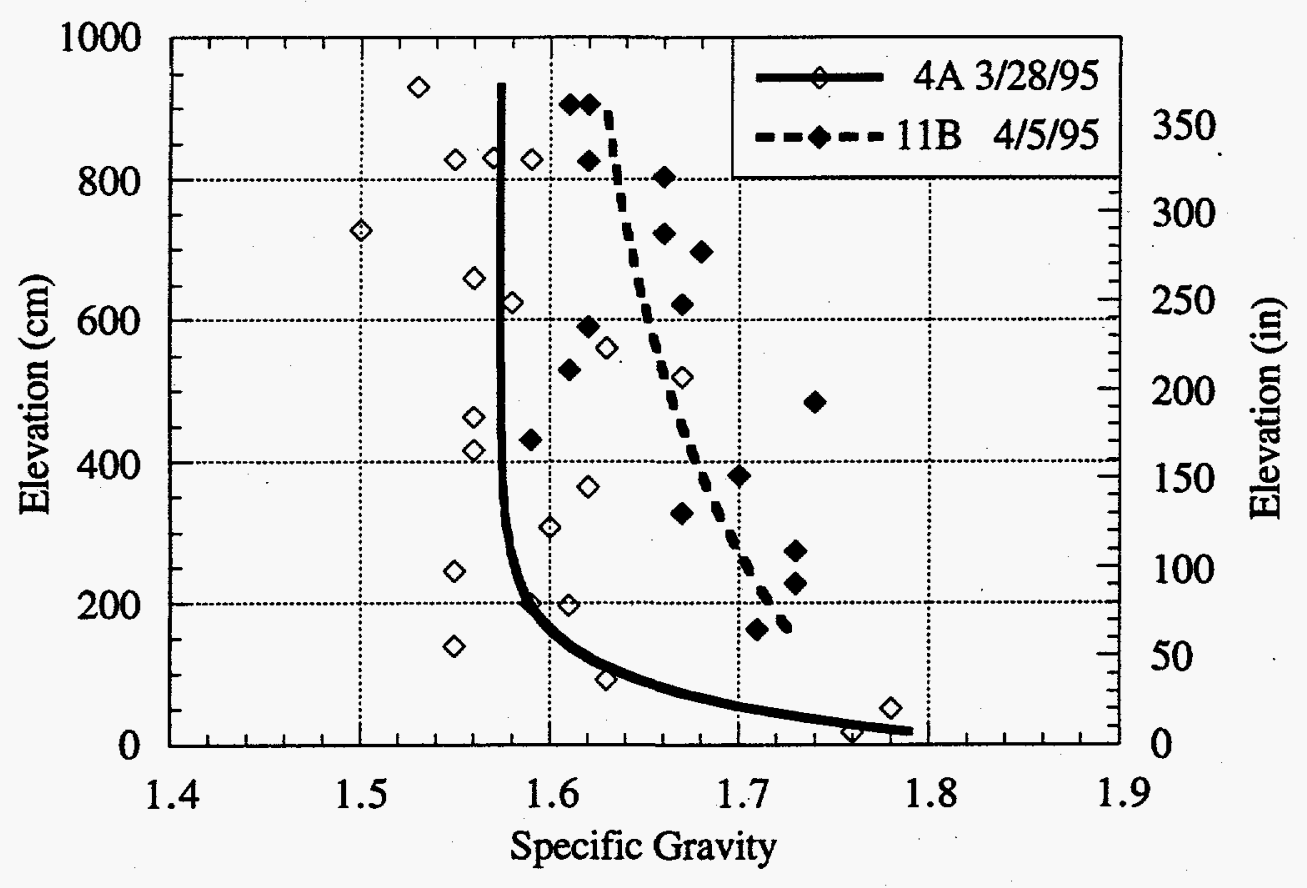

Figure 3.12. Static Density Versus Elevation

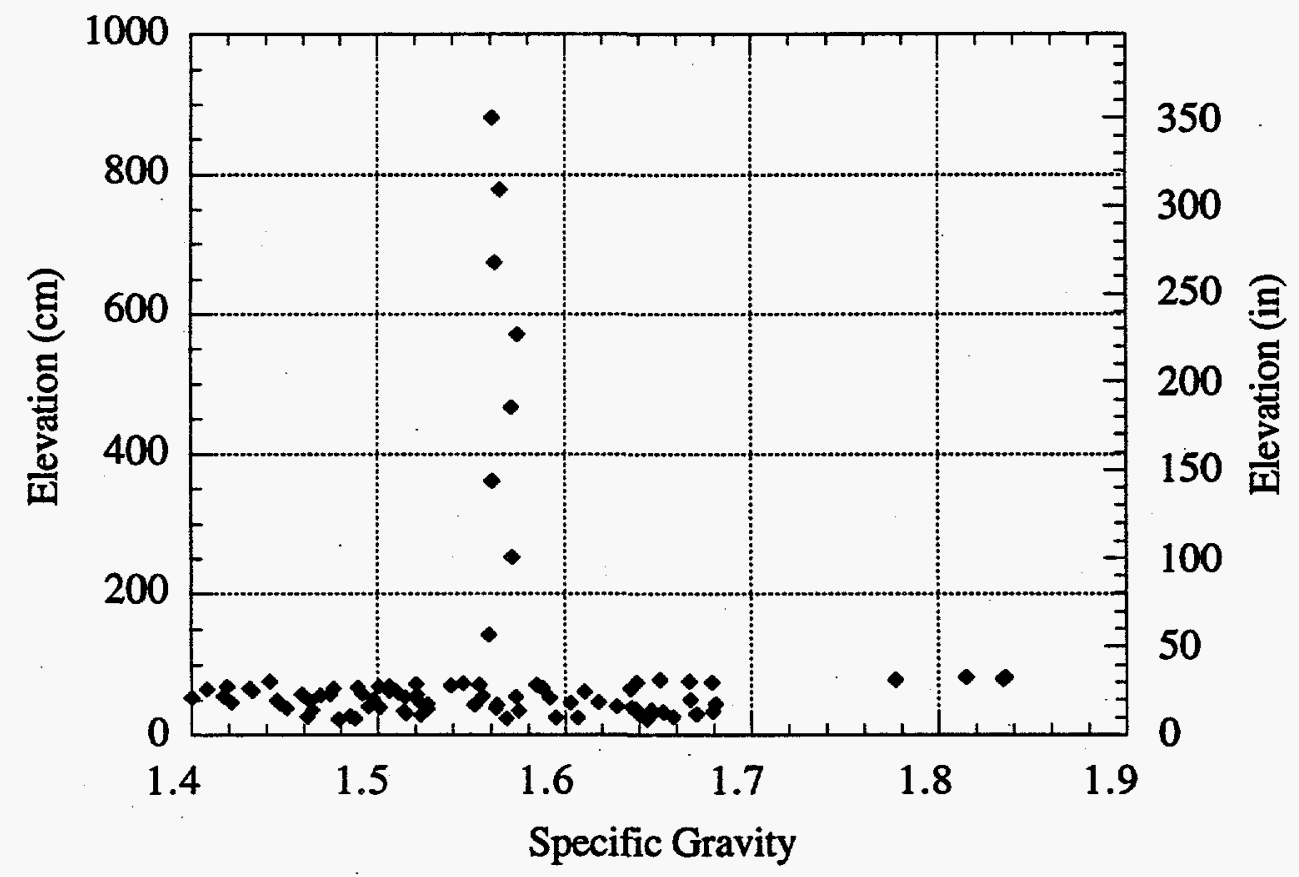

Figure 3.13. Density by the Dynamic Method Versus Elevation 
between pump runs. The first test (4A) was run one day after the mixer pump was operated; the second (11B) took place four days after operation of the mixer pump. However, dynamic data from $4 \mathrm{~A}$ indicate widely varying densities in the settled layer-from 1.4 to $1.7 \mathrm{~g} / \mathrm{cm}^{3}$. This uncertainty cannot be explained by measurement error alone. Dynamic measurements should provide reasonable immunity to the problem caused by fluid yield strength, because drag forces cancel when using this approach. More study of this question is needed.

\subsection{Error Analysis}

The precision with which we are able to measure quantities such as density and drag force depends primarily on the accuracy of the load cell chosen for the cable tension measurements. All data reported here were obtained with a nominal 444-N (100-lb) full-scale load cell. Because of the way the cable is deployed over the pulley, the effective load limit of this load cell is actually 222 $\mathrm{N}$. The advertised error for this load cell is $0.1 \%$ of the full-scale reading, or $0.2 \mathrm{~N}$ regardless of load. Indeed, our data show that the standard deviation of measurements made under static and dynamic conditions is in almost all cases $0.2 \mathrm{~N}$, and we will adopt this as the measurement error for all of our tests. In hindsight, these tests could have been performed with a nominal $222 \mathrm{~N}$ (50lb) full-scale load cell, which would have resulted in a measurement standard deviation of $0.1 \mathrm{~N}$, and significant improvements would have been realized especially in our density measurements. During the second test, on April 5, 1995, plans were made to use this load cell; however, practical difficulties occurred in the field that disallowed its use.

\subsubsection{Drag Force}

The drag force on the ball and cable depends on several load cell measurements. The contribution to the measurement error of the weight per unit length of cable is negligible, because that value is known to be more than $0.5 \%$ from laboratory measurements. The error in the buoyancy force exerted on the cable can also be neglected. While the fractional uncertainty in this value is similar to those of other measured quantities, the magnitude of this force is quite small. Even with the ball near the bottom of the tank, the volume of fluid displaced by the cable is less than $20 \%$ of the volume of the ball. The surface tension force due to cable wetting is also negligible $(<0.2 \mathrm{~N})$. All other quantities, such as the buoyancy force on the ball, the pulley friction, and the total measured tensions, contribute to the overall uncertainty. The uncertainty in the combined drag force $\mathrm{D}$ (ball and cable) is given by

$$
\delta \mathrm{D}=\delta \mathrm{B}_{b}+\delta \mathrm{T}_{i}+\delta f
$$

where $\mathrm{T}_{\mathrm{i}}$ denotes either an upward or a downward tension measurement.

Each measured force has an uncertainty of $0.2 \mathrm{~N}$. The buoyancy force exerted on the ball is determined from a total tension measurement in the fluid and a reference tension measurement (the same reference measurement is used for $T_{\mathfrak{i}}$ ). The frictional force is determined as the difference of two measurements, each with an uncertainty of $0.2 \mathrm{~N}$, divided by two. The uncertainty in the drag force becomes the square root of the sum of three squared values, each of which represents measurements of the tension in the cable and has an uncertainty of $0.2 \mathrm{~N}$. That is 


$$
\delta \mathrm{D}=\left[\delta \mathrm{T}_{\mathrm{i}}^{2}+\delta \mathrm{T}_{\mathrm{i}}^{2}+\frac{\delta \mathrm{T}_{\mathrm{i}}^{2}}{\sqrt{2}}\right]^{1 / 2}
$$

or

$$
\delta D \sim 0.3 \text { Newton }
$$

since

$$
\delta \mathrm{T}_{\mathrm{i}}=0.2 \text { Newton. }
$$

Except for measurements made at high speeds and measurements made in the settled layer, this value generally exceeds the measured drag forces.

\subsubsection{Density}

Density is determined by weighing the ball in the dome space above the fluid and then weighing it immersed in the fluid. The weight difference is due to the buoyancy force of the fluid exerted on the ball, and this force is proportional to the local fluid density. The cable provides a complication in that its weight and the buoyancy of the fluid on the cable must also be accounted for. The correction is a function of the depth at which the measurement is being made. The effect of the cable is small, because the volume of the immersed cable is never more than about $20 \%$ of the ball volume. One must know the density as a function of depth in order to solve for the buoyancy on the cable. In practice, what has been done is to solve for the cable buoyancy in an iterative manner using an average density for the entire waste rather than the true depth-dependent density. This procedure is valid to a high degree of precision if the density does not vary significantly with depth and if the contribution of the cable to the total buoyancy is small compared with the buoyancy force acting on the ball. Both conditions are met here, and negligible error is introduced by use of this approximate solution. The fractional uncertainty in the density is given by

$$
\frac{\delta \rho}{\rho}=\frac{\delta V}{V}+\frac{\delta B_{b}}{B_{b}}
$$

Let us consider the uncertainty in the buoyancy force, which is given by

$$
\delta \mathrm{B}_{\mathrm{b}}=\delta \mathrm{T}_{\mathrm{i}}+\delta \mathrm{B}_{\mathrm{c}}
$$

The uncertainty in the term involving the cable is negligible and to very good approximation

$$
\delta B_{b}=\delta T_{i}
$$

The uncertainty in $\Delta R$ is composed of two uncertainties, one for the reference measurement and one for the measurement in the fluid. Both of these measurements are uncertain by $0.2 \mathrm{~N}$. However, the same reference measurement is used for all determinations of density. If this meas- 
urement is in error, it will contribute systematically to all density determinations. Typically, the buoyancy force is about $6.2 \mathrm{~N}$. The fractional uncertainty in the measurement of the buoyancy force on the ball is then

$$
\frac{\delta B_{b}}{B_{b}}=\frac{0.2}{6.2}=0.03
$$

This error is a random error. In addition, there is a systematic error of $3 \%$, which can act to shift the final density profile either up or down by this amount. Returning to Eq. (3.18), we now consider the error in the ball volume. It is less than $1 \%$ of the total volume by laboratory measurement. This error will also contribute in a systematic manner to the error in the density, and thus we can expect a total systematic error of $4 \%$. In the plots of the density as a function of depth then, each point shown in the plots is uncertain by $3 \%$ of value, and the entire curve can be shifted up or down by $4 \%$ of the average value. 


\subsection{Void Fraction}

The void fraction instrument (VFI) is designed to measure the volume fraction of free gas, or void, existing at specific locations in a tank as opposed to dissolved gas in the liquid waste or gas absorbed on the solids. The VFI does not measure nor depend on the composition of the gas. It is deployed vertically through a riser by means of a crane and measures the void fraction in waste samples collected over a radius of $76.2 \mathrm{~cm}(2.5 \mathrm{ft})$ about the riser center about every $61 \mathrm{~cm}(2 \mathrm{ft})$ of elevation. Once the waste sample is isolated in the sample chamber, the chamber is pressurized with nitrogen gas. The void fraction is calculated from the initial and final pressures and temperatures and known system volumes. This section describes the physical system, theory of operation, uncertainties, and the reduction of data obtained from the deployment in risers 11B and 4A in Tank 241-SY-101.

\subsection{Description Of Void Fraction Instrument}

The VFI is shown deployed in a tank in Figure 4.1. The sample chamber and cover, an arm for lateral deployment and positioning of the chamber, pneumatic actuators, and temperature sensors are inside the tank. The equipment enclosure, outside of the tank, houses the pressurizing source and related hardware and temperature and the pressure sensors. A lifting point allows the device to be lowered into and removed from the tank by a crane. A long section of stainless steel pipe connects the lower and upper parts of the device. Inside this pipe, a very small-diameter line connects the pressurizing source to the sample chamber. Temperature sensors and pneumatic lines to run the actuators are also inside the pipe. The sample chamber, the exposed O-ring seals, the sample cover, the swing arm structure, the pivot point, and the pneumatically actuated cylinders are shown in more detail in Figure 4.2.

The gas compression technique for calculating void fraction uses three confined volumes: those of the sample chamber, the pressurization chamber, and the line that connects them. Each of these volumes and the deployment of the entire instrument are described in this section.

\subsubsection{Pressurizing Chamber and Connecting Line}

The pressurization chamber is connected to a supply of high-pressure nitrogen and can be remotely charged up to $3.45 \mathrm{Mpa}(500 \mathrm{psi})$. It can be isolated from the connecting line by a remotely operated valve. The volume of the pressurization chamber has been measured at $101.1 \pm 0.40 \mathrm{cc}\left(6.171 \pm 0.24\right.$ in. $\left.{ }^{3}\right)$. This includes the chamber itself, the volume of the lines between the valves on either side of the chamber, and the volume of the pressure transducers and lines connected to them. The volume of the pressurization chamber is selected to be approximately one-fourth that of the sample chamber to optimize overall system accuracy at void fractions of 0.2 to 0.3 . The pressurization chamber expands slightly with increasing internal pressure. However, this volume change is insignificant and does not affect system accuracy. 


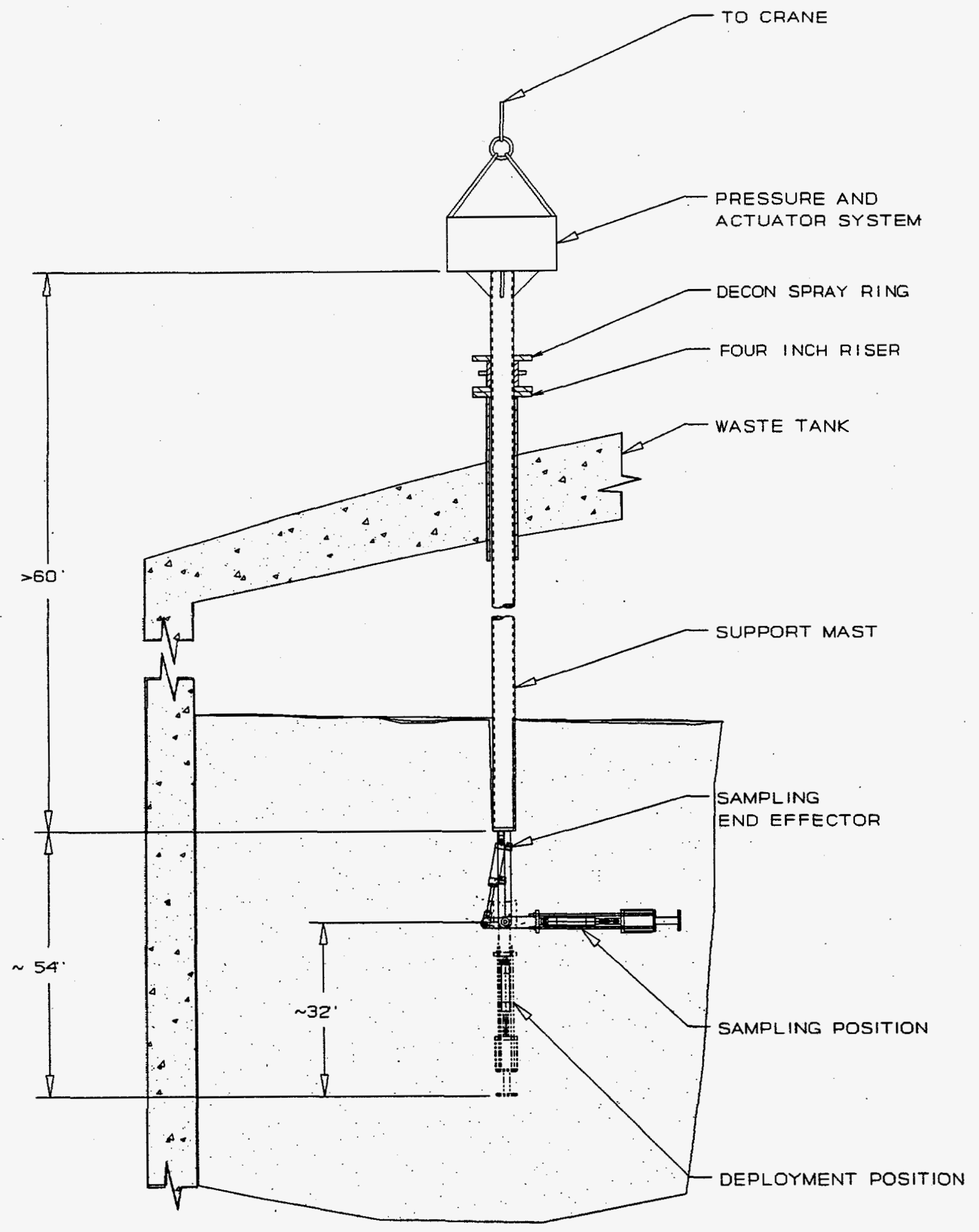

Figure 4.1. Void Fraction Instrument Deployed in a Tank 


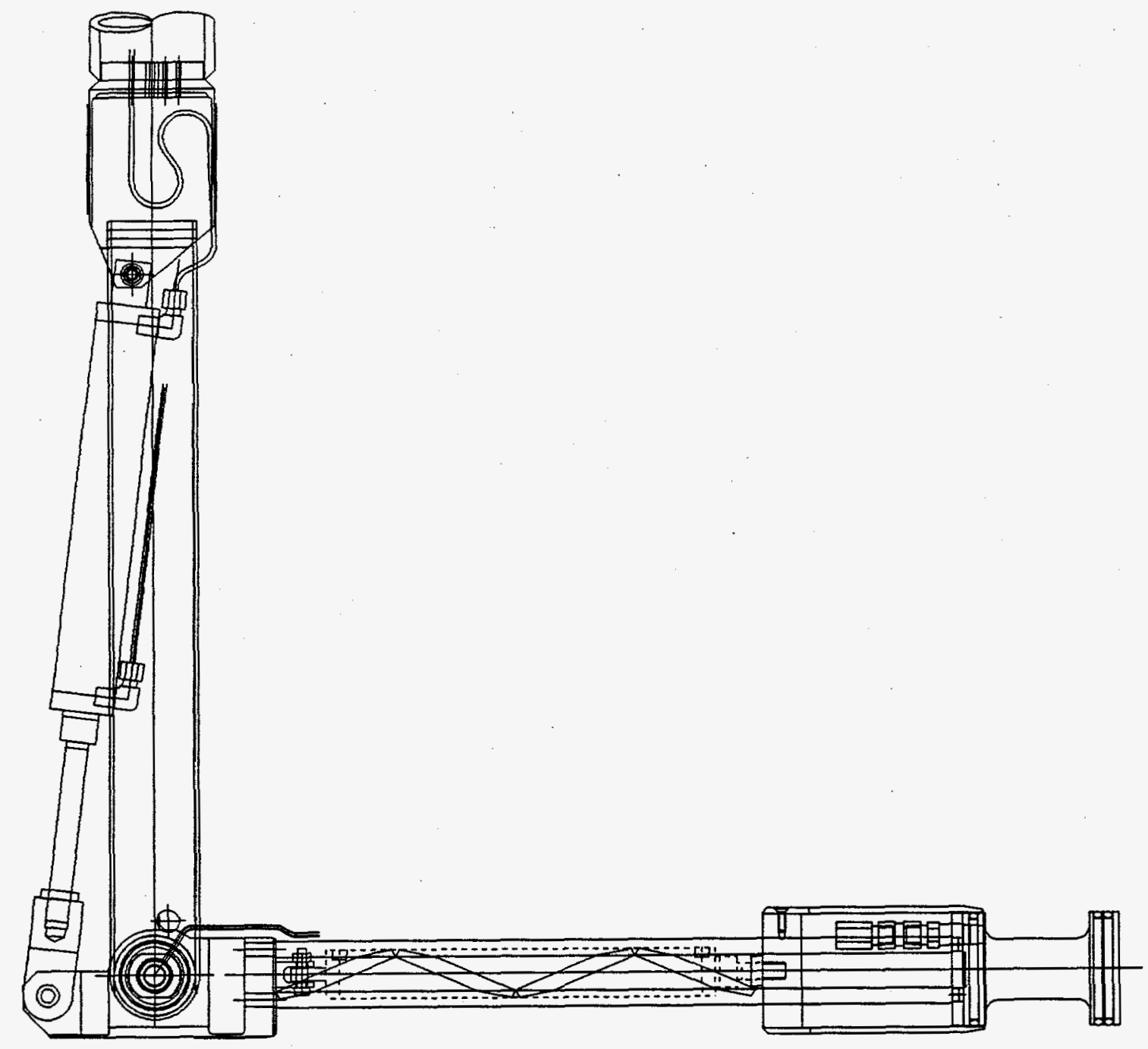

Figure 4.2. Void Fraction Instrument Rotating Arm Components 
The connecting line is a small, $1.6 \mathrm{~m}(1 / 16$-in.)-inside diameter, $18.3-\mathrm{m}(60-\mathrm{ft})$-long steel tube that connects the sample chamber and the pressurization chamber. The line wall thickness is $0.5 \mathrm{~mm}(0.02 \mathrm{in}$.). There is a check valve between the connecting line and the sample chamber so that waste cannot flow up into the line. The volume of the line includes the fittings below the solenoid valve at the bottom of the pressurization chamber and the fittings above the check valve at the sample chamber. The volume of the line and fittings has been measured as $27.04 \pm 1.16 \mathrm{cc}$ $\left(1.65 \pm 0.071\right.$ in. $\left.^{3}\right)$. The calculated volumetric compliances of the line and fittings and the measured compliance of the pressure transducer are insignificant.

\subsubsection{Sample Chamber}

The waste sample containing trapped gas is captured in the sample chamber. Three orthogonal views of the sample chamber are shown in Figure 4.3. The chamber is machined from a cylinder of stainless steel that has been chrome-plated. The side ligaments connecting the front and back of the chamber are intended to slice through and minimally deform the waste. The intent is to provide a straight path for the part of the waste that will be captured in the chamber. As the cover is closed, the sample is isolated using another slicing motion. The motion of the confining cover does not alter the effectiveness of the seals or change the internal volume of the sample chamber.

The sample chamber has a measured volume of $366.7 \mathrm{cc}\left(22.38 \mathrm{in.}{ }^{3}\right)$. The sample chamber is the most compliant component in the system. Its volume increases slightly as it is pressurized. While only a minor contributor to the overall system error if neglected, the compliance of the sample chamber has been included in the void fraction calculation. Once the chamber is closed and pressurized, no external force is required to keep it closed since the pressures acting on the opposite ends of the chamber are equal.
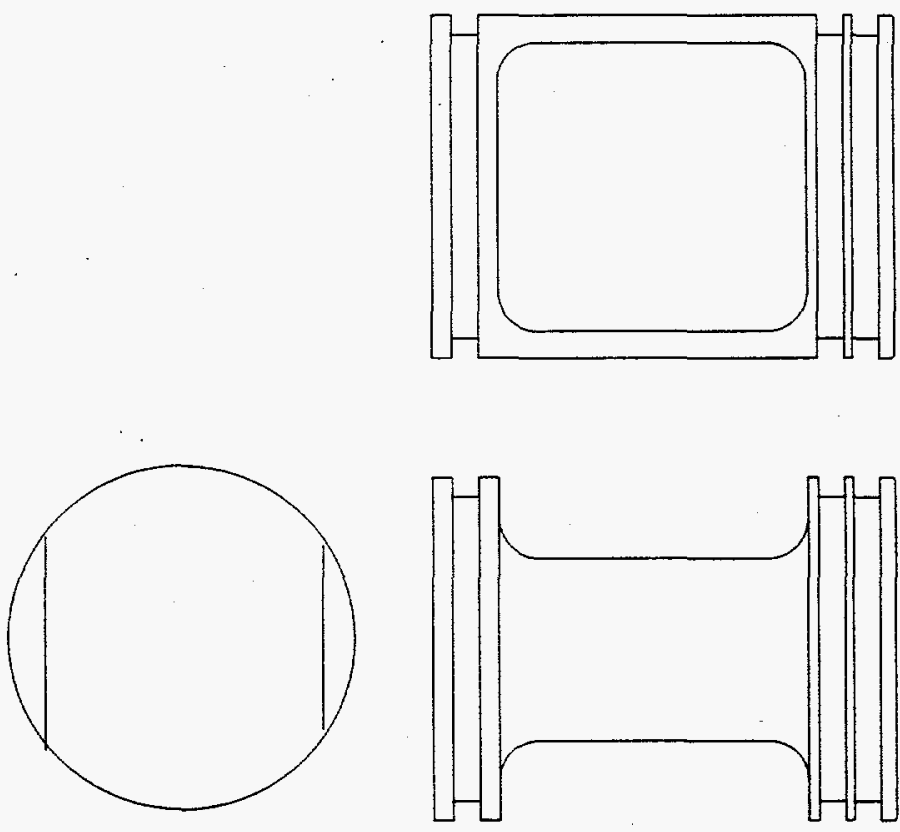

Figure 4.3. Void Fraction Instrument Sample Chamber 


\subsubsection{Seals}

The seals on the sample chamber deserve special consideration. Three O-rings seal the sample chamber; one at the rear and two at the front of the chamber. The single seal at the rear operates in a piston groove sliding in a cylinder. The two seals in the front are compressed by a taper on the leading edge of the cover as the chamber is closed. This may introduce additional wear to these seals, which are also exposed to potential impact and abrasion damage during deployment of the device with the chamber opened. Two seals give some additional backup for this failure mode.

The O-ring seals must not allow unacceptable leakage during pressurization. Fortunately, the time required to take the measurements from the time the sample chamber is first pressurized is typically about a minute, during which minor leakage can be tolerated without compromising measurement accuracy. Testing with the selected type and size of $\mathrm{O}$-rings on a mockup of the sample chamber in a waste simulant with the same chemical components as the tank waste has provided confidence in the selected seal design.(a) These tests showed no detectable degradation of the O-rings after simulated void fraction measurement missions. Absence of leakage can be confirmed by monitoring the final equilibrium pressure for an extended period.

The O-rings were inspected after deployment in riser 11B and they showed no damage at all. No wear, scratches or other marks were visible. The leaking of the seals during the deployment in this riser was likely due to an object or particle that disturbed the seals and kept the cover from completely closing.

During every close and open cycle of the cover, the two outer seals are compressed between the cover and the O-ring grooves. Normally, O-rings are compressed this way only when they are initially installed. Testing the seals has shown that is this not a problem; however, the way the pressure in the sample chamber is released significantly affects their reliability. The pressure across the seals during opening could be as high as $3.45 \mathrm{Mpa}(500 \mathrm{psi})$. In early tests with the chamber pressurized to over $1.72 \mathrm{MPa}(250 \mathrm{psi}$ ), the O-rings were blown out of their grooves when the cover was opened. To prevent this, vent holes were drilled near the end of the cover, and the cover opening rate was limited. With these modifications, the internal pressure is vented before the O-rings are exposed, and they are not blown from their grooves even with an internal pressure of $3.45 \mathrm{Mpa}(500 \mathrm{psi}$ ) and a void fraction of $100 \%$. The vent holes do not damage the O-rings. High-speed video of the O-rings during worst-case opening conditions has shown that they do not move detectably when the cover is opened.

A second issue related to opening the cover is the pressure pulse produced. If the pressure pulse in the waste were too energetic, nearby trapped gas might be released. This could affect the

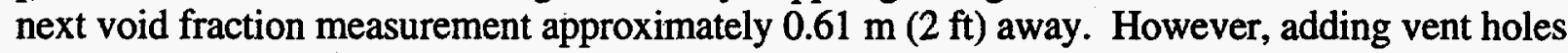
and reducing the opening rate mitigates this effect.

(a) Alzheimer, J. M. 1994. Testing of Void Fraction Measurement Device Seals and Sample Chamber Opening Response. Letter report, Pacific Northwest Laboratory, Richland, Washington. 


\subsubsection{Deployment of the VFI}

Figure 4.1 shows the lower end of the device in both the deployment and the sampling positions. The device is lowered through one of the four-inch risers and into the top part of the liquid layer in the deployment orientation.

Water lancing is performed in a separate operation to penetrate the crust layer. During deployment in riser 11B, the VFI penetrated the crust with little resistance. A hole had been waterlanced through the crust a considerable time before the deployment. The load on the crane decreased by approximately $890 \mathrm{~N}(200 \mathrm{lb})$ as the VFI past through the crust. In riser $4 \mathrm{~A}$, the water lance had been used only a few days before deployment of the VFI, and no decrease was detected in the load as the crust was penetrated.

Once below the crust, the swing arm is rotated 90 degrees to the horizontal. Once rotated to the horizontal, the device is then lowered to the desired depth in the tank. As the device is lowered, the tank waste flows around the swing arm, sample cover, and sample chamber. The geometry of the sample chamber was selected to minimize the disturbance of the waste as much as possible so that the trapped bubbles are not released as a sample is captured.

To allow the sample chamber metal to come into thermal equilibrium with the waste, the VFI is held in the waste for several minutes after insertion before being moved to the first sample location. Once initial thermal equilibrium of the sample chamber and waste is established, additional hold times between sample locations are not required because the temperature does not vary enough in the waste to adversely effect the measurements. For the initial sample location, the sample chamber had previously been at the ambient air temperature, which was near freezing during December and January. The temperatures in the equipment enclosure are controlled and do not undergo any changes that could adversely effect the accuracy of the results. The temperatures on the mast are not controlled. For some samples, the temperatures on the mast outside the tank were significantly lower than that part of the mast inside the waste. However, the temperature at the individual mast temperature sensors had reached steady-state values because the same hold time was used for reaching thermal equilibrium of the sample chamber and waste.

The arm is rotated below the crust but above the nonconvective layer to minimize the loads on the swing arm and pivot. With the yield strength of the nonconvective sludge estimated as high as $6,700 \mathrm{~Pa}$, the drag on the horizontal arm and chamber in the nonconvective layer could be as high as $2,225 \mathrm{~N}(500 \mathrm{lb})$, based on a projected area of approximately $840 \mathrm{~cm}^{2}(130 \mathrm{in.} 2)$ and an estimated effective yield zone four times the projected area. The arm is designed for this load when it is in the horizontal orientation, but the pneumatic cylinder is not strong enough to rotate the arm at these high loads. Neither is the arm designed to withstand the high torque associated with rotating about the vertical axis while in sludge of this strength.

When the VFI is in the intended location, the sample chamber is closed by sliding the cover horizontally over the sample chamber and making a seal at the O-rings. After pressurizing the sample and measuring the void fraction, the cover is returned to its original location, releasing the sample. The device can then be lowered to a new test location and another measurement taken. 
After all measurements from a riser are completed, the swing arm is returned to the initial, vertical configuration, and the device is removed from the tank.

The detailed steps in making generic void fraction measurements are as follows:

1. The VFI is lowered to the desired elevation with the valve closed between the pressurization chamber and the line. The pressure in the connecting line is approximately equal to the pressure in the waste at the previous sample location. If the pressure in the line were significantly higher, gas would flow out of the line through the check valve. Because thedevice has probably just been lowered from a higher elevation, the pressure in the line is slightly lower than the pressure in the waste at the sample site due to the increasing hydrostatic pressure.

2. The pressurization chamber is pressurized to approximately $3.45 \mathrm{Mpa}$ ( $500 \mathrm{psi}$ ) by remotely opening a valve between the high-pressure cylinder and the pressurization chamber. Once charged, the valve between the high-pressure cylinder and the pressurization chamber is closed.

3. After sufficient time for the nitrogen gas to reach thermal equilibrium, the pressures in the pressurization chamber and the connecting line are measured and recorded, along with the temperature of the pressurization chamber, connecting line, and sample chamber.

4. The valve between the pressurization chamber and the connecting line is opened. Gas from. the pressurization chamber flows into the connecting line and the sample chamber. The temperature of the gas in the pressurization chamber will drop due to expansion, while the gas temperature in the sample will rise due to compression. The long length of smalldiameter connecting line precludes rapid pressure changes. The thermal mass of the surrounding container structure is much larger than the gas and thermal equilibrium is achieved relatively quickly. Cold testing confirmed this.

5. When the system approaches thermal equilibrium, the pressure in the three chambers come to a final, uniform steady-state value. If leakage occurs at the seals, the pressure would continue to drop as material is lost from the sample chamber. The data collection process includes an adequate number of readings to ensure that unacceptable leakage can be detected.

6. The temperatures of the three volumes are recorded along with the final equilibrium pressure.

7. If a second pressurization of the same sample is desired, the valve between the pressurization chamber and the connecting line is closed, the pressurization chamber repressurized, and steps 2 through 6 are repeated.

8. With the valve between the pressurization chamber and the connecting line closed, the sample chamber is opened. The higher-pressure gas in the connecting line flows through the check valve and into the tank. The line pressure drops to the pressure of the waste at the sample chamber. This pressure is recorded as the initial sample chamber pressure. 
9. Based on the various pressure and temperature readings that are recorded and the known volumes, the void fraction of the sample is calculated.

10. Steps 1 through 9 are repeated for the next location.

\subsection{Calculation of the Void Fraction}

The void fraction is determined by carefully measuring the compressibility of a sample of waste. The trapped gases in the waste sample are assumed compressible, while the solids and liquids are incompressible. The higher the void fraction is in the waste the more compliant or compressible the waste. The void fraction instrument compresses the waste sample with nitrogen gas. By knowing the initial and final conditions, the parameters of the system, and the approximate characteristics of the waste, the void fraction can be accurately calculated. Following is a derivation of the required equations and a method to estimate the system error caused by individual parameter errors.

\subsubsection{Analytic Model Formulation}

The basic concept in determining the void fraction is that the number of moles of gas in the system is conserved during the pressurization. The initial amount of gas includes the gas in the pressurization chamber and the connecting line and free gas existing as bubbles or pockets in the waste sample. The final amount of gas in the system includes the gas in the pressurization chamber and the connecting line, the free gas remaining in the waste, and a small amount that may have condensed or dissolved in the waste.

The pressurizing chamber, connecting line, and sample chamber have their own temperature, pressure, and volume. The initial and final pressures and temperatures of the nitrogen gas charge in the pressurizing chamber are measured for each test. The pressures in the connecting lines are measured with a pressure transducer. The gas temperatures in the connecting lines vary along their length. The lines extend from inside the equipment enclosures through the support masts and to the sample chambers. The gas inside the connecting lines and fittings is at essentially the same temperature as the tube walls at equilibrium. The tube wall temperatures are measured at several locations along the lines and averaged to calculate the void fractions.

The temperature of the waste in the sample chamber is measured by RTDs about one meter from the sample chamber near the lower arm pivot at the same elevation. The initial pressure in the sample chamber is assumed equal to the ambient hydrostatic pressure of the waste. At the end of each test, after the sample chamber is opened, the gas in the connecting line escapes through the check valve until equilibrium is reached. The line pressure, measured by a pressure transducer in the equipment enclosure, is then recorded as the initial waste pressure.

The following nomenclature will be used to define the volumes and properties in the model: 


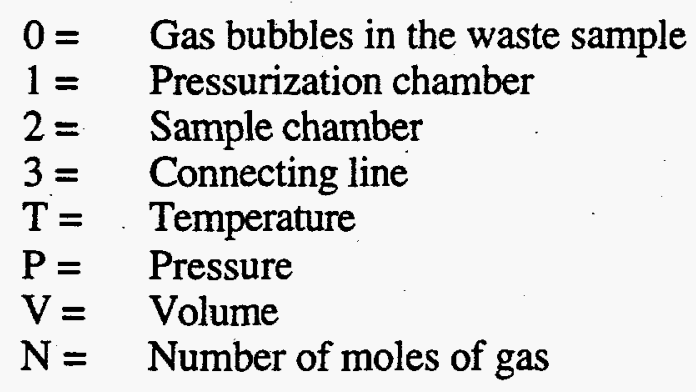

The subscripts $i$ and $f$ indicate initial and final conditions, respectively. For example, $P 1_{i}$ is the initial pressure in the pressurization chamber and $\mathrm{T}_{\mathrm{f}}$ is the final temperature in the connecting line. All pressures and temperatures are absolute. Pressure and temperature changes are denoted with a $\Delta$; for example, $\Delta \mathrm{P} 1=\mathrm{P} 1_{\mathrm{f}}-\mathrm{P} 1_{\mathrm{i}}$.

The volumes of the pressurization chamber and connecting line are essentially constant and do not change with pressure. The pressurization chamber is a thick-walled, steel vessel. The connecting line itself is very rigid and does not expand detectably during pressurization. The sample chamber, however, is less rigid than the connecting line and pressurization chamber. The cover undergoes hoop expansion, and the sample chamber length increases because the side ligaments stretch when pressurized. These effects have been included in the model by computing a change in sample chamber volume proportional to the pressure change:

$$
\Delta \mathrm{V} 2=\mathrm{B}^{*}\left(\mathrm{P} 2_{\mathrm{f}}-\mathrm{P} 2_{\mathrm{i}}\right) * \mathrm{~V} 2_{\mathrm{i}}
$$

where $B$ is the volumetric compliance of sample chamber.

The gas in the system is assumed to behave as an ideal gas. If the volume, pressure, and temperature of the gas in each volume are all known, the number of moles of gas can be calculated using ideal gas state relations. The gas in the waste sample may depart from ideal gas behavior for a number of reasons. Some of the species, specifically ammonia, may dissolve in the liquid as pressure increases. The mixture itself may follow a non-ideal relation at higher pressures. These effects are included in the calculation as if a small fraction of the gas in the sample chamber were physically removed from the system.

Equating the initial and final amount of gas in the system results in the following:

$$
\mathrm{N} 1_{\mathrm{i}}+\mathrm{N} 2_{\mathrm{i}}+\mathrm{N} 3_{\mathrm{i}}=\mathrm{N} 1_{\mathrm{f}}+\mathrm{N} 2_{\mathrm{f}}+\mathrm{N} 3_{\mathrm{f}}+\mathrm{Nz}
$$

where $\mathrm{Nz}$ is the number of moles of gas, originally in the sample chamber, that condenses or otherwise 'disappears.' We define $\mathrm{Nz}$ as a simple fraction, $\mathrm{k}$, of the initial number of moles in the sample chamber

$$
\mathrm{Nz}=\mathrm{kN} 2_{\mathrm{i}}
$$

From the ideal gas law, the relationship between the pressures, volumes, temperatures, and moles of gas is given by: 


$$
\mathrm{N}=\frac{\mathrm{PV}}{\mathrm{RT}}
$$

where $\mathrm{R}$ is the universal gas constant. Substituting in (4.1) the various numbers of moles yields

$$
\begin{aligned}
\frac{P 1_{i} V 1}{R T 1_{i}}+\frac{P 2_{i} V 0}{R T 2_{i}}+\frac{P 3_{i} V 3}{R T 3_{i}}= & \\
& \frac{P 1_{f} V 1}{R T 1_{f}}+\frac{P 2_{f} V 0}{R T 2_{f}}+\frac{P 2_{f} \Delta V 2}{R T 2_{f}}+\frac{P 3_{f} V 3}{R T 3_{f}}+k \frac{P 2_{j} V 0}{R T 2_{i}}
\end{aligned}
$$

Now define the volume ratios, $\mathrm{K} 1=\mathrm{V} 1 / \mathrm{V} 2$ and $\mathrm{K} 2=\mathrm{V} 3 / \mathrm{V} 2$, and the void fraction, $\alpha=\mathrm{V} 0 / \mathrm{V} 2$. Substituting these definitions for the volume ratios in (4.2), applying the definition of pressure and temperature differentials, and solving for the void fraction yields

$$
\alpha=\frac{K 1\left(\frac{P 1_{i}+\Delta P 1}{T 1_{i}+\Delta T 1}-\frac{P 1_{i}}{T 1_{i}}\right)+K 3\left(\frac{P 3_{i}+\Delta P 3}{T 3_{i}+\Delta T 3}-\frac{P 3_{i}}{T 3_{i}}\right)+\beta \Delta P 2 \frac{P 2_{i}+\Delta P 2}{T 2_{i}+\Delta T 2}}{\frac{P 2_{i}}{T 2_{i}}-(1+k) \frac{P 2_{i}+\Delta P 2}{T 2_{i}+\Delta T 2}}
$$

The initial and final temperatures in each volume are essentially the same because the thermal mass of the gas relative to the waste and instrument hardware is very small. The gas temperature quickly comes into thermal equilibrium with the waste or hardware. If $\Delta \mathrm{T} 1, \Delta \mathrm{T} 2$, and $\Delta \mathrm{T} 3$ are zero, $\mathrm{T} 1_{\mathrm{i}}=\mathrm{T} 1_{\mathrm{f}}=\mathrm{T} 1, \mathrm{~T} 2_{\mathrm{i}}=\mathrm{T} 2_{\mathrm{f}}=\mathrm{T} 2$, and $\mathrm{T} 3_{\mathrm{i}}=\mathrm{T} 3_{\mathrm{f}}=\mathrm{T} 3$. Equation (4.3) can be simplified to

$$
\alpha=\frac{\mathrm{K} 1 \frac{\mathrm{T} 2}{\mathrm{~T} 1} \Delta \mathrm{P} 1+\mathrm{K} 3 \frac{\mathrm{T} 2}{\mathrm{~T} 3} \Delta \mathrm{P} 3+\beta \Delta \mathrm{P} 2\left(\mathrm{P} 2_{\mathrm{i}}+\Delta \mathrm{P} 2\right)}{\mathrm{P} 2_{\mathrm{i}}-(1+\mathrm{k})\left(\mathrm{P} 2_{\mathrm{i}}+\Delta \mathrm{P} 2\right)}
$$

Either of these equations can be used to calculate the void fraction from the initial and final pressures and temperatures, system volumes, compliance of the sample chamber, and assumed properties of the trapped gas.

\subsubsection{System Uncertainty Analysis}

The uncertainty in the calculated void fraction due to errors in the individual parameters can be estimated by taking derivatives of Equation (4.4) with respect to each of the individual parameters. The estimate of the error in the void fraction prediction due to an error in parameter $Q$ is then 


$$
\Delta \alpha_{\mathrm{Q}}=\Delta \mathrm{Q} \frac{\mathrm{d} \alpha}{\mathrm{dQ}}
$$

where $\Delta \mathrm{Q}$ is the error in the parameter $\mathrm{Q}$, and $\mathrm{d} \alpha / \mathrm{dQ}$ is the derivative of the void fraction equation with respect to parameter $Q$. This equation is valid for small values of parameter errors. The complete expressions for the various d $\alpha / \mathrm{dQ}$ terms are given in Appendix $\mathrm{E}$.

To evaluate the total system error for actual operating conditions, a baseline set of conditions was selected from data set 12-21-95.016, recorded December 21, 1995, approximately $43 \mathrm{~cm}$ (17 in.) from the tank bottom at riser 11B. These parameters and their estimated errors are listed in Table 4.1. The estimates of the errors are based on sensor calibration data, calculated values based on the physical system, or estimates of the waste properties. These parameters are discussed in more detail in Appendix $\mathrm{E}$.

These parameter errors were then used to estimate the overall error in the void fraction measurements due to these individual errors at voids of 2,15 and $30 \%$. This represents the total

Table 4.1. Void Fraction Parameter Error Estimates

\begin{tabular}{|c|c|c||}
\hline Parameter & Value & $\begin{array}{c}\text { Estimate Error in } \\
\text { Parameter }\end{array}$ \\
\hline \hline $\mathrm{T} 1$ & $293.6 \mathrm{~K}$ & $0.5 \mathrm{~K}$ \\
\hline $\mathrm{T} 2$ & $319.8 \mathrm{~K}$ & $1.0 \mathrm{~K}$ \\
\hline $\mathrm{T} 3$ & $301.0 \mathrm{~K}$ & $1.0 \mathrm{~K}$ \\
\hline$\Delta \mathrm{T} 1$ & $0.1 \mathrm{~K}$ & $0.1 \mathrm{~K}$ \\
\hline$\Delta \mathrm{T} 2$ & $0.1 \mathrm{~K}$ & $0.1 \mathrm{~K}$ \\
\hline$\Delta \mathrm{T} 3$ & $0.1 \mathrm{~K}$ & $0.1 \mathrm{~K}$ \\
\hline $\mathrm{P} 1_{\mathrm{i}}$ & $3.22 \mathrm{MPa}$ & $2.07 \mathrm{kPa}$ \\
\hline $\mathrm{P} 2_{\mathrm{i}}$ & $0.246 \mathrm{MPa}$ & $6.9 \mathrm{kPa}$ \\
\hline $\mathrm{P} 3_{\mathrm{i}}$ & $0.236 \mathrm{MPa}$ & $2.07 \mathrm{kPa}$ \\
\hline $\mathrm{PF}$ & $\mathrm{Calculated}$ & $2.07 \mathrm{kPa}$ \\
\hline $\mathrm{K} 1$ & 0.2755 & $0.004 \mathrm{~K} 1$ \\
\hline $\mathrm{K} 3$ & 0.0637 & $0.050 \mathrm{~K} 3$ \\
\hline $\mathrm{k}$ & 0.0185 & $0.5 \mathrm{k}$ \\
\hline$B$ & $7.13 \mathrm{cc} / \mathrm{MPa}$ & $0.2 \mathrm{~B}$ \\
\hline
\end{tabular}


range of void fraction for which the device was designed. For each void fraction, two pressurizations were considered. The first started with the sample chamber at ambient pressure (2.43 atm); the second started with the sample chamber at the final equilibrium pressure for the previous case to simulate a double pressurization.

The predicted errors in the void fraction for these cases are listed in Table 4.2. All errors are given in percent void. The individual error contributors ranged from virtually zero up to slightly less than half a percent. The errors in the pressure and temperature measurements were not major contributors to the overall void fraction error because of the very accurate sensors used and the high pressure. For the range 0 to $15 \%$ void, the parameters with major contributions to the overall error were 1) connecting line volume, 2) the parameter ' $\mathrm{k}$ ' that models the real gas behavior, and 3) the compliance of the sample chamber.

Table 4.2. Estimate of Error Contributions for System Parameters (in units of \% void)

\begin{tabular}{||c|c|c|c|c|c|c||}
\hline \multirow{2}{*}{ Parameter } & \multicolumn{2}{|c|}{$2 \%$ void } & \multicolumn{2}{c|}{$15 \%$ void } & \multicolumn{2}{c|}{$30 \%$ void } \\
\cline { 2 - 7 } & First $\Delta \mathrm{P}$ & Second $\Delta \mathrm{P}$ & First $\Delta \mathrm{P}$ & Second $\Delta \mathrm{P}$ & First $\Delta \mathrm{P}$ & Second $\Delta \mathrm{P}$ \\
\hline $\mathrm{P} 1_{\mathrm{i}}$ & 0.000 & 0.000 & 0.000 & 0.000 & 0.000 & 0.000 \\
\hline$\Delta \mathrm{P} 1$ & 0.027 & 0.027 & 0.036 & 0.036 & 0.046 & 0.046 \\
\hline $\mathrm{P} 2_{\mathrm{i}}$ & 0.009 & 0.008 & 0.064 & 0.063 & 0.161 & 0.159 \\
\hline$\Delta \mathrm{P} 2$ & 0.004 & 0.004 & 0.020 & 0.020 & 0.049 & 0.049 \\
\hline $\mathrm{P} 3_{\mathrm{i}}$ & 0.000 & 0.000 & 0.000 & 0.000 & 0.000 & 0.000 \\
\hline$\Delta \mathrm{P} 3$ & 0.006 & 0.006 & 0.008 & 0.008 & 0.010 & 0.010 \\
\hline $\mathrm{T} 1$ & 0.017 & 0.004 & 0.038 & 0.017 & 0.064 & 0.036 \\
\hline$\Delta \mathrm{T} 1$ & 0.011 & 0.014 & 0.011 & 0.016 & 0.012 & 0.017 \\
\hline $\mathrm{T} 2$ & 0.004 & 0.008 & 0.045 & 0.048 & 0.092 & 0.094 \\
\hline$\Delta \mathrm{T} 2$ & 0.001 & 0.001 & 0.006 & 0.008 & 0.011 & 0.016 \\
\hline $\mathrm{T} 3$ & 0.022 & 0.005 & 0.022 & 0.009 & 0.022 & 0.012 \\
\hline$\Delta \mathrm{T} 3$ & 0.002 & 0.003 & 0.003 & 0.003 & 0.003 & 0.004 \\
\hline $\mathrm{k}$ & 0.021 & 0.029 & 0.156 & 0.214 & 0.323 & 0.471 \\
\hline $\mathrm{K} 1$ & 0.039 & 0.010 & 0.090 & 0.040 & 0.149 & 0.085 \\
\hline $\mathrm{K} 3$ & 0.333 & 0.082 & 0.333 & 0.141 & 0.334 & 0.182 \\
\hline $\mathrm{B} 3$ & 0.211 & 0.063 & 0.164 & 0.096 & 0.132 & 0.106 \\
\hline $\mathrm{ISuml}$ & 0.708 & 0.264 & 0.997 & 0.718 & 1.409 & 1.289 \\
\hline $\mathrm{rms}$ & 0.399 & 0.113 & 0.425 & 0.292 & 0.547 & 0.561 \\
\hline
\end{tabular}


Some method must be used to combine the individual errors into an overall system error. The most conservative method is to sum the absolute value of all contributors. Even for this conservative approach, the errors sum to less than one percent for voids under $15 \%$ observed in 241-SY-101. If the less conservative approach is taken, that of calculating the root mean square of the individual errors, the errors are generally less than half the summed values.

The table shows that errors calculated for the second pressurizations are all less than for the first pressurizations. Increased accuracy on the second pressurization might imply that double pressurizations should be used for all samples. However, the overall system accuracy depends much more strongly on the insertion related factors. For all tests in the laboratory and in 241-SY101 , the calculated void fractions for first and second pressurizations were nearly identical. The spatial variations in the void fractions are larger than the differences between first and second pressurization readings. The use of available time appears better spent in obtaining additional data at other locations rather than using double pressurizations.

\subsubsection{Overall Sampling Uncertainty}

This section addresses errors stemming from small bubble size, insertion errors, waste yield strength, and thermal equilibrium effects. The solubility of ammonia (and other gases) was previously addressed by Allemann (1994) and found to be neglible.

\subsubsection{Bubble Size}

The pressure inside the bubbles is greater than the 1.5-2.5 atm ambient hydrostatic pressure in the waste because of surface tension. If the surface tension pressure is significant, the VFI would under-predict the void fraction. However the pressure added by surface tension is negligible except for very small bubbles. Surface tension adds $0.0004 \mathrm{~atm}$ to a 1 -mm-diameter bubble and only 0.04 atm to a 10 -micron bubble. Surface tension becomes significant only for bubbles less than one micron in diameter. Studies of gas release signatures from Brewster et al. (1995) and photomicrographs of core samples from Tank 241-SY-101 (Herting et al. 1991) indicate that the volume average bubble size is on the order of a few hundred microns.

\subsubsection{Waste Yield Strength}

The waste must have some strength in order to retain the gas bubbles. As the waste sample is compressed, the pressure inside the bubbles can be slightly less than the pressure measured by the pressure transducer, because the surrounding material supports some of the load. On the other hand, surface tension will increase the pressure slightly. The relatively high pressurization pressure minimizes both effects.

\subsubsection{Thermal Equilibrium}

The temperatures inside the bubbles are not necessarily the same as the pressures and temperatures measured by the transducers. The bubbles' temperatures will tend to increase temporarily upon compression until heat transfer to the waste reestablishes equilibrium. Bubbles 
have negligible thermal mass compared with the waste and system hardware, so the transient time is short and the initial and final temperatures are essentially equal. Thermal equilibrium of the sample due to gas compression is not an issue, even for the largest bubbles.

However, thermal equilibrium between the waste and the VFI structure must be considered, particularly for the first void fraction measurement after the VFI enters the waste. Transient heat transfer calculations indicate that a 10-minute wait is sufficient to reduce the maximum temperature difference to below $0.6^{\circ} \mathrm{C}\left(1^{\circ} \mathrm{F}\right)$. A 20 -minute wait is used in actual testing to ensure thermal equilibrium.

The temperature of the waste in the sample chamber is measured by RTDs located about one meter from the sample chamber near the lower arm pivot at the same elevation. The temperature profiles for 241-SY-101 and other tanks indicate that the temperature is predominantly a function of elevation and not horizontal location, at least for the risers that are available for void fraction instrument deployments.

\subsubsection{Insertion Effects}

In addition to the systematic errors discussed above, there are uncertainties involving the sampling process. Though the sample chamber is designed to minimize it, capturing a sample creates some unavoidable disturbance of the waste. The effects of this disturbance are complex, and the uncertainty they may cause in the void fraction is extremely difficult to quantify.

Insertion and capture may cause some amount of gas to be released or otherwise avoid capture because of relative motion of bubbles and waste when the cover is closed. This problem has been evaluated experimentally using a viscous fluid containing neutrally buoyant spheres 3.2 and $6.4 \mathrm{~mm}$ in diameter to create simulated voids up to $30 \%$.(a) The findings indicate that the VFI consistently captures slightly less gas than exists in the waste. The discrepancy between the actual void fraction and the captured void fraction increases with bubble size. The error was $-2.5 \%$ void with 6.4-mm spheres, but below $-1 \%$ with 3.2-mm spheres. With bubbles less than $1 \mathrm{~mm}$, the error is estimated to be less than $-0.1 \%$ void. All indications are that this holds for $241-S Y-101$ waste. If the gas is held in a sludge with some yield strength, the waste will not flow, and the bubbles cannot avoid or move out of the sample chamber as the cover closes. Thus the void capture efficiency in sludge should be much better than with relatively large, neutrally buoyant spheres.

Including both the effects of the system errors and deployment related uncertainties, the maximum uncertainty is estimated at $-0.4 \%,+0.6 \%$ void under the conditions expected in Tank 241-SY-101. The system analysis above has shown the overall error due to parameter uncertainties to be below $\pm 0.5 \%$ at voids below $15 \%$. The $0.1 \%$ offset error due to deployment for bubbles smaller than $1 \mathrm{~mm}$ could only cause the void fraction to be slightly under-measured. This range of errors is well within the design requirements of the system.

(a) Abbot, J.R., and C. Unal. Sampling Ability of the In-Situ Voidmeter Instrument. LANL letter report TSA-6-94-316 (M110), November 16, 1994. 


\subsection{VFI Data from Tank 241-SY-101}

The first VFI deployment, on December 21, 1994, was through riser 11B. The lower arm was first pointed northwest toward the center of the tank (mixer pump) and then northeast, away from the center of the tank. For the second deployment on January 17, 1995, through riser 4A, four orientations were planned, although only three were used. The details of the measurement locations are listed in Tables 4.3 and 4.4.(a) These locations were selected in part because of the waste characteristics that can be inferred from the multi-instrument tree (MIT) temperature profiles from risers $17 \mathrm{~B}$ and $17 \mathrm{C}$ (see Figure 2.1). The temperature profiles indicate a convective layer of mixed slurry from below the crust to about $130 \mathrm{~cm}$ (50 in.) from tank bottom.

The first traverse of the first test on December 21 confirmed that the mixed slurry layer held very little if any trapped gas. Therefore, for the second traverse, the first measurement location was set at about four feet from the bottom, and the higher planned measurement locations were skipped. The crane began unloading at about $76 \mathrm{~cm}$ (30 in.), indicating increased resistance to the sample arm. At the lowest sample location, about $56 \mathrm{~cm}$ (22 in.) elevation, the sample chamber would not hold pressure, and testing in riser $11 \mathrm{~B}$ was terminated.

Table 4.3. VFI Test Sequence in Riser 11B, 241-SY-101

\begin{tabular}{||c|c|c||}
\hline \hline \multirow{2}{*}{ Test Number } & \multicolumn{2}{|c|}{ Distance from tank bottom } \\
\cline { 2 - 3 } & (inches) & (meters) \\
\hline \hline \multicolumn{2}{|c|}{ First Traverse - 330 degrees (west from north) } \\
\hline 1 & 331 & 8.4 \\
\hline 2 & 306 & 7.8 \\
\hline 3 & 282 & 7.2 \\
\hline 4 & 257 & 6.5 \\
\hline 5 & 233 & 5.9 \\
\hline 6 & 209 & 5.3 \\
\hline 7 & 185 & 4.7 \\
\hline 8 & 161 & 4.1 \\
\hline 9 & 160 & 4.1 \\
\hline 10 & 135 & 3.4 \\
\hline 11 & 112 & 2.8 \\
\hline 12 & 88 & 2.2 \\
\hline
\end{tabular}

(a) Alzheimer, J.M. Data Acquisition Plan for Tank 101 -SY Void Fraction Measurement Device, Rev. 2. Letter report PNL-MIT-011295, Pacific Northwest Laboratory, Richland, Washington. 
Table 4.3. VFI Test Sequence in Riser 11B, 241-SY-101

\begin{tabular}{|c|c|c|}
\hline \multirow{2}{*}{ Test Number } & \multicolumn{2}{|c|}{ Distance from tank bottom } \\
\hline & (inches) & (meters) \\
\hline \multicolumn{3}{|c|}{ First Traverse - 330 degrees (contd) } \\
\hline 13 & 66 & 1.7 \\
\hline 14 & 42 & 1.1 \\
\hline 15 & 17 & 0.4 \\
\hline 16 & 10 . & 0.3 \\
\hline 17 & 10 & 0.3 \\
\hline \multicolumn{3}{|c|}{$\begin{array}{c}\text { Second Traverse }-150 \text { degrees } \\
\text { (** indicates that the test was skipped) }\end{array}$} \\
\hline $18 * *$ & 336 & 8.5 \\
\hline $19 * *$ & 312 & 7.9 \\
\hline $20 * *$ & 288 & 7.3 \\
\hline $21 * *$ & 264 & 6.7 \\
\hline $22 * *$ & 24 & 6.1 \\
\hline $23 * *$ & 216 & 5.5 \\
\hline $24 * *$ & 192 & 4.9 \\
\hline $25 * *$ & 168 & 4.3 \\
\hline $26 * *$ & 168 & 3.7 \\
\hline $27 * *$ & 144 & 3.7 \\
\hline $28 * *$ & 120 & 3.0 \\
\hline $29 * *$ & 96 & 2.4 \\
\hline $30 * *$ & 72 & 1.8 \\
\hline 31 & 42 & 1.1 \\
\hline 32 & 30 & 0.7 \\
\hline 33 & 12 & 0.3 \\
\hline \multicolumn{3}{|c|}{ Seals leaked - no data on test 33} \\
\hline $34 * *$ & 12 & 0.3 \\
\hline
\end{tabular}


Table 4.4. VFI Test Sequence in Riser 4A, 241-SY-101

\begin{tabular}{|c|c|c|}
\hline \multirow{2}{*}{ Test Number } & \multicolumn{2}{|c|}{ Distance from tank bottom } \\
\hline & (inches) & (meters) \\
\hline \multicolumn{3}{|c|}{ First traverse - 330 degrees } \\
\hline 1 & 337 & 8.6 \\
\hline 2 & 192 & 4.9 \\
\hline 3 & 144 & 3.7 \\
\hline 4 & 98 & 2.5 \\
\hline 5 & 60 & 1.5 \\
\hline 6 & 37 & 0.9 \\
\hline 7 & 13 & 0.3 \\
\hline \multicolumn{3}{|c|}{ Second traverse - 150 degrees } \\
\hline 8 & 71 & 1.8 \\
\hline 9 & 48 & 1.2 \\
\hline 10 & 26 & 0.7 \\
\hline 11 & 25 & 0.6 \\
\hline 12 & 19 & 0.5 \\
\hline \multicolumn{3}{|c|}{ Third traverse - 60 degrees } \\
\hline 13 & 37 & 0.9 \\
\hline 14 & 16 & 0.4 \\
\hline 15 & 16 & 0.4 \\
\hline \multicolumn{3}{|c|}{$\begin{array}{l}\text { Fourth traverse }-240 \text { degrees } \\
(* * \text { - test canceled })\end{array}$} \\
\hline $16 * *$ & 48 & 1.2 \\
\hline $17 * *$ & 36 & 0.9 \\
\hline $18 * *$ & 24 & 0.6 \\
\hline $19 * *$ & 12 & 0.3 \\
\hline $20 * *$ & \multicolumn{2}{|c|}{ Just below or touching crust. } \\
\hline
\end{tabular}


The initial and final temperatures used for the pressurization chamber $\left(T 1_{i}\right.$ and $\left.T 1_{f}\right)$ are the average of the two temperature sensors attached to the chamber. The initial and final temperatures used for the sample chamber $\left(\mathrm{T}_{\mathrm{i}}\right.$ and $\left.\mathrm{T} 2_{\mathrm{f}}\right)$ are the average of the two temperature sensors located near the pivot pin. While these sensors are not at the sample chamber, they are at the same depth in the waste and should be at virtually the same temperature as the sample. The initial and final temperatures used for the connecting line $\left(\mathrm{T}_{\mathrm{i}}\right.$ and $\left.\mathrm{T} 3_{\mathrm{f}}\right)$ are averages of all ten temperature sensors. This weights the temperatures somewhat higher for the three sensors located in the equipment enclosure and the two at the sample chamber which is considered appropriate since the majority of the internal volume of the connecting line is not associated with the line itself but with the fittings just below the solenoid valve and at the check valve at the sample chamber.

The initial and final pressures of the pressurization chamber $\left(P 1_{i}\right.$ and $\left.P 1_{f}\right)$ are the average of the two pressure transducers connected to the chamber. The initial and final pressures of the line and sample chamber are all measured using the pressure transducer in the connecting line just below the solenoid valve at the bottom of the pressurization chamber.

The calculated void fraction values are plotted in Figure 4.4 with the error bands included $(+0.6 \%,-0.4 \%$ void, $\pm 10 \mathrm{~cm}$ level $)$. The pressures and temperatures used in calculating the void fraction for the two deployments are given in Tables 4.5 and 4.6 along with the calculated void fractions. The void fractions were calculated using the volumes and other parameters given in Section 4.2. 


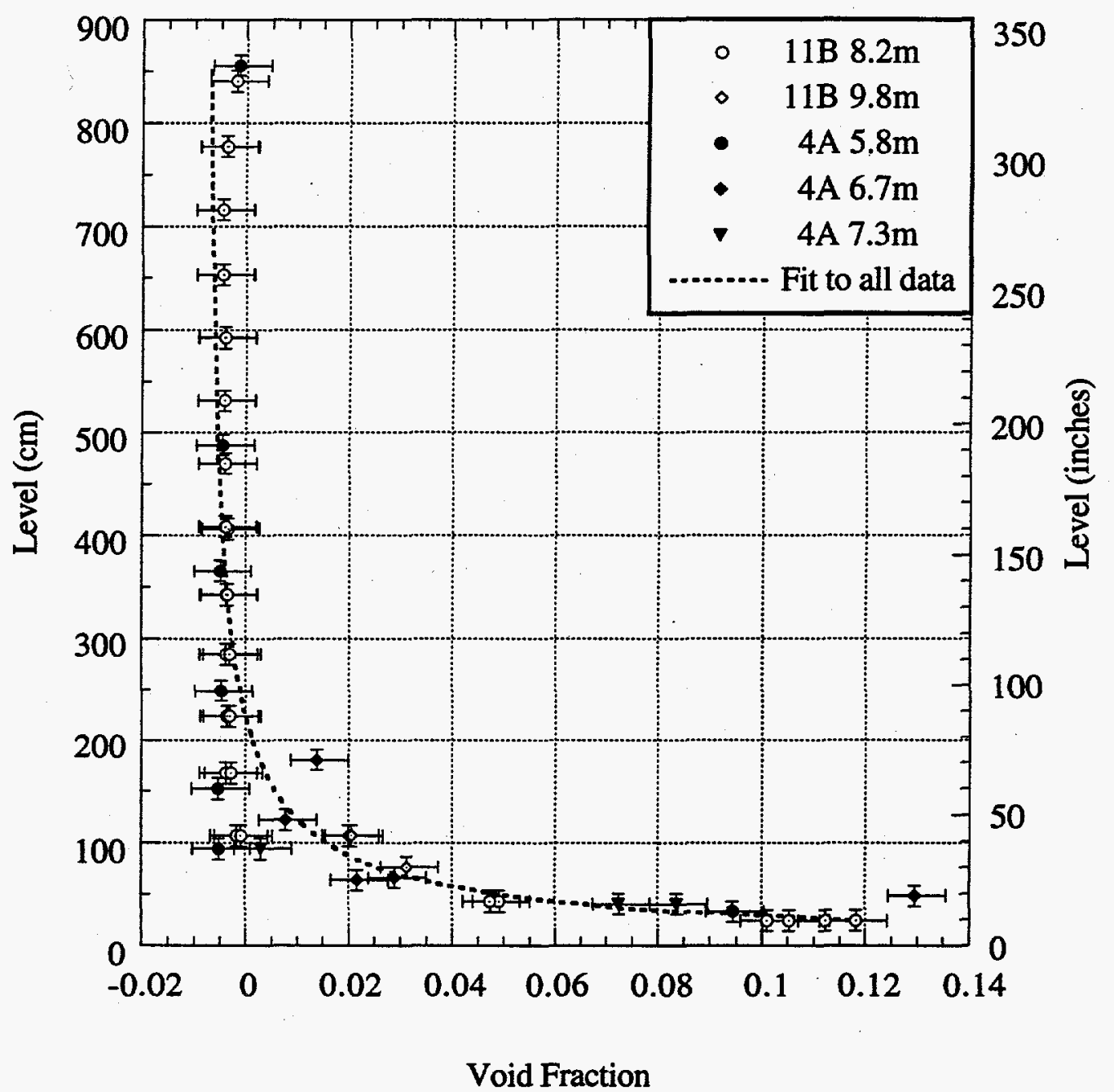

Figure 4.4. Calculated Void Fractions in Tank 241-SY-101 
Table 4.5. Temperatures and Pressures Used to Calculate Void Fraction, December 21, 1994 - Riser 11B

\begin{tabular}{|c|c|c|c|c|c|c|c|c|c|c|c|c|c|c|c|}
\hline Elev & $T 1_{i}$ & $\bar{T} 2_{i}$ & $\overline{T 3_{i}}$ & $\overline{T l_{f}}$ & $T 2_{f}$ & $T 3_{f}$ & $T 4_{f}$ & $\bar{P} 1_{\mathbf{i}}$ & $\overline{\mathrm{P} 2_{\mathrm{i}}}$ & $\mathbf{P} 3_{i}$ & $\overline{P 1_{\mathbf{f}}}$ & $\mathrm{P} 2_{\mathrm{f}}$ & $\mathbf{P} \mathbf{3}_{\mathrm{f}}$ & $\mathrm{P} 4_{\mathrm{f}}$ & Void \\
\hline (in) & & & & $\left({ }^{\circ} \mathrm{K}\right)$ & & & & & & & (psia) & & & & $(\%)$ \\
\hline 331 & 296.3 & 318.3 & 299.9 & 296.3 & 318.4 & 299.9 & 297.3 & 465.9 & 17.2 & 13.4 & 372.9 & 372.0 & 372.0 & 372.0 & -0.19 \\
\hline 306 & 296.6 & 319.4 & 300.2 & 296.6 & 319.4 & 300.2 & 297.5 & 465.5 & 20.1 & 17.2 & 375.2 & 374.2 & 374.2 & 374.2 & -0.38 \\
\hline 306 & 296.8 & 319.6 & 300.4 & 296.8 & 319.7 & 300.4 & 297.6 & 464.3 & 374.2 & 373.9 & 445.9 & 444.8 & 444.8 & 444.8 & -0.36 \\
\hline 257 & 297.2 & 320.2 & 300.5 & 297.2 & 320.2 & 300.6 & 297.8 & 465.3 & 21.6 & 20.8 & 376.2 & 375.1 & 375.1 & 375.1 & -0.44 \\
\hline 257 & 297.3 & 320.2 & 300.5 & 297.3 & 320.2 & 300.5 & 297.6 & 464.5 & 375.1 & 373.9 & 446.4 & 444.9 & 444.9 & 444.9 & -0.46 \\
\hline 233 & 297.3 & 320.4 & 300.5 & 297.3 & 320.4 & 300.5 & 297.5 & 465.2 & 22.7 & 21.4 & 376.1 & 375.0 & 375.0 & 375.0 & -0.42 \\
\hline 233 & 297.4 & 320.4 & 300.5 & 297.4 & 320.4 & 300.5 & 297.5 & 464.4 & 375.0 & 374.3 & 446.2 & 444.8 & 444.8 & 444.8 & -0.4 \\
\hline 185 & 297.3 & 320.6 & 301.6 & 297.3 & 320.6 & 301.7 & 297.2 & 465.1 & 375.9 & 375.1 & 447.0 & 445.5 & 445.5 & 445.5 & -0.39 \\
\hline 161 & 297.2 & 320.6 & 302.0 & 297.2 & 320.6 & 302.0 & 296.8 & 466.2 & 26.8 & 25.5 & 377.9 & 376.6 & 376.6 & 376.6 & -0.4 \\
\hline 161 & 297.1 & 320.6 & 302.1 & 297.0 & 320.6 & 302.1 & 296.3 & 466.0 & 376.6 & 375.4 & 447.7 & 446.3 & 446.3 & 446.3 & -0.38 \\
\hline 160 & 296.8 & 320.6 & 302.0 & 296.8 & 320.6 & 302.1 & 295.8 & 467.0 & 27.0 & 26.7 & 378.2 & 377.1 & 377.1 & 377.1 & -0.34 \\
\hline 160 & 296.6 & 320.6 & 302.0 & 296.6 & 320.5 & 302.0 & 295.4 & 466.7 & 377.1 & 376.3 & 448.3 & 446.8 & 446.8 & 446.8 & -0.33 \\
\hline 135 & 296.3 & 320.5 & 301.9 & 296.2 & 320.5 & 301.9 & 295.1 & 467.3 & 28.3 & 26.8 & 378.9 & 377.7 & 377.7 & 377.7 & -0.38 \\
\hline 135 & 296.1 & 320.5 & 301.9 & 296.0 & 320.5 & 301.8 & 294.7 & 467.1 & 377.7 & 376.8 & 448.8 & 447.4 & 447.4 & 447.4 & -0.35 \\
\hline 112 & 295.8 & 320.6 & 301.8 & 295.7 & 320.6 & 301.8 & 294.7 & 467.4 & 29.7 & 28.4 & 379.3 & 378.2 & 378.2 & 378.2 & -0.37 \\
\hline 112 & 295.6 & 320.6 & 301.7 & 295.5 & 320.6 & 301.7 & 294.3 & 467.3 & 378.2 & 377.6 & 449.0 & 447.7 & 447.7 & 447.7 & -0.3 \\
\hline
\end{tabular}


Table 4.5 (contd)

\begin{tabular}{|c|c|c|c|c|c|c|c|c|c|c|c|c|c|c|c|}
\hline Elev & $\mathrm{Tl}_{\mathbf{i}}$ & $\mathrm{T}_{\mathrm{i}}$ & $\mathrm{T}_{\mathbf{i}}$ & $T 1_{f}$ & $T 2_{\mathrm{f}}$ & $T 3_{f}$ & $T 4_{f}$ & $\mathbf{P} 1_{\mathbf{i}}$ & $\mathbf{P} 2_{\mathbf{i}}$ & $\overline{P 3} 3_{i}$ & $\mathbf{P} 1_{\mathbf{f}}$ & $\mathrm{P} 2_{\mathrm{f}}$ & $\mathbf{P 3}_{\mathrm{f}}$ & $\mathrm{P}_{\mathrm{f}}$ & Void \\
\hline (in) & \multicolumn{7}{|c|}{$\left({ }^{\circ} \mathrm{K}\right)$} & \multicolumn{7}{|c|}{ (psia) } & $(\%)$ \\
\hline 88 & 295.3 & 320.6 & 301.5 & 295.2 & 320.6 & 301.5 & 293.9 & 467.3 & 31.2 & 29.7 & 379.4 & 378.2 & 378.2 & 378.2 & -0.36 \\
\hline 88 & 295.1 & 320.6 & 301.5 & 295.0 & 320.6 & 301.4 & 293.5 & 467.1 & 378.2 & 377.4 & 448.8 & 447.5 & 447.5 & 447.5 & -0.3 \\
\hline 66 & 294.7 & 320.6 & 301.2 & 294.6 & 320.6 & 301.2 & 293.3 & 467.1 & 32.7 & 31.1 & 379.7 & 378.5 & 378.5 & 378.5 & -0.37 \\
\hline 66 & 294.5 & 320.6 & 301.1 & 294.5 & 320.6 & 301.1 & 293.0 & 467.0 & 378.5 & 377.9 & 448.8 & 447.5 & 447.5 & 447.5 & -0.28 \\
\hline 42 & 294.1 & 320.4 & 301.0 & 294.0 & 320.4 & 300.9 & 292.5 & 466.8 & 34.3 & 32.5 & 378.0 & 376.8 & 376.8 & 376.8 & -0.17 \\
\hline 42 & 293.9 & 320.4 & 300.9 & 293.9 & 320.4 & 300.9 & 292.5 & 466.7 & 376.8 & 375.4 & 447.8 & 446.3 & 446.3 & 446.3 & -0.08 \\
\hline 17 & 293.6 & 319.8 & 301.0 & 293.5 & 319.8 & 301.0 & 292.4 & 466.7 & 35.7 & 34.2 & 338.0 & 336.6 & 336.6 & 336.6 & 4.916 \\
\hline 17 & 293.4 & 319.7 & 301.2 & 293.4 & 319.7 & 301.2 & 292.3 & 466.6 & 336.6 & 334.3 & 427.1 & 425.3 & 425.3 & 425.3 & 4.731 \\
\hline 9.7 & 293.1 & 318.7 & 301.5 & 293.1 & 318.7 & 301.4 & 292.2 & 466.4 & 35.9 & 35.5 & 303.0 & 301.8 & 301.8 & 301.8 & 10.52 \\
\hline 9.7 & 293.0 & 318.6 & 301.7 & 292.9 & 318.5 & 301.7 & 292.1 & 466.4 & 301.8 & 300.6 & 403.3 & 401.9 & 401.9 & 401.9 & 10.1 \\
\hline 9.7 & 292.8 & 318.4 & 301.8 & 292.7 & 318.4 & 301.7 & 291.9 & 466.9 & 35.9 & 35.9 & 296.4 & 295.4 & 295.4 & 295.4 & 11.82 \\
\hline 9.7 & 292.7 & 318.3 & 301.8 & 292.6 & 318.2 & 301.8 & 291.9 & 466.8 & 295.4 & 294.8 & 398.6 & 397.5 & 397.5 & 397.5 & 11.22 \\
\hline 42 & 291.0 & 320.3 & $301.0^{\circ}$ & 291.0 & 320.3 & 301.0 & 290.2 & 465.9 & 33.9 & 14.6 & 356.1 & 355.0 & 355.0 & 355.0 & 2.064 \\
\hline 42 & 290.9 & 320.3 & 301.0 & 290.8 & 320.2 & 300.9 & 290.1 & 466.1 & 355.0 & 353.2 & 437.9 & 436.8 & 436.8 & 436.8 & 1.999 \\
\hline 30 & 290.7 & 320.1 & 300.9 & 290.6 & 320.0 & 300.8 & 289.9 & 465.9 & 34.6 & 34.6 & 351.1 & 350.3 & 350.3 & 350.3 & 3.129 \\
\hline
\end{tabular}


Table 4.6. Temperatures and Pressures Used to Calculate Void Fraction, January 17, 1995 - Riser 4A

\begin{tabular}{|c|c|c|c|c|c|c|c|c|c|c|c|c|c|c|c|}
\hline Elev & $T 1_{\mathbf{i}}$ & $T 2_{i}$ & $\bar{T} 3_{i}$ & $\overline{\mathrm{T} 1_{\mathrm{f}}}$ & $T 2_{f}$ & $\mathrm{~T} 3_{\mathrm{f}}$ & $T 4_{f}$ & $\overline{\mathbf{P} 1_{\mathbf{i}}}$ & $\overline{\mathrm{P} 2}$ & $\bar{P} 3_{i}$ & $P 1_{f}$ & $\mathrm{P} 2_{\mathrm{f}}$ & $\mathbf{P 3}_{\mathrm{f}}$ & $\mathbf{P} 4_{f}$ & \multirow{3}{*}{\begin{tabular}{|l|} 
Void \\
$(\%)$ \\
-0.14 \\
\end{tabular}} \\
\hline (in) & \multicolumn{7}{|c|}{$\left({ }^{\circ} \mathrm{K}\right)$} & \multicolumn{7}{|c|}{ (psia) } & \\
\hline 337 & 287.2 & 317.8 & 290.8 & 287.2 & 317.9 & 290.8 & 288.2 & 454.8 & 25.0 & 13.6 & 364.3 & 363.9 & 363.9 & 363.9 & \\
\hline 192 & 287.3 & 319.7 & 292.1 & 287.3 & 319.7 & 292.2 & 288.2 & 457.7 & 27.4 & 21.7 & 371.0 & 370.4 & 370.4 & 370.4 & -0.44 \\
\hline 144 & 287.4 & 319.0 & 293.7 & 287.3 & 319.0 & 293.8 & 288.3 & 458.5 & 29.0 & 27.2 & 373.4 & 372.7 & 372.7 & 372.7 & -0.49 \\
\hline 98 & 287.4 & 318.9 & 294.8 & 287.4 & 318.9 & 294.8 & 288.3 & 458.0 & 30.5 & 28.8 & 373.4 & 372.6 & 372.6 & 372.6 & -0.47 \\
\hline 60 & 287.6 & 319.1 & 296.0 & 287.6 & 319.1 & 296.1 & 288.4 & 457.8 & 33.3 & 30.4 & 374.1 & 373.4 & 373.4 & 373.4 & -0.52 \\
\hline 37 & 287.7 & 319.9 & 296.5 & 287.6 & 319.9 & 296.5 & 288.6 & 461.0 & 34.8 & 32.6 & 377.1 & 376.3 & 376.3 & 376.3 & -0.51 \\
\hline 13 & 287.7 & 319.3 & 297.6 & 287.7 & 319.2 & 297.6 & 288.3 & 460.1 & 35.9 & 34.1 & 306.2 & 305.6 & 305.6 & 305.6 & 9.441 \\
\hline 71 & 287.7 & 319.8 & 296.4 & 287.6 & 319.8 & 296.3 & 287.6 & 459.9 & 31.9 & 31.7 & 359.7 & 359.0 & 359.0 & 359.0 & 1.391 \\
\hline 48 & 287.5 & 319.8 & 296.4 & 287.4 & 319.8 & 296.4 & 287.5 & 460.9 & 33.5 & 31.9 & 365.7 & 365.0 & 365.0 & 365.0 & 0.777 \\
\hline 26 & 287.4 & 319.8 & 297.1 & 287.3 & 319.8 & 297.1 & 287.5 & 460.9 & 34.8 & 33.7 & 349.4 & 348.7 & 348.7 & 348.7 & 2.895 \\
\hline 25 & 287.3 & 319.7 & 297.5 & 287.3 & 319.7 & 297.5 & 287.7 & 462.1 & 35.0 & 34.7 & 356.1 & 355.4 & 355.4 & 355.4 & 2.172 \\
\hline 19 & 287.3 & 319.4 & 298.2 & 287.2 & 319.4 & 298.1 & 287.6 & 461.3 & 35.4 & 34.9 & 288.7 & 288.0 & 288.0 & 288.0 & 12.96 \\
\hline 37 & 287.2 & 319.7 & 299.7 & 287.1 & 319.7 & 299.8 & 287.7 & 459.1 & 34.0 & 31.4 & 369.0 & 368.3 & 368.3 & 368.3 & 0.304 \\
\hline 16 & 287.1 & 319.4 & 300.2 & 287.1 & 319.3 & 300.3 & 287.6 & 459.6 & 35.5 & 34.5 & 312.6 & 312.0 & 312.0 & 312.0 & 8.373 \\
\hline 16 & 287.1 & 319.2 & 300.4 & 287.0 & 319.2 & 300.3 & 287.2 & 460.4 & 35.6 & 35.5 & 320.2 & 319.5 & 319.5 & 319.5 & 7.245 \\
\hline
\end{tabular}




\subsection{References}

Abramowitz, M., and I. A. Stegun. 1964. Handbook of Mathematical Functions. U.S. Government Printing Office, Washington, D.C.

Allemann, R. T., Z. I. Antoniak, W. D. Chvala, L. E. Efferding, J. G. Fadeff, J. R. Friley, W. B. Gregory, J. D. Hudson, J. J. Irwin, N. W. Kirch, T. E. Michener, F. E. Panisko, C. W. Stewart, and B. M. Wise. 1994. Mitigation of Tank 241-SY-101 by Pump Mixing: Results of Testing Phases A and B. PNL-9423, Pacific Northwest Laboratory, Richland, Washington.

Allemann, R. T. 1994. Some Theories of Dissolved Gas Release from Tank 241-SY-101. PNL10091, Pacific Northwest Lavboratory, Richland, Washington.

Antoniak, Z. I. 1993 Historical Trends is Tank 241-SY-101 Waste Temperatures and Levels. PNL-8880, Pacific Northwest Laboratory, Richland, Washington.

Babad, H., G. D. Johnson, and D. A. Reynolds. 1992. Understanding the Cyclic Venting Phenomena in Hanford Site High-Level Wast Tanks: The Evaluation of Tank 241-SY-101. WHC-SA-1364-FP, Westinghouse Hanford Company, Richland, Washington

Brewster, M. E., N. B. Gallagher, J. D. Hudson, and C. W. Stewart. 1995. The Behavior, Quantity, and Location of Undissolved Gas in Tank 241-SY-101. PNL-10681, Pacific Northwest Laboratory, Richland, Washington.

Chhabra, R. P. 1993. Bubbles, Drops, and Particles in Non-Newtonian Fluids. CRC Press, Boca Raton, Florida.

Gauglitz, P.A., L.A. Mahoney, D.P. Mendoza, and M.C. Miller. 1994. Mechanisms of Gas Bubble Retention. PNL-10120, Pacific Northwest Laboratory, Richland, Washington.

Hopkins, J.D. 1994. Criteria for Flammable Gas Watch List Tanks. WHC-EP-0702 Rev 0, Westinghouse Hanford Company, Richland, Washington.

Johnson, G.D. 1995. Strategy for Resolution of the Flammable Gas Safety Issue. WHC-SDWM-TI-691 Rev 0, Westinghouse Hanford Company, Richland, Washington.

Kreith, F., and M. S. Bohn. 1986. Principles of Heat Transfer, 4th ed. Harper \& Row, Cambridge, Massachusetts, p. 109.

Panton; R. L. 1984. Incompressible Flow. John Wiley \& Sons, Inc.

Shepard, C. L., M. A. Chieda, L. J. Kirihara, J. R. Phillips, A. Shekarriz, G. Terrones, J. Abbott, C. Unal, K. O. Pasamehmetoglu, A. Graham, and T. I. Stokes. 1995. Acquisition and Reduction of Data Obtained from Tank 101-SY In-Situ Ball Rheometer. PNL-10170, Pacific Northwest Laboratory, Richland, Washington.

C. W. Snoek. 1990. "A Selection of New Developments in Multiphase Flow Measurement Techniques." Experimental Thermal and Fluid Science, 3: 6-73. 
Stewart, C.W., J.D. Hudson, J.R. Friley, F.E. Panisko, Z.I. Antoniak, J.J. Irwin, F.G. Fadeff, L.E. Efferding, T.E. Michener, N.W. Kirch, and D.A. Reynolds. 1994. Mitigation of Tank 241 SY-101 by Pump Mixing: Results of Full-Scale Testing. PNL-9959, Pacific Northwest Laboratory, Richland, Washington.

Sullivan, L. H. 1995. A Safety Assessment for Proposed Pump Mixing Operations to Mitigate Episodic Gas Releases in Tank 241-241-SY-101: Hanford Site, Richland Washington. LAUR-923196 Rev. 14, Los Alamos National Laboratory, Los Alamos, New Mexico. 
Appendix A

\section{Ball Rheometer Data}




\section{Appendix A}

\section{Ball Rheometer Data}

Raw data in the form of a plot of the force measured by the load cell versus distance below the reference level are given in Figure A.1. These data were recorded from the intial, full-depth pass in riser 4A on March 28, 1995. The upper portion, where the ball is entering the liquid, is shown in Figure 3.2 in the main document. The details of the bottom $100 \mathrm{~cm}$ are shown in Figure A.2. 


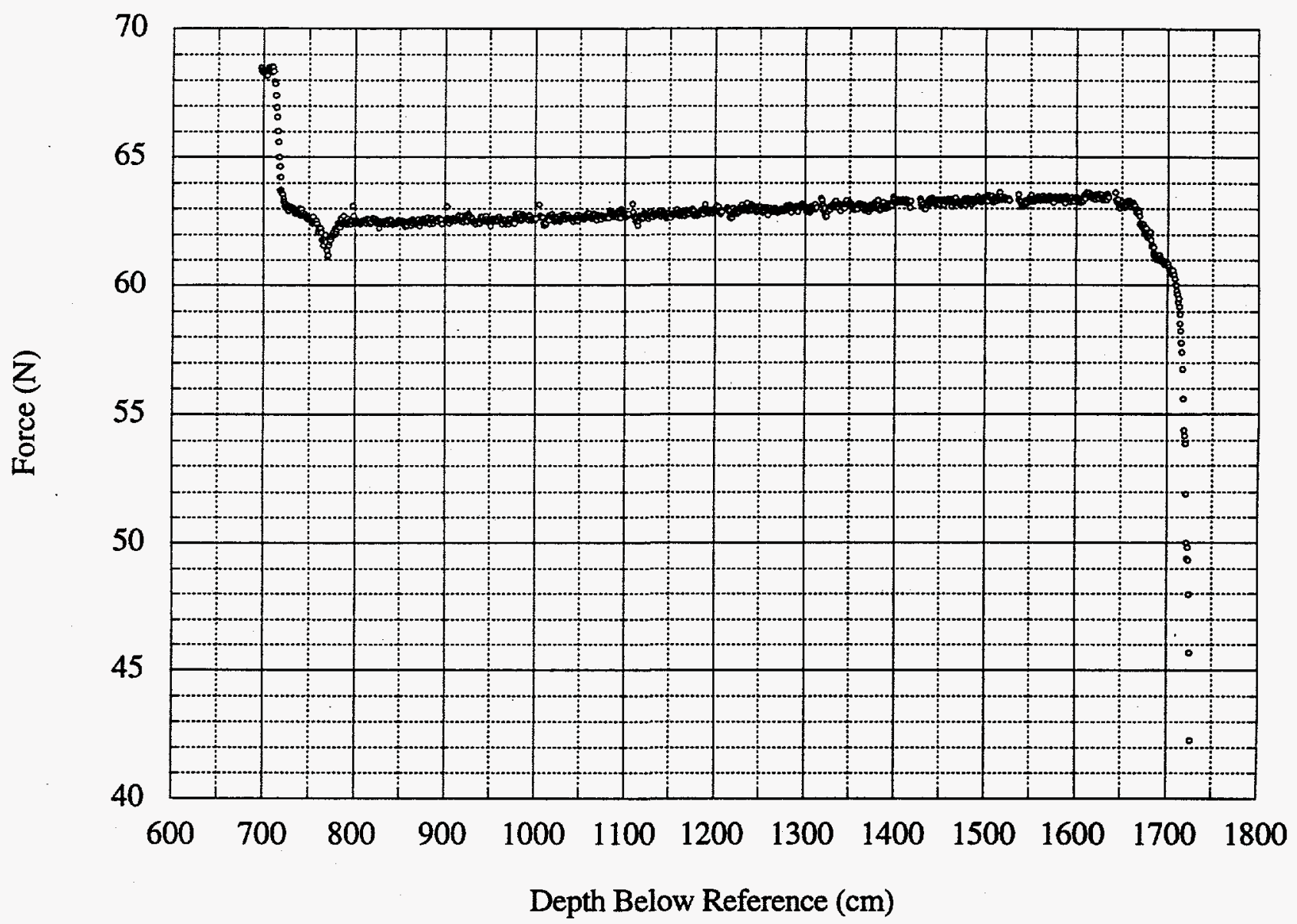

Figure A.1. Force Versus Depth - Initial Pass in Riser 4A 


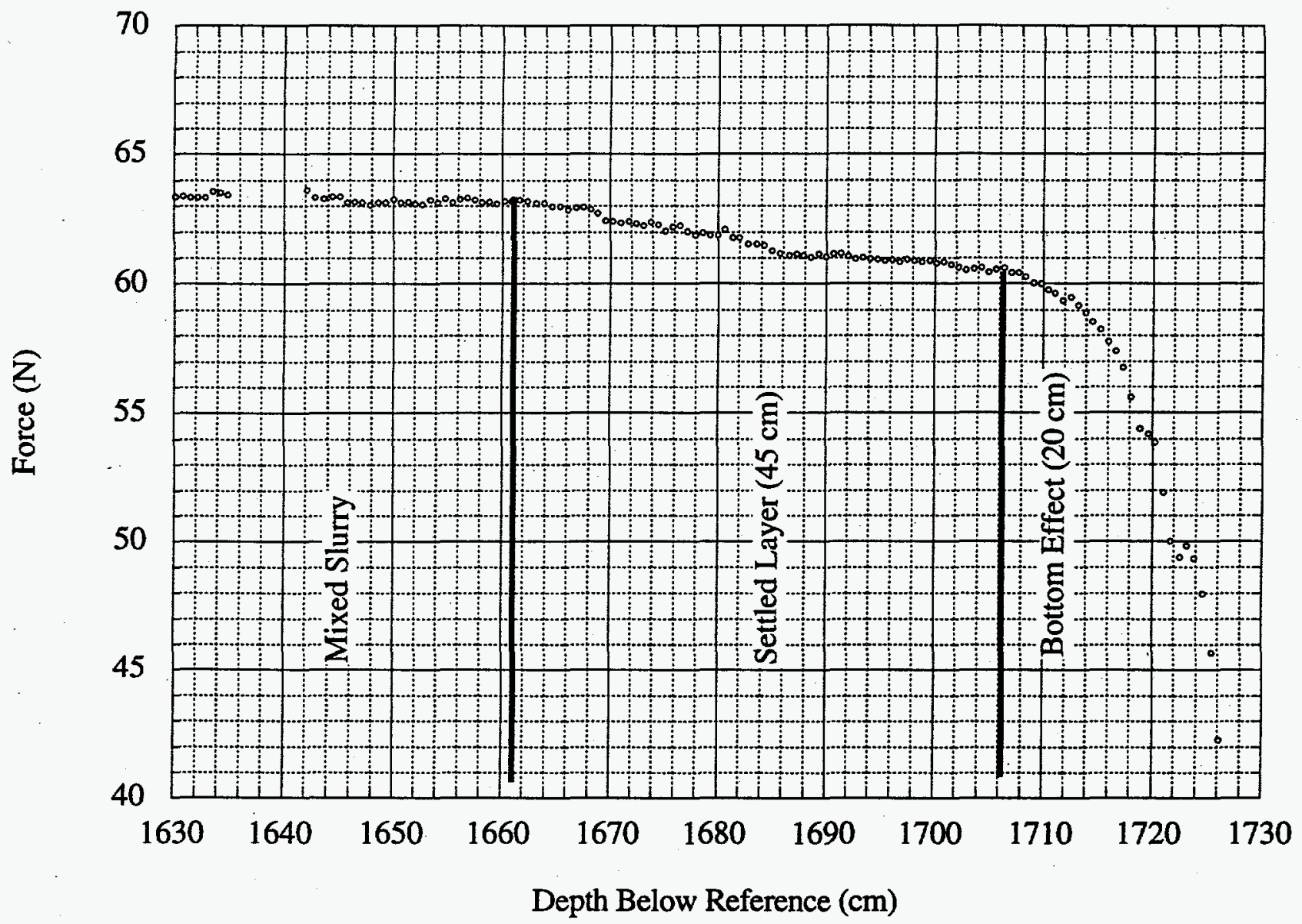

Figure A.2. Force Versus Depth - Bottom Layers 


\section{Appendix B}

Selected Raw Data from Void Fraction Instrument 


\section{Appendix B}

\section{Selected Raw Data from Void Fraction Instrument}

For each of the void fraction measurements, five arm temperatures, two pressurization chamber temperatures, three enclosure temperatures, two pressurization chamber pressures and one line pressure are recorded approximately every two seconds for almost the entire duration of the measurement that can range from eight to fifteen minutes depending whether one or two pressurizations are used. The initial reading from the position sensor is also recorded at the beginning of each data set.

While most of these data are not used in the actual void fraction calculation, they are all recorded so that the time histories of individual sensor measurements can be examined as needed. Table B.1 is an abbreviated listing of one typical data set. This data set was for sample 12-2194.016 taken December 21,1994 , in riser 11B with the sample chamber 17.3 inches from the bottom of the tank. The sample was pressurized twice, and the entire duration of the recorded data is approximately 15 minutes. The format of the data presented in Table B. 1 is slightly different from that recorded by the computer to improve readability. Also, most of the data lines have been removed to save space. All temperature data are recorded in degrees Celsius and pressures in pounds per square inch absolute. The five arm temperatures are measured at various locations along the long mast, with the first listed temperature near the top (equipment enclosure end) and the last two at the pivot near the lower arm. The chamber temperatures are from inside the pressurization chamber. The enclosure temperatures are from inside the equipment enclosure at the top of the mast. The two chamber pressures are from the pressurization chamber, and the line pressure is measured inside the equipment enclosure just below the solenoid valve that separates the pressurization chamber from the connecting line.

The void fraction measurement device goes through a fixed operating cycle for each sample location. The time for each of these steps is indicated below for sample 12-21-94.016.

Step 1) Move to desired sample location and close the sample chamber, trapping a waste sample 06:31:7 pm.

Step 2) Open the inlet valve to the pressurization chamber and allow chamber to reached desired pressure - shortly after 06:31:37 pm (shortly after 06:39:06 pm for second pressurization).

Step 3) Close inlet valve to pressurization chamber - shortly before 06:33:39 pm (shortly before 06:41:05 pm for second pressurization).

Step 4) Monitor temperatures in pressurization chamber until temperatures are not changing, to ensure thermal equilibrium of the chamber and nitrogen gas used for pressurization has been achieved - 06:33:39 pm (06:41:05 pm for second pressurization). 
Table B.1. Data Set 12-21-94.016 (Abbreviated)

File: $\quad 12-21-94.016$

Wednesday, December 21, 1994 06:30 PM

Program: Void Fraction.vi v1.0

Elevation: 357.0

\begin{tabular}{|c|c|c|c|c|c|c|c|c|c|c|c|c|c|}
\hline \multirow{2}{*}{$\begin{array}{l}\text { Time } \\
\text { 06:31:37 PM }\end{array}$} & \multicolumn{5}{|c|}{$\begin{array}{c}\text { Arm } \\
\text { Temperatures } \\
\text { (C) }\end{array}$} & \multicolumn{2}{|c|}{$\begin{array}{c}\text { Chamber } \\
\text { Temperatures } \\
\text { (C) }\end{array}$} & \multicolumn{3}{|c|}{$\begin{array}{c}\text { Enclosure } \\
\text { Temperatures } \\
\text { (C) }\end{array}$} & \multicolumn{2}{|c|}{$\begin{array}{c}\text { Chamber } \\
\text { Pressures } \\
\text { (psi) }\end{array}$} & \multirow{2}{*}{$\begin{array}{c}\text { Line } \\
\text { Pressure } \\
\text { (psi) } \\
34.20\end{array}$} \\
\hline & \multicolumn{12}{|c|}{ Temperatures Stabilized } & \\
\hline 06:33:39 PM & 12.92 & 24.41 & 46.91 & 47.14 & 46.46 & 20.63 & 20.47 & 21.28 & 20.27 & 16.49 & 467.70 & 467.20 & 34.20 \\
\hline 06:33:41 PM & 12.92 & 24.43 & 46.91 & 47.14 & 46.44 & 20.63 & 20.47 & 21.28 & 20.27 & 16.42 & 467.70 & 467.20 & 34.20 \\
\hline 06:33:43 PM & 12.92 & 24.45 & 46.90 & 47.13 & 46.44 & 20.64 & 20.47 & 21.28 & 20.27 & 16.49 & 467.70 & 467.20 & 34.20 \\
\hline 06:33:45 PM & 12.93 & 24.45 & 46.91 & 47.14 & 46.46 & 20.64 & 20.47 & 21.28 & 20.27 & 16.42 & .467 .70 & 467.20 & 34.20 \\
\hline 06:33:47 PM & 12.93 & 24.47 & 46.90 & 47.13 & 46.46 & 20.64 & 20.46 & 21.17 & 20.27 & 16.42 & 467.70 & 467.20 & 34.20 \\
\hline \multicolumn{14}{|c|}{ 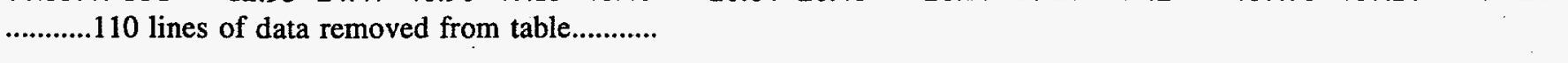 } \\
\hline 06:37:29 PM & 13.03 & 26.12 & 46.95 & 47.02 & 46.35 & 20.53 & 20.38 & 21.28 & 20.19 & 16.27 & 466.90 & 466.40 & 34.20 \\
\hline 06:37:31 PM & 13.03 & 26.14 & 46.95 & 47.00 & 46.35 & 20.53 & 20.37 & 21.28 & 20.27 & 16.27 & 466.90 & 466.40 & 34.20 \\
\hline 06:37:33 PM & 13.02 & 26.15 & 46.95 & 47.02 & 46.36 & 20.53 & 20.37 & 21.28 & 20.27 & 16.27 & 466.90 & 466.40 & 34.20 \\
\hline 06:37:35 PM & 13.01 & 26.18 & 46.95 & 47.00 & 46.35 & 20.52 & 20.37 & 21.17 & 20.19 & 16.35 & 466.90 & 466.40 & 34.20 \\
\hline $06: 37: 37 \mathrm{PM}$ & 13.03 & 26.19 & 46.96 & 47.00 & 46.35 & 20.52 & 20.37 & 21.17 & 20.19 & 16.35 & 466.90 & 466.40 & 34.20 \\
\hline \multicolumn{14}{|c|}{ Opened Valve YV11 } \\
\hline 06:37:41 PM & 13.01 & 26.21 & 46.95 & 47.00 & 46.34 & 20.52 & 20.37 & 21.17 & 20.27 & 16.35 & 466.90 & 466.40 & 34.20 \\
\hline 06:37:42 PM & 13.01 & 26.22 & 46.95 & 47.00 & 46.35 & 20.52 & 20.37 & 21.50 & 20.19 & 16.42 & 466.90 & 466.40 & 34.20 \\
\hline \multicolumn{14}{|c|}{ 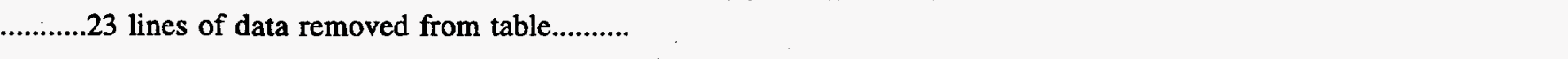 } \\
\hline $\begin{array}{l}\text { 06:38:29 PM } \\
\text { Closed Valve Y }\end{array}$ & 13.05 & 26.35 & 46.96 & 46.98 & 46.33 & 20.47 & 20.28 & 21.36 & 20.19 & 16.35 & 338.30 & 337.80 & 337.20 \\
\hline 06:38:33 PM & 13.05 & 26.37 & 46.96 & 46.99 & 46.34 & 20.47 & 20.28 & 21.36 & 20.19 & 16.35 & 338.30 & 337.80 & 337.20 \\
\hline 06:38:34 PM & 13.05 & 26.38 & 46.96 & 46.99 & 46.33 & 20.47 & 20.28 & 21.28 & 20.19 & 16.35 & 338.30 & 337.80 & 337.20 \\
\hline \multicolumn{14}{|c|}{ 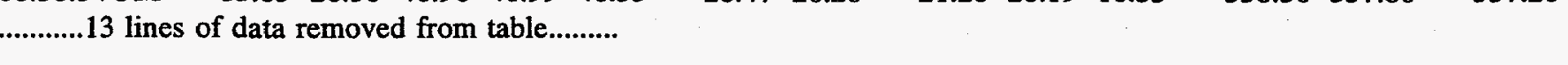 } \\
\hline 06:39:01 PM & 13.07 & 26.57 & 46.97 & 46.98 & 46.33 & 20.45 & 20.28 & 21.17 & 20.12 & 16.42 & 338.20 & 337.70 & 336.60 \\
\hline \multicolumn{14}{|c|}{ Line Pressure Stabilized } \\
\hline $\begin{array}{l}\text { 06:39:06 PM } \\
\text { Temperatures S }\end{array}$ & $\begin{array}{r}13.07 \\
\text { abilized }\end{array}$ & 26.57 & 46.97 & 46.98 & 46.33 & 20.45 & 20.28 & 21.17 & 20.12 & 16.42 & 338.20 & 337.70 & 336.60 \\
\hline 06:41:05 PM & 13.13 & 27.38 & 46.97 & 46.93 & 46.29 & 20.47 & 20.27 & 21.28 & 20.27 & 16.42 & 467.60 & 467.10 & 335.50 \\
\hline 06:41:07 PM & 13.14 & 27.39 & 46.97 & 46.93 & 46.27 & 20.47 & 20.27 & 21.28 & 20.19 & 16.42 & 467.60 & 467.10 & 335.40 \\
\hline \multicolumn{14}{|c|}{ 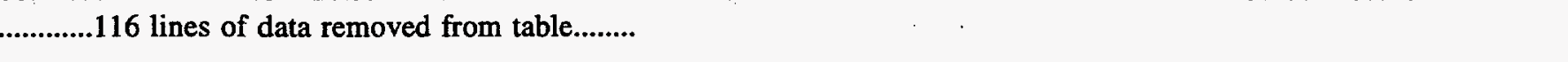 } \\
\hline $\begin{array}{l}06: 45: 01 \mathrm{PM} \\
06 \cdot 45 \cdot 03 \mathrm{PM}\end{array}$ & 13.28 & 28.73 & 46.99 & 46.87 & 46.22 & 20.36 & 20.19 & 21.17 & 20.19 & 16.60 & 466.80 & 466.40 & 334.30 \\
\hline $06: 45: 03 \mathrm{PM}$ & 13.28 & 28.76 & 46.98 & 46.87 & 46.22 & 20.36 & 20.19 & 21.17 & 20.12 & 16.42 & 466.80 & 466.40 & 334,30 \\
\hline
\end{tabular}


Table B.1 (Contd)

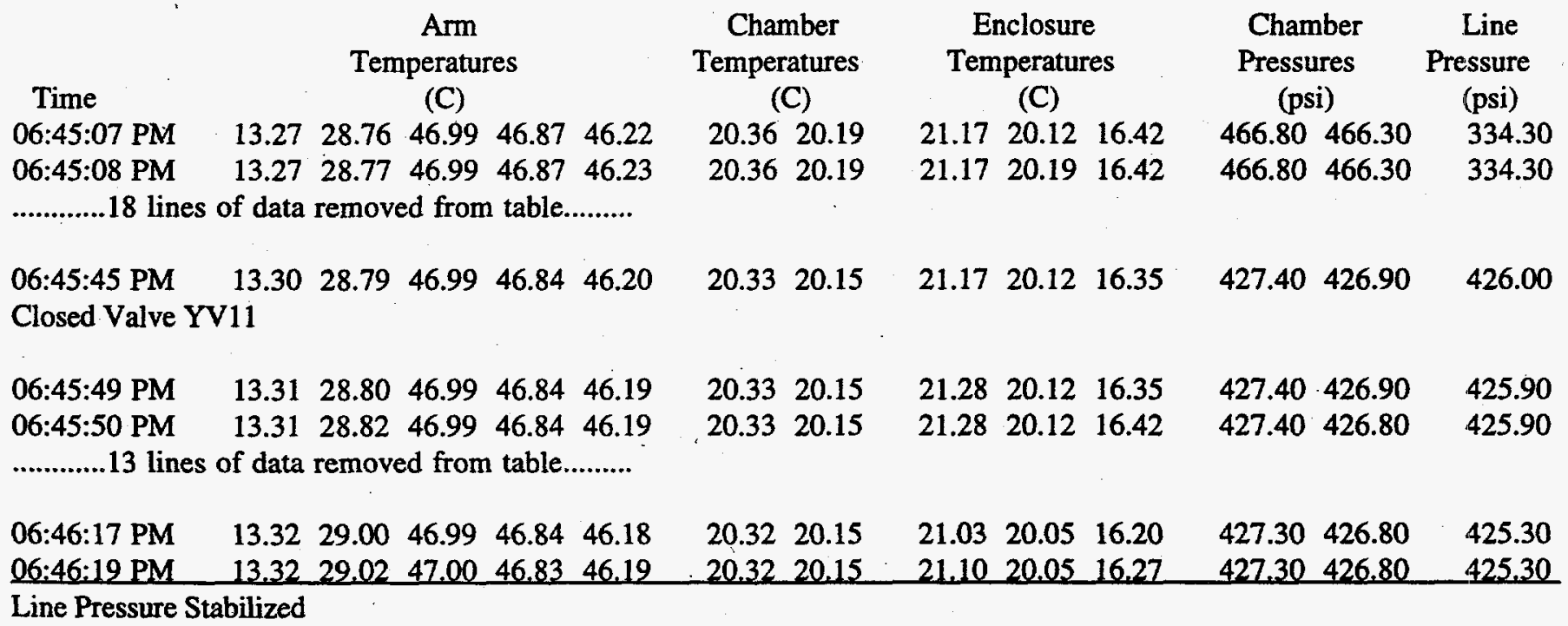

Line Pressure

\begin{tabular}{cc} 
Time & (psi) \\
\hline 06:46:21 PM & 425.30 \\
06:46:22 PM & 425.30 \\
06:46:24 PM & 425.20 \\
06:46:26 PM & 425.20 \\
06:46:28 PM & 425.20 \\
06:46:30 PM & 425.20 \\
06:46:32 PM & 425.10 \\
06:46:34 PM & 425.10 \\
06:46:36 PM & 425.10 \\
06:46:38 PM & 425.10 \\
06:46:40 PM & 425.00 \\
06:46:42 PM & 425.00 \\
06:46:44 PM & 425.00 \\
06:46:46 PM & 361.80 \\
06:46:48 PM & 230.60 \\
06:46:50 PM & 150.50 \\
06:46:52 PM & 150.50 \\
06:46:54. PM & 99.10 \\
06:46:56 PM & 80.60 \\
06:46:58 PM & 58.80 \\
06:47:00 PM & 48.20 \\
06:47:02 PM & 42.70 \\
06:47:04 PM & 39.60 \\
06:47:06 PM & 38.70
\end{tabular}

Line Pressure

\begin{tabular}{cc} 
Time & (psi) \\
\hline 06:47:08 PM & 38.70 \\
06:47:10 PM & 37.50 \\
06:47:12 PM & 36.70 \\
06:47:14 PM & 36.40 \\
06:47:16 PM & 36.30 \\
06:47:18 PM & 36.20 \\
06:47:20 PM & 36.10 \\
06:47:22 PM & 36.10 \\
06:47:24 PM & 36.00 \\
06:47:26 PM & 35.90 \\
06:47:28 PM & 35.90 \\
06:47:30 PM & 35.80 \\
06:47:32 PM & 35.80 \\
06:47:34 PM & 35.80 \\
06:47:36 PM & 35.80 \\
06:47:38 PM & 35.80 \\
06:47:40 PM & 35.80 \\
06:47:42 PM & 35.70 \\
06:47:44 PM & 35.70 \\
06:47:46 PM & 35.70 \\
06:47:48 PM & 35.70 \\
06:47:50 PM & 35.70 \\
06:47:52 PM & 35.70 \\
06:47:54 PM & 35.70 \\
\hline
\end{tabular}


Step 5) Monitor pressurization chamber pressures to be sure pressures are not changing. This step also ensures that the nitrogen gas in the chamber is in thermal equilibrium with the chamber and no unacceptable leaks are present - 06:33:39 pm to 06:37:37 pm (06:41:05 $\mathrm{pm}$ to $06: 45: 03 \mathrm{pm}$ for second pressurization).

Step 6) Open the valve between the pressurization chamber and the connecting line. Monitor the chamber pressures until equilibrium is observed - 06:37:41 pm to 06:38:29 pm (06:45:07 $\mathrm{pm}$ to $06: 45: 45 \mathrm{pm}$ for second pressurization).

Step 7) Close the valve between the pressurization chamber and the connecting line. Monitor the line pressure to be sure line pressure is stationary. This is used to detect possible leaks in the sample chamber seals or elsewhere - 06:38:29 pm to 06:39:01 pm (06:45:49 pm to 06:46:19 pm for second pressurization).

Step 8) Calculate an estimated, preliminary void fraction based on initial and final pressures and temperatures of pressurization chamber, line, and sample chamber. The initial pressure of the sample chamber is estimated for this calculation (see step 10).

Step 9) If desired, repeat steps 2 through 8 to obtain a second void fraction measurement of same sample. For this second pressurization, the sample chamber will initially be at the final equilibrium pressure of the first pressurization. The sample chamber is not opened after the first pressurization.

Step 10) Open the sample chamber cover and monitor the line pressure. The line pressure will drop until in equilibrium with the waste in the tank at the sample chamber. This equilibrium pressure is the initial sample pressure used in the void fraction calculations 06:46:21 pm to 06:47:54 pm.

Plots of the chamber pressure and line pressure for the above sequence are shown in Figures B.1 through B.4. For most of the test sequence, the pressures are stationary. The pressure changes only when the valve between the pressurization chamber and the connecting line or the sample chamber cover is opened. The rest of the test sequence is spent charging the pressurization chamber and ensuring that the temperatures and pressures of the gas in the pressurization chamber have reached steady state values.

For the first four minutes, the pressures in both the pressurization chamber and the line are essentially stationary. Once the valve is opened, the pressurization chamber drops and the line pressure increases quickly. The line pressure is measured just below the valve and is separated from the sample chamber by the $18.3 \mathrm{~m}(60 \mathrm{ft})$ of $0.635-\mathrm{mm}(0.025-\mathrm{in}$.) ID tubing. Therefore, the measured line pressure is really not the pressure of the sample chamber or the average pressure of the line but a local pressure at the upper end of the connecting line. The measured line pressure overshoots the final equilibrium pressure until gas can travel to the sample chamber to achieve equilibrium. The pressurization chamber pressure also slightly overshoots the final equilibrium pressure because the nitrogen gas cools as it expands upon leaving the chamber before being quickly heated by the small-diameter tubing and other hardware. 


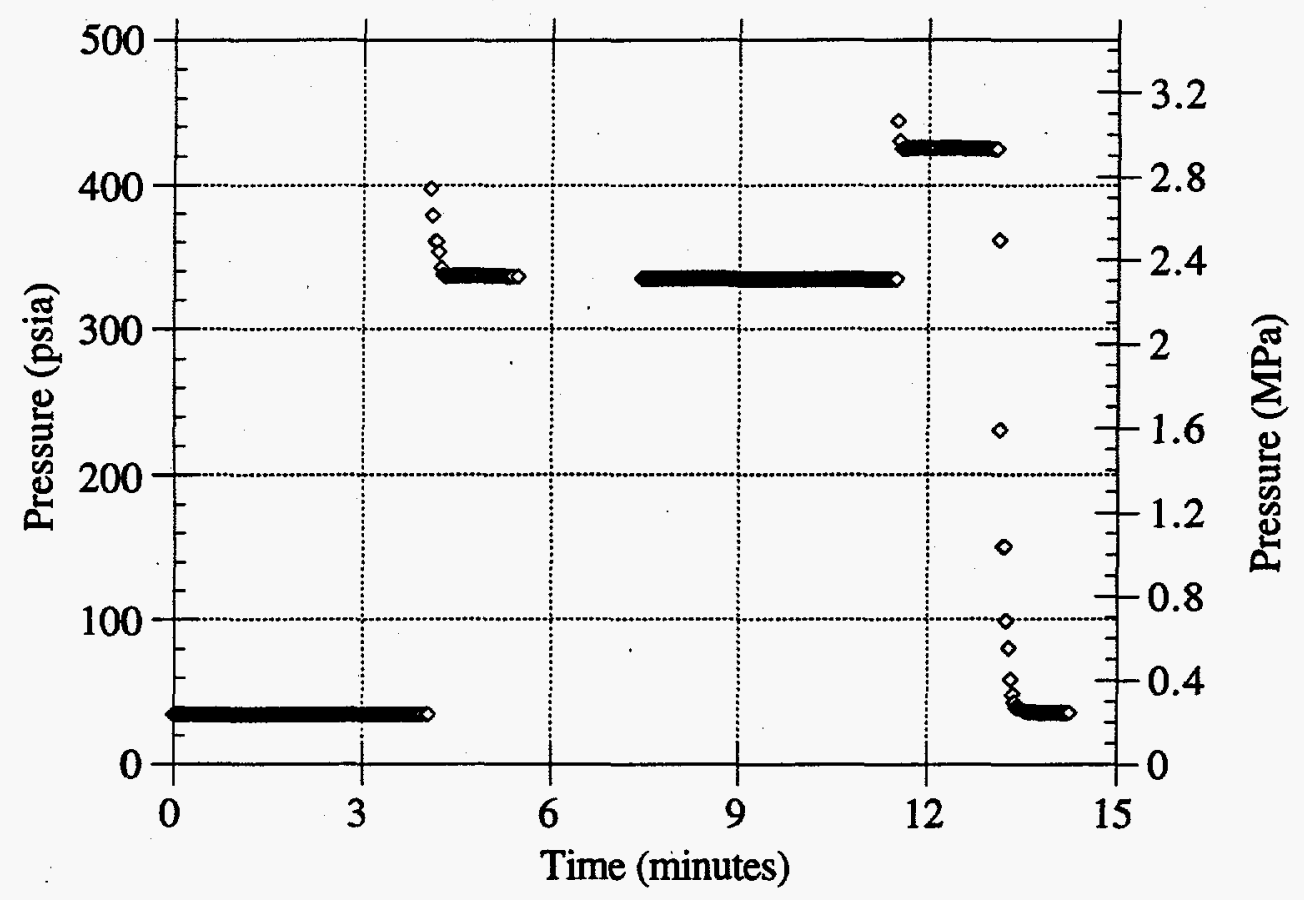

Figure B.1. Line Pressure for Sample 12-21-94.016

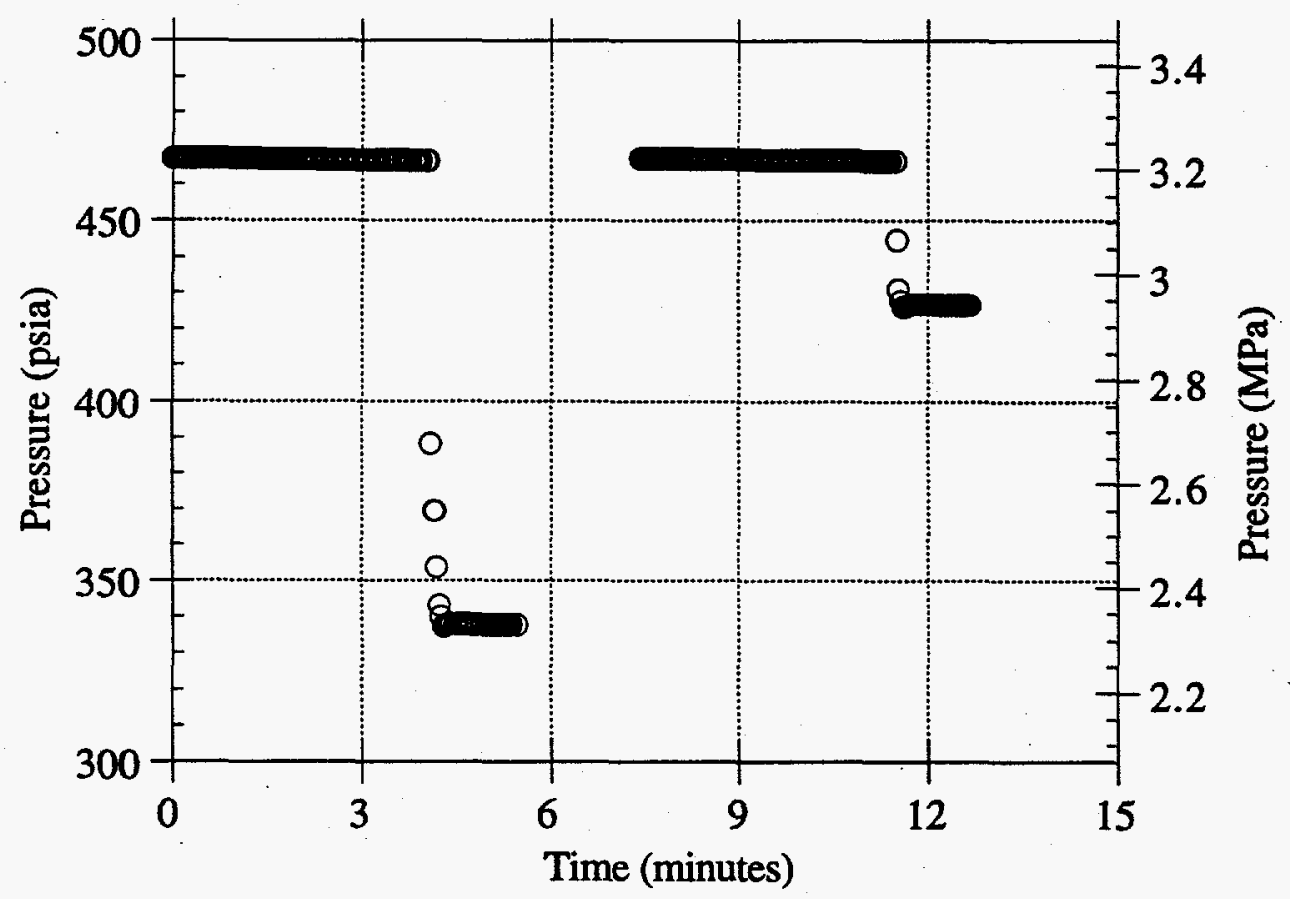

Figure B.2. Pressurization Chamber Pressure for Sample 12-21-94.016 


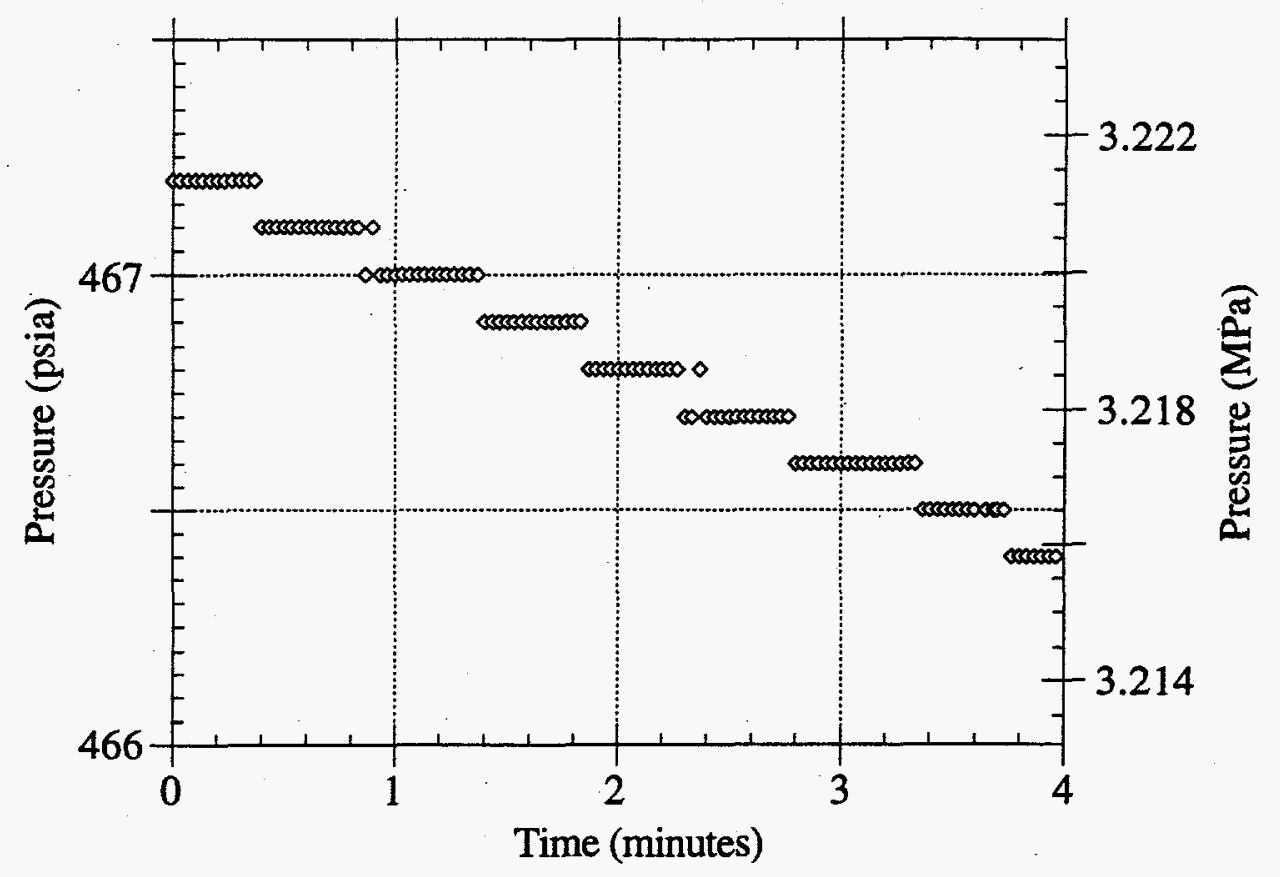

Figure B.3. Sample 12-21-94.016 Pressurization Chamber Pressure Detail

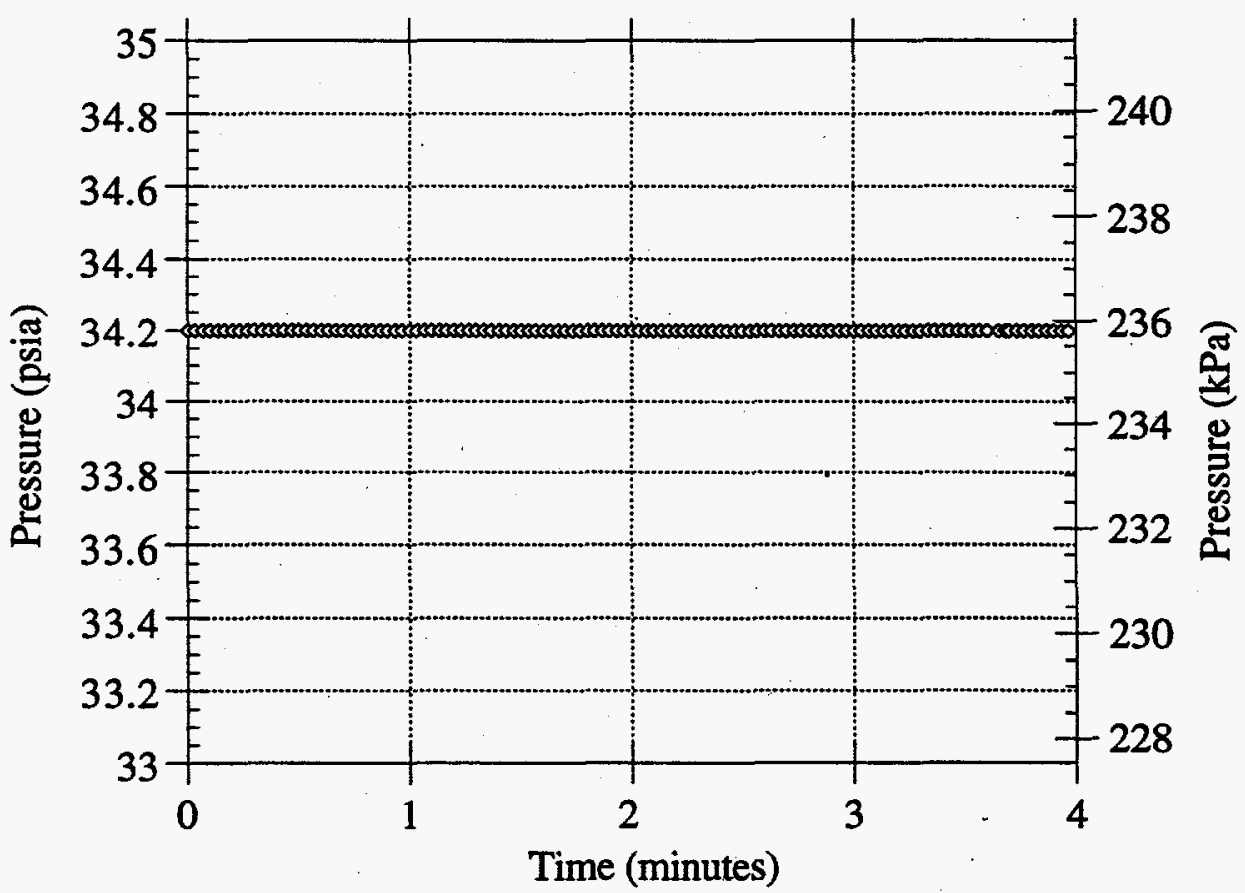

Figure B.4. Sample 12-21-94.016 Line Pressure Details 
Figure B. 3 shows that the initial pressure in the pressurization chamber is not completely stationary and decreases approximately $5.5 \mathrm{kPa}(0.8 \mathrm{psi})$ over the four minutes. This change is essentially linear and is attributed to a very small leak in the chamber itself. Figure B.4 shows the pressure in the line is not changing detectably over this same time. Therefore, the valve between the chamber and line is not leaking. This minor drop in chamber pressure does not affect overall system accuracy.

Figures B.5 and B.6 show the pressures of the pressurization chamber and the line just before opening the valve for the second pressurization. As in the first pressurization, the chamber pressure drops very slowly at a steady rate. The line pressure is also dropping slowly, which indicates that the seals on the sample chamber may be leaking a small amount. The ability to detect these small pressure changes is the result of the sensitive pressure transducers and is not an indication of a problem. These small pressure drops do not affect system accuracy significantly. Testing in the lab showed that a leak that could adversely affect data quality would not allow the system to come to equilibrium as determined by the pressure checks that are performed before and after the valve between the pressurization chamber and the line is opened and closed.

Figures B.7 and B.8 show the pressures for two successive samples, 12-21-94.016 and 12-21-94.017. The first sample was $43 \mathrm{~cm}$ (17 in.) from the tank bottom, and the second was $25 \mathrm{~cm}$ (10 in.) from the tank bottom. The time between the starts of the measurements was approximately 20 minutes, which is representative of the time required for any double pressurization. The initial pressures for both samples were nearly identical since they were separated by such a small distance. However, the equilibrium pressures for the second sample were noticeably lower than those for the first, indicating that the void fraction for the second sample is higher than for the first.

For each sample, only five data points in the sequence are used to calculate the void fraction. For sample 12-21-94.016, data from 06:37:37 pm, 06:39:01 pm, 06:45:03 pm, 06:46:19 pm and 06:47:54 pm were used. The first of these data sets was used to establish the initial temperatures and pressures for the first pressurization, except that the fifth data set was used to establish the initial sample chamber pressure. The second set was used for the final temperatures and pressures for the first pressurization. The third set was used for the initial conditions for the second pressurization, while the fourth data set was used for the second pressurizations final conditions. The final line pressure for time 06:47:54 pm was used for the initial sample chamber pressure. The same approach was used for all other void fraction samples, although some samples were only pressurized one time. All data sets were selected from the same locations in the recorded data.

Tables B. 2 and B. 3 present the data used for each of the samples for the two deployments. TE1, TE2, TE3, and TE4 are all located in the equipment enclosure. TE1 and TE2 measure the temperature inside the equipment enclosure; TE3 and TE4 measure the temperature of the pressurization chamber; TE5, TE6, and TE7 measure the line temperature in the mast. TE5 is near the top; TE6 is near the middle; and TE7 is near the bottom. TE8 and TE9 measure the temperature at the pivot and are used for the sample chamber temperature.

PIT1, PIT2, and PIT3 are all located inside the equipment enclosure. PIT1 and PIT2 measure the pressure in the pressurization chamber. PIT 3 measures the pressure in the connecting line just below the solenoid valve at the bottom of the pressurization chamber. 


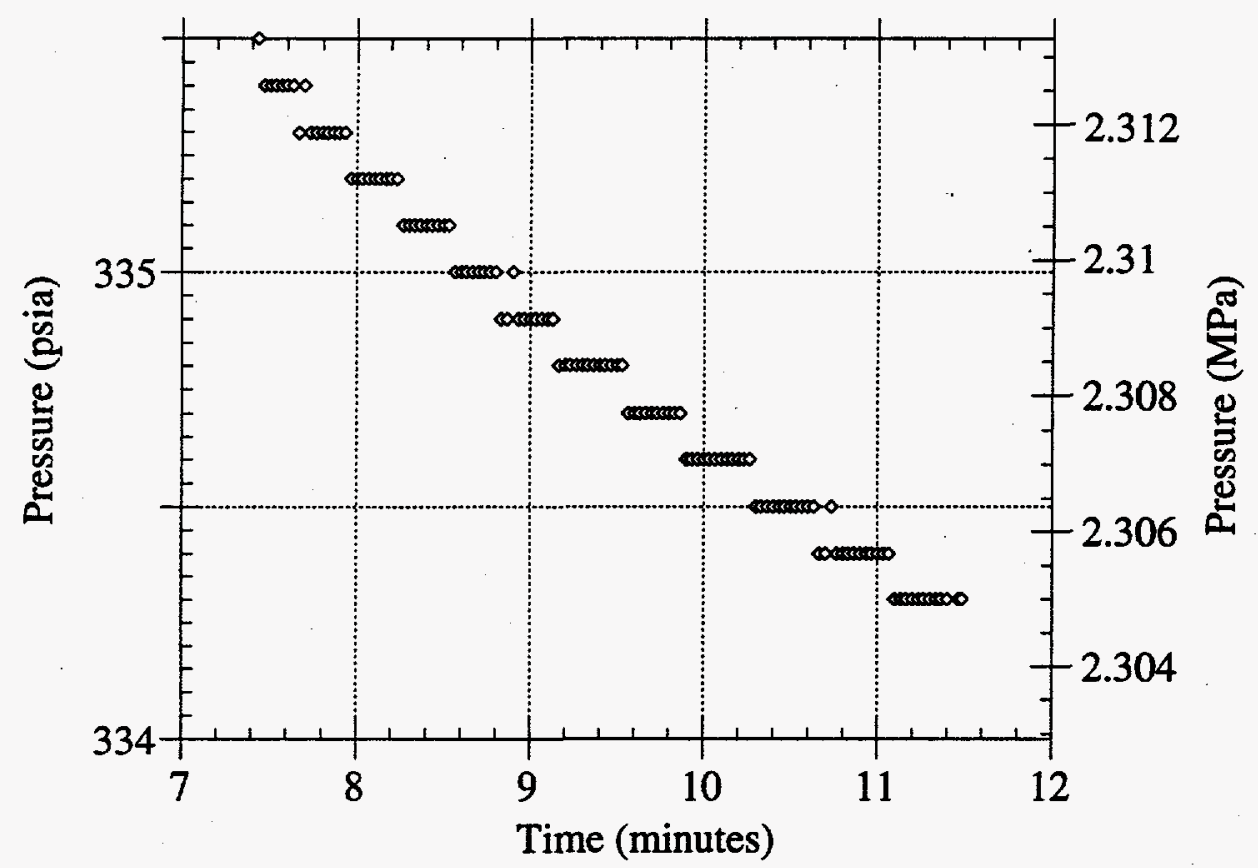

Figure B.5. Sample 12-21-94.016 Second Pressurization Chamber Pressure Detail

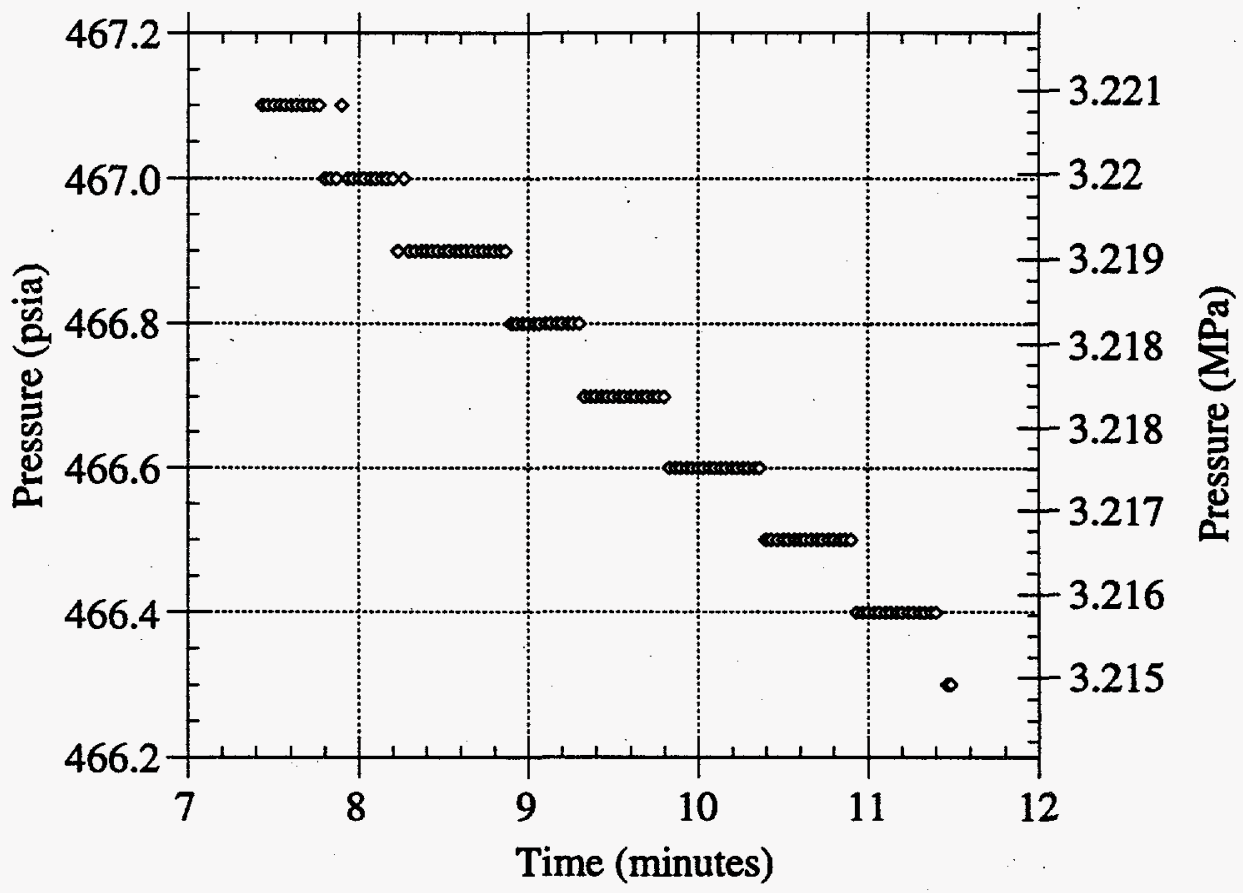

Figure B.6. Sample 12-21-94.016 Second Pressurization Line Pressure Detail B.8 


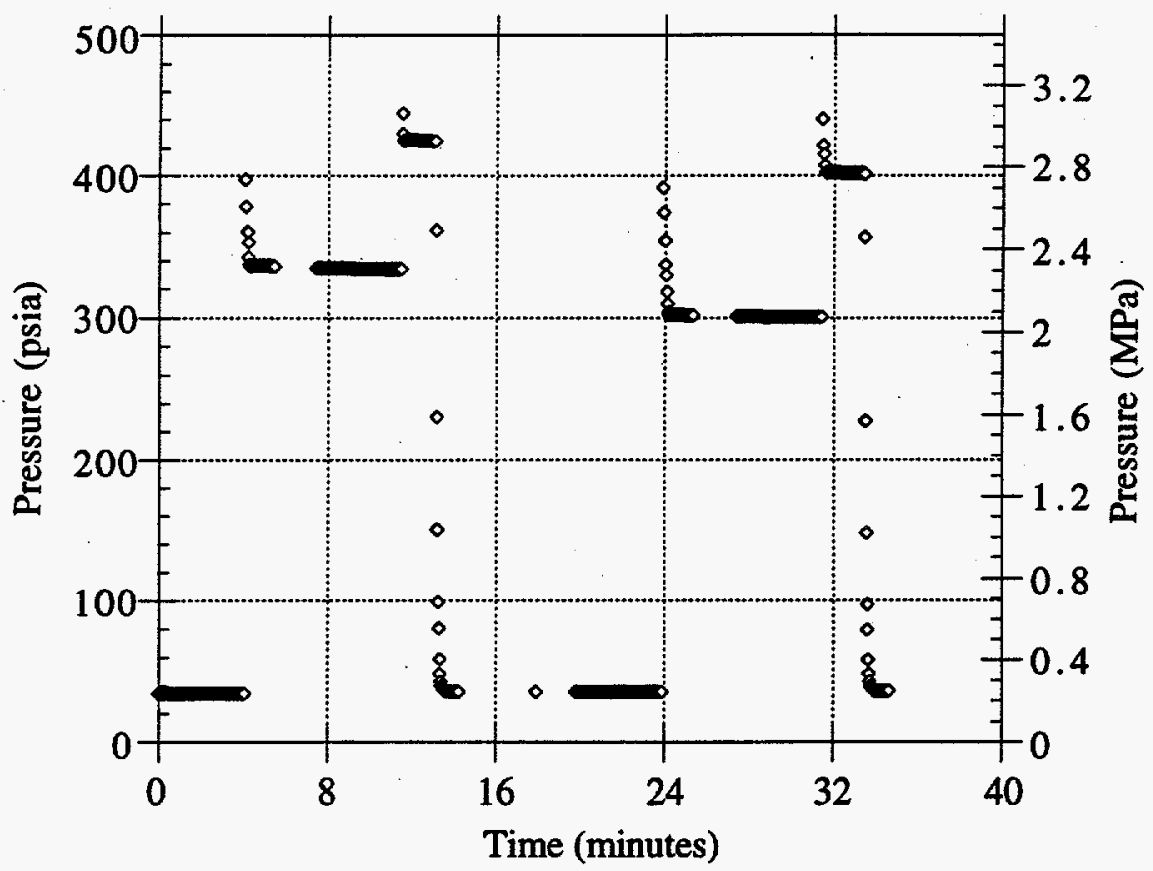

Figure B.7. Comparison of Samples 12-21-94.016 and 12-21-94.017 Line Pressures

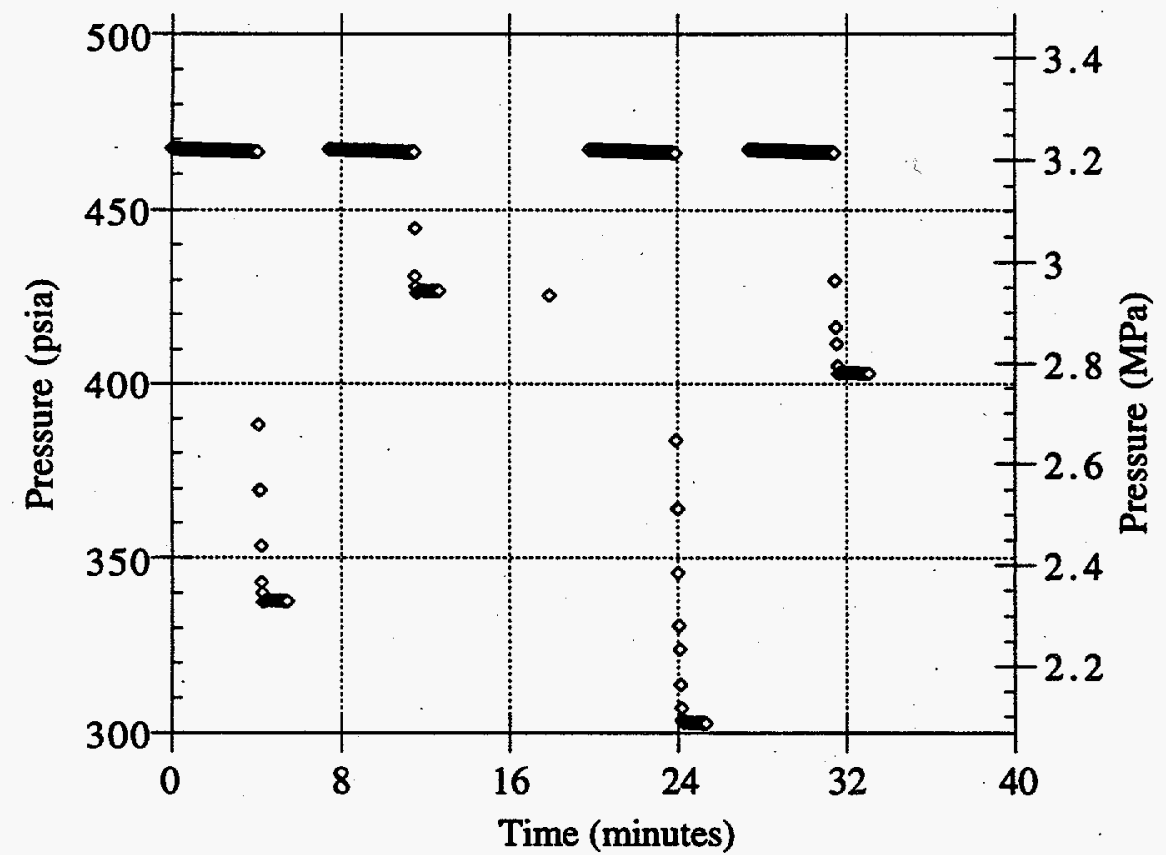

Figure B.8. Comparison of Samples 12-21-94.016 and .017 Pressurization Chamber Pressures 
Table B.2. Void Fraction Measurement Device - Selected Data Points

Data Taken at Riser 11B of Tank 241-SY-101 on December 21, 1994

Sample Number 12-21-94.002 Elevation 330.8

TE1 TE2 TE3 TE4 TE5 TE6 TE7 TE8 TE9 TE10 PIT1 PIT2 PIT3 PIT4! $25.2824 .4823 .1923 .0718 .6618 .9620 .4645 .5344 .7122 .74466 .1465 .6 \quad 13.4 \quad 17.2$

25.3524 .4123 .1923 .0518 .6818 .9320 .5345 .6244 .8622 .74373 .1372 .6372 .0

25.5024 .5523 .3223 .1918 .6218 .7220 .8446 .0345 .3622 .81464 .6464 .2371 .6372 .0

25.4224 .5523 .3423 .2118 .5818 .6820 .9046 .0745 .4022 .81445 .4445 .0444 .0

Sample Number 12-21-94.003 Elevation 306.4

TE1 TE2 TE3 TE4 TE5 TE6 TE7 TE8 TE9 TE10 PIT1 PIT2 PIT3 PIT4!

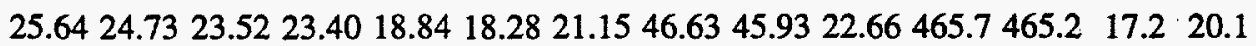

25.6424 .6623 .5323 .3818 .9118 .2621 .1946 .6545 .9322 .81375 .4374 .9374 .2

25.6424 .8823 .6723 .5419 .1417 .9821 .4446 .8346 .1522 .81464 .5464 .1373 .9374 .2

25.7124 .8823 .6923 .5519 .1217 .9521 .4846 .8546 .1722 .66446 .1445 .7444 .8

Sample Number 12-21-94.004 Elevation 281.6

TE1 TE2 TE3 TE4 TE5 TE6 TE7 TE8 TE9 TE10 PIT1 PIT2 PIT3 PIT4!

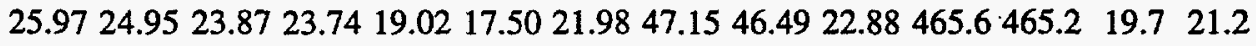
26.0425 .0223 .8823 .7219 .0217 .4522 .0547 .1646 .5022 .66376 .4375 .9375 .1 26.1124 .9523 .9923 .8618 .9217 .1122 .3447 .1746 .5222 .74464 .5464 .1374 .3375 .1 26.1125 .1024 .0123 .8718 .8817 .0422 .4147 .1846 .5322 .74446 .5446 .0444 .9

Sample Number 12-21-94.005 Elevation 257

TE1 TE2 TE3 TE4 TE5 TE6 TE7 TE8 TE9 TE10 PIT1 PIT2 PIT3 PIT4! $26.1125 .124 .1323 .9918 .6516 .5222 .8547 .4046 .6422 .55465 .5465 .0 \quad 20.821 .6$ 26.1825 .0224 .1223 .9718 .5816 .4722 .8947 .4046 .6422 .81376 .4375 .9375 .1 25.8624 .8824 .1924 .0518 .2616 .1823 .1447 .4046 .6822 .48464 .7464 .3373 .9375 .1 26.0424 .8824 .224 .0618 .1916 .1323 .2047 .4246 .6922 .55446 .6446 .1444 .9

Sample Number 12-21-94.006 Elevation 232.9

TE1 TE2 TE3 TE4 TE5 TE6 TE7 TE8 TE9 TE10 PIT1 PIT2 PIT3 PIT4! 25.7924 .8824 .2524 .1218 .1515 .7523 .5147 .5746 .9022 .26465 .4465 .021 .422 .7 25.8624 .8024 .2424 .0818 .2215 .7423 .5647 .5846 .9122 .34376 .3375 .8375 .0 25.9724 .8824 .2824 .1318 .4115 .5123 .7447 .6146 .9222 .34464 .6464 .2374 .3375 .0 25.9724 .8024 .2824 .1318 .4415 .4723 .7847 .6046 .9222 .34446 .4446 .0444 .8

Sample Number 12-21-94.007 Elevation 209.2

TE1 TE2 TE3 TE4 TE5 TE6 TE7 TE8 TE9 TE10 PIT1 PIT2 PIT3 PIT4!

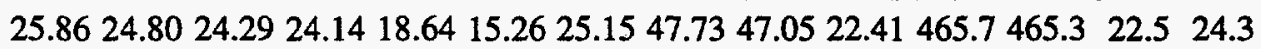
$25.8624 .8024 .2724 .1118 .6515 .2825 .3847 .7247 .0422 .41376 .8376 .3 \quad 375.5$ 25.8624 .8024 .2924 .1618 .6815 .2626 .2047 .7547 .0622 .34465 .0464 .6374 .6375 .5 25.9724 .9524 .2924 .1518 .6815 .2526 .2547 .7547 .0622 .26446 .8446 .4445 .2

Sample Number 12-21-94.008 Elevation 184.5

TE1 TE2 TE3 TE4 TE5 TE6 TE7 TE8 TE9 TE10 PIT1 PIT2 PIT3 PIT4! $25.9724 .7324 .3024 .1618 .6515 .3531 .4047 .8047 .1222 .26466 .2465 .8 \quad 24.0 \quad 25.7$ 25.9724 .7324 .2724 .1118 .6315 .3932 .1247 .8047 .1322 .34377 .3376 .9375 .9 25.57 24.48 24.27 24.12 18.59 15.56 35.09 47.79 47.11 21.97 465.3 464.9 375.1375.9 25.6424 .4824 .2624 .1118 .5915 .6235 .5347 .7947 .0921 .97447 .2446 .7445 .5 


\section{Table B.2 (Contd)}

Sample Number 12-21-94.009 Elevation 160.7

TE1 TE2 TE3 TE4 TE5 TE6 TE7 TE8 TE9 TE10 PIT1 PIT2 PIT3 PIT4! $25.3524 .3324 .1223 .9818 .3616 .03 \quad 40.2647 .7947 .1321 .17466 .4466 .0 \quad 25.526 .8$ 25.4224 .2624 .0823 .9218 .3316 .1240 .6947 .7947 .1321 .17378 .1377 .6376 .6 25.0223 .7923 .9923 .8318 .0716 .5342 .5947 .7947 .0920 .56466 .2465 .8375 .4376 .6 25.1023 .7923 .9523 .8018 .0316 .6242 .8847 .7847 .1120 .56447 .9447 .5446 .3

Sample Number 12-21-94.010 Elevation 159.6

TE1 TE2 TE3 TE4 TE5 TE6 TE7 TE8 TE9 TE10 PIT1 PIT2 PIT3 PIT4! 24.55 23.43.23.76 23.60 17.63 17.19 44.17 47.75 47.09 19.72 467.2 466.8 $26.7 \quad 27.0$ 24.7323 .4323 .7023 .5317 .5817 .2944 .3347 .7547 .0719 .72378 .4377 .9377 .1 $24.3323 .1023 .5723 .4117 .31 \quad 17.6644 .97 .47 .7547 .0519 .36466 .9466 .4376 .3377 .1$ 24.3323 .1723 .5323 .3717 .2517 .7445 .0847 .7347 .0519 .29448 .5448 .1446 .8

Sample Number 12-21-94.011 Elevation 135

TE1 TE2 TE3 TE4 TE5 TE6 TE7 TE8 TE9 TE10 PIT1 PIT2 PIT3 PIT4! $24.0422 .8823 .2023 .0616 .6718 .4845 .7647 .7347 .0518 .89467 .5467 .0 \quad 26.8 \quad 28.3$ $23.9722 .7423 .1522 .9916 .6318 .6345 .8247 .7347 .0319 .03 \quad 379.1378 .6377 .7$ 23.7222 .6623 .0122 .8416 .2719 .2746 .0647 .7047 .0318 .74467 .3466 .8376 .8377 .7 23.5722 .4122 .9722 .8116 .2019 .3946 .1147 .7347 .0218 .67449 .0448 .5447 .4

Sample Number 12-21-94.012 Elevation 111.9 TE1 TE2 TE3 TE4 TE5 TE6 TE7 TE8 TE9 TE10 PIT1 PIT2 PIT3 PIT4! 23.50 22.34 22.71 22.56 15.53 20.27 46.34 47.76 47.07 18.81 467.6 467.2 $28.4 \quad 29.7$ 23.50 22.34 22.65 22.48 15.44 20.38 46.39 47.77 47.07 18.67 379.5 379.0 378.2 23.1721 .9722 .5222 .3614 .9720 .8746 .5147 .7547 .0718 .27467 .5467 .0377 .6378 .2 23.1021 .9722 .4722 .3214 .8820 .9446 .5247 .7547 .0618 .34449 .2448 .7447 .7

Sample Number 12-21-94.013 Elevation 87.6 TE1 TE2 TE3 TE4 TE5 TE6 TE7 TE8 TE9 TE10 PIT1 PIT2 PIT3 PIT4! $22.7421 .5722 .2122 .0614 .2621 .4546 .6347 .7947 .0917 .98467 .5467 .0 \quad 29.7 \quad 31.2$ 22.7421 .5722 .1521 .9914 .2121 .5046 .6647 .7747 .0917 .87379 .6379 .1378 .2 22.7421 .6522 .0121 .8613 .9021 .7946 .7047 .7847 .0917 .80467 .3466 .8377 .4378 .2 22.4121 .1721 .9721 .8213 .8321 .8546 .7447 .7847 .0917 .51449 .0448 .5447 .5

Sample Number 12-21-94.014 Elevation 65.7

TE1 TE2 TE3 TE4 TE5 TE6 TE7 TE8 TE9 TE10 PIT1 PIT2 PIT3 PIT4! 22.26 20.96 21.64 21.47 13.33 22.28 46.82 47.78 47.09 $17.36467 .3466 .8 \quad 31.132 .7$ 22.2620 .9621 .5721 .4013 .3222 .3446 .8447 .7747 .0917 .18379 .9379 .4378 .5 21.8620 .7421 .4221 .2613 .1222 .5846 .8447 .7747 .0916 .82467 .2466 .7377 .9378 .5 21.9720 .8121 .3821 .2213 .0722 .6446 .8647 .7847 .1116 .89449 .0448 .6447 .5

Sample Number 12-21-94.015 Elevation 41.7 TE1 TE2 TE3 TE4 TE5 TE6 TE7 TE8 TE9 TE10 PIT1 PIT2 PIT3 PIT4! 21.65 20.56 21.03 20.88 12.83 23.01 46.90 47.62 46.96 $16.60467 .0466 .5 \quad 32.5 \quad 34.3$ 21.57 20.27 20.9720.80 12.85 23.07 46.91 47.63 46.95 16.35 378.3 377.7 376.8 21.36 20.2720.84 20.67 12.85 23.29 46.90 47.59 46.92 16.49466 .9466 .5375 .4376 .8 21.4320 .1920 .8020 .6312 .8623 .3446 .9147 .5846 .9316 .49448 .0447 .5446 .3 


\section{Table B.2 (Contd)}

Sample Number 12-21-94.016 Elevation 17.3

TE1 TE2 TE3 TE4 TE5 TE6 TE7 TE8 TE9 TE10 PIT1 PIT2 PIT3 PIT4! $21.1720 .1920 .5220 .3713 .0326 .1946 .9647 .0046 .3516 .35466 .9466 .4 \quad 34.235 .7$ 21.1720 .1220 .4520 .2813 .0726 .5746 .9746 .9846 .3316 .42338 .2337 .7336 .6 $21.1720 .1220 .3620 .1913 .2828 .7646 .9846 .8746 .22 \quad 16.42466 .8466 .4334 .3336 .6$ 21.10 20.05 20.32 20.15 13.32 29.02 47.00 46.83 46.19 16.27 427.3 426.8 425.3

Sample Number 12-21-94.017 Elevation 9.7 TE1 TE2 TE3 TE4 TE5 TE6 TE7 TE8 TE9 TE10 PIT1 PIT2 PIT3 PIT4! $20.8819 .8020 .0619 .91 \quad 13.7934 .2147 .0645 .9045 .28 \quad 16.35466 .6466 .1 \quad 35.535 .9$ 20.8819 .8019 .9919 .8213 .8333 .9947 .0545 .8645 .2516 .42303 .3302 .7301 .8 20.8119 .7219 .9219 .7614 .1237 .0147 .1045 .7145 .1016 .35466 .6466 .2300 .6301 .8 20.7419 .7219 .8619 .7114 .1937 .2347 .1045 .6845 .0816 .49403 .6403 .0401 .9

Sample Number 12-21-94.018 Elevation 9.7 TE1 TE2 TE3 TE4 TE5 TE6 TE7 TE8 TE9 TE10 PIT1 PIT2 PIT3 PIT4! $20.4819 .5019 .7219 .5814 .5738 .5447 .1445 .5344 .9016 .49467 .1466 .6 \quad 35.935 .9$ 20.4819 .5019 .6619 .4914 .5837 .5847 .1445 .5344 .8816 .35296 .6296 .1295 .4 20.4119 .2919 .6119 .4714 .8539 .3347 .1645 .4344 .8016 .42467 .0466 .5294 .8295 .4 20.3419 .5019 .5719 .4114 .8838 .9847 .1645 .4044 .7816 .42398 .9398 .3397 .5

Sample Number 12-21-94.019 Elevation 41.8 TE1 TE2 TE3 TE4 TE5 TE6 TE7 TE8 TE9 TE10 PIT1 PIT2 PIT3 PIT4!

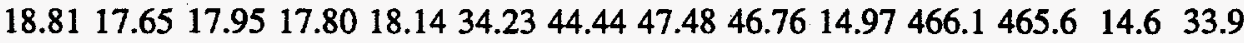
18.7417 .6517 .8917 .7318 .3033 .9744 .6147 .4646 .7614 .89356 .4355 .8355 .0 18.8917 .8017 .8017 .6519 .0633 .1545 .2147 .4646 .7614 .97466 .3465 .8353 .2355 .0 18.6717 .5117 .7717 .6219 .1833 .0045 .3047 .4446 .7314 .75438 .1437 .6436 .8

Sample Number $12-21-94.020 \quad$ Elevation 29.7 TE1 TE2 TE3 TE4 TE5 TE6 TE7 TE8 TE9 TE10 PIT1 PIT2 PIT3 PIT4! $18.4117 .43 \quad 17.5917 .4420 .0831 .9945 .8347 .2646 .5914 .42466 .1465 .634 .634 .6$ 18.4117 .3617 .5417 .3620 .1431 .8945 .9047 .2246 .5614 .49351 .4350 .8350 .3 
Table B.3. Void Fraction Measurement Device - Selected Data Points Data Taken at Riser 4A of Tank 241-SY-101 on January 17, 1995

Sample Number 01-17-95.001 Elevation 336.9

TE1 TE2 TE3 TE4 TE5 TE6 TE7 TE8 TE9 TE10 PIT1 PIT2 PIT3 PIT4!

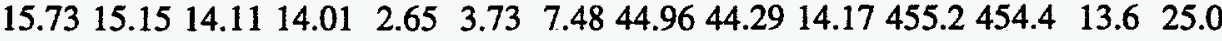
$15.8715 .0414 .0913 .98 \quad 2.66 \quad 3.75 \quad 7.6745 .1244 .4614 .09364 .7363 .9363 .9$

Sample Number 01-17-95.002 Elevation 191.6

TE1 TE2 TE3 TE4 TE5 TE6 TE7 TE8 TE9 TE10 PIT1 PIT2 PIT3 PIT4!

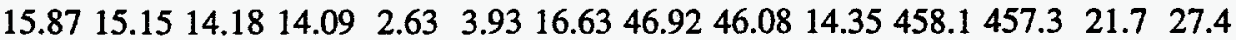

$15.8715 .2214 .1714 .05 \quad 2.643 .9917 .2246 .9546 .1014 .09371 .4370 .6370 .4$

Sample Number 01-17-95.003 Elevation 144.2

TE1 TE2 TE3 TE4 TE5 TE6 TE7 TE8 TE9 TE10 PIT1 PIT2 PIT3 PIT4!

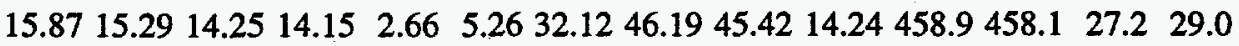

$15.8715 .2914 .2414 .112 .68 \quad 5.4432 .8346 .2145 .4014 .35373 .8373 .0372 .7$

Sample Number $01-17-95.004$ Elevation 97.9

TE1 TE2 TE3 TE4 TE5 TE6 TE7 TE8 TE9 TE10 PIT1 PIT2 PIT3 PIT4!

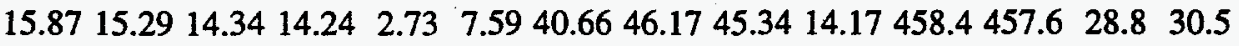

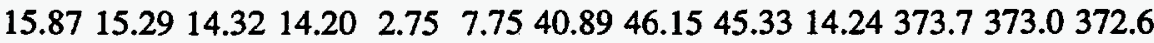

Sample Number 01-17-95.005 Elevation 59.7

TE1 TE2 TE3 TE4 TE5 TE6 TE7 TE8 TE9 TE10 PIT1 PIT2 PIT3 PIT4!

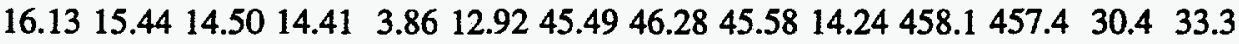

16.1315 .4414 .4814 .373 .9213 .0445 .5446 .3045 .5814 .24374 .5373 .7373 .4

Sample Number 01-17-95.006 Elevation 36.7

TE1 TE2 TE3 TE4 TE5 TE6 TE7 TE8 TE9 TE10 PIT1 PIT2 PIT3 PIT4!

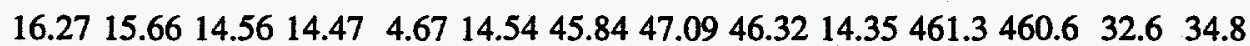
$16.3515 .7314 .5514 .43 \quad 4.7314 .6445 .8647 .1046 .3314 .24377 .4376 .7376 .3$

Sample Number 01-17-95.007 Elevation 13.3

TE1 TE2 TE3 TE4 TE5 TE6 TE7 TE8 TE9 TE10 PIT1 PIT2 PIT3 PIT4!

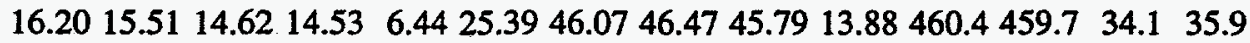

$16.1315 .5814 .5914 .44 \quad 6.5025 .5346 .0746 .4445 .7513 .88306 .6305 .8305 .6$

Sample Number 01-17-95.008 Elevation 71.4

TE1 TE2 TE3 TE4 TE5 TE6 TE7 TE8 TE9 TE10 PIT1 PIT2 PIT3 PIT4!

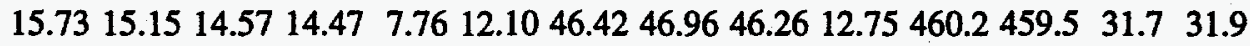

$15.7314 .9714 .5514 .41 \quad 7.7212 .1246 .4246 .9546 .2612 .75360 .1359 .3359 .0$

Sample Number 01-17-95.009 Elevation 48.2

TE1 TE2 TE3 TE4 TE5 TE6 TE7 TE8 TE9 TE10 PIT1 PIT2 PIT3 PIT4!

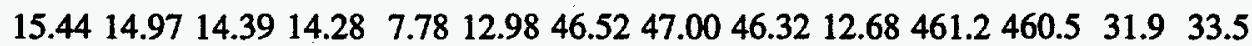

15.5814 .8214 .3614 .227 .8113 .0546 .5647 .0246 .3212 .68366 .1365 .3365 .0

Sample Number 01-17-95.010 Elevation 25.5

TE1 TE2 TE3 TE4 TE5 TE6 TE7 TE8 TE9 TE10 PIT1 PIT2 PIT3 PIT4!

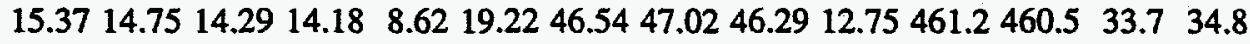
$15.3714 .8914 .2614 .11 \quad 8.7019 .3346 .5447 .0046 .2912 .68349 .8349 .0348 .7$

B.13 


\section{Table B.3 (Contd)}

Sample Number 01-17-95.011 Elevation 25.3

TE1 TE2 TE3 TE4 TE5 TE6 TE7 TE8 TE9 TE10 PIT1 PIT2 PIT3 PIT4!

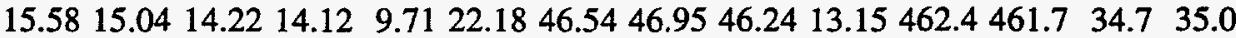

$15.5815 .04 \quad 14.2014 .069 .7921 .7546 .5746 .9646 .2313 .15356 .5355 .7355 .4$

Sample Number 01-17-95.012 Elevation 18.5

TE1 TE2 TE3 TE4 TE5 TE6 TE7 TE8 TE9 TE10 PIT1 PIT2 PIT3 PIT4! $15.4414 .7514 .1614 .0510 .8829 .3446 .5946 .5945 .91 \quad 13.15461 .7460 .934 .935 .4$ 15.4414 .7514 .1113 .9610 .9128 .4346 .5946 .5945 .8913 .08289 .0288 .3288 .0

Sample Number 01-17-95.013 Elevation 36.9

TE1 TE2 TE3 TE4 TE5 TE6 TE7 TE8 TE9 TE10 PIT1 PIT2 PIT3 PIT4!

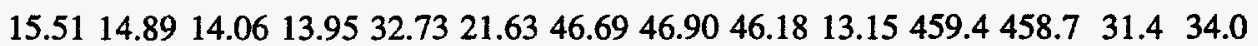
15.6615 .0414 .0513 .9133 .1121 .4646 .7046 .9046 .1913 .08369 .4368 .6368 .3

Sample Number 01-17-95.014 Elevation 16.4 TE1 TE2 TE3 TE4 TE5 TE6 TE7 TE8 TE9 TE10 PIT1 PIT2 PIT3 PIT4! $15.2914 .6414 .01 \quad 13.9132 .9528 .0146 .7346 .5445 .8712 .90459 .9459 .2 \quad 34.5 \quad 35.5$ 15.4414 .8913 .9813 .8332 .9427 .8946 .7346 .5245 .8612 .97313 .0312 .2312 .0

Sample Number 01-17-95.015 Elevation 16.3 TE1 TE2 TE3 TE4 TE5 TE6 TE7 TE8 TE9 TE10 PIT1 PIT2 PIT3 PIT4! 15.2214 .6413 .9913 .8831 .4132 .0946 .7346 .3945 .7012 .75460 .8460 .035 .535 .6 15.1514 .5713 .9513 .8131 .3130 .9346 .7346 .3845 .6912 .50320 .5319 .8319 .5 


\section{Appendix C}

\section{Determination of Void Fraction Instrument}

System Volumes 



\section{Appendix C}

\section{Determination of VFI System Volumes}

The void fraction instrument is made up of three separate volumes. Different methods were used to measure each of these volumes. The sample chamber volume was measured by completely filling the chamber with water, collecting the water from inside the chamber, weighing the water, and calculating the volume based on the density of water. But the pressurization chamber and the connecting line could not be filled with water. Earlier testing on the void fraction instrument (VFI) showed that, at least while in the horizontal position, the water in the connecting line and fittings was not entirely removed by the purging with nitrogen gas. Any residual water in the pressurization chamber or line would have reduced the accuracy of the measurements and the actual volumes would be under-predicted.

The volume of the pressurization chamber was determined by connecting it with a pressure vessel of precisely known volume and calculating the volume using the ideal gas law from the known volume of the bomb and the initial and final pressures. Once the volume of the pressurization chamber was known, it was used to "bomb" the connecting line and determine its volume again using the ideal gas law and the initial and final pressures.

\section{Sample Chamber}

The volume of the sample chamber was determined by filling it with water, then collecting the water and determining its volume. The sample chamber was placed into a container of water in the 306 East High Bay with the cover open and the mast horizontal. The lower arm was in the vertical orientation with the sample chamber completely immersed in water at the bottom. All air bubbles were removed from the sample chamber, and any air trapped in the recess for the check valve was also removed. The cover was closed and a full chamber of water isolated. The arm was then rotated to the horizontal. All water on the outside of the VFI was wiped up with paper towel so that none remained.

A container with lid for collecting the water from the sample chamber was weighed on a calibrated scale along with a paper towel. The sample chamber cover was opened and the water collected into the container using a large funnel. The paper towel was used to wipe all the water from the inside of the sample chamber and from the funnel. The lid on the container was closed with the paper towel inside. The container with paper towel and water was then weighed on the same scale. The tare weight of the container, lid, and paper towel was 56.61 grams, and the gross weight was 423.28 grams, for a net weight of 366.67 grams. At one cubic centimeter per gram, the volume is $366.7 \mathrm{cc}\left(22.38 \mathrm{in.}^{3}\right)$. The volume of the sample chamber was only measured once

officially using this method. Several other measurements using a similar method without the paperr towel produced slightly less volume for the sample chamber. The volume of the sample chamber was also calculated from the dimensions of the chamber as $364.3 \mathrm{cc}(22.23 \mathrm{in.}$. $)$. 


\section{Pressurization Chamber}

The volume of the pressurization chamber was found by using a specially fabricated apparatus constructed of two heavy walled brass pressure vessels, a calibrated pressure transducer, valves, and connecting fittings. The two pressure vessels had internal volume of about five and a quarter cubic inches. They had removable caps so that the internal volumes could be reduced by adding blocks of known size. The first vessel was connected to a nitrogen bottle at a valve. The two vessels were also connected with another valve between. The second vessel was connected to a vent line by a third valve.

With the valve between the vessels closed, the first vessel was pressurized from the nitrogen bottle up to approximately $34 \mathrm{~atm}(500 \mathrm{psi})$ and while the second vessel was vented to atmospheric pressure. The inlet and outlet valves were closed and the gas in the vessels allowed to come to thermal equilibrium. When the valve between the two vessels was opened, the nitrogen gas flowed from the first vessel into the second until pressure and thermal equilibrium were reached. Using the ideal gas law, the ratio of the two vessel volumes could be determined. This was done several time to establish an average volume ratio.

One of the vessels was then opened and an aluminum block of measured volume inserted. The above test was repeated with three different sizes of fill blocks to determine the actual volumes of the two vessels. A small adaptor fitting was then connected to the outlet valve of the second vessel. This adaptor fitting was connected to the inlet solenoid valve for the pressurization chamber. With the solenoid valve closed, the adaptor fitting was bombed several times so that its volume could be determined. Once the adaptor fitting was characterized, the pressurization chamber was bombed several times using the known volumes of the second vessel and adaptor. An average volume of $101.1 \mathrm{cc}(6.171 \mathrm{in} .3)$ was determined with a standard deviation of $0.2 \mathrm{cc}$ $\left(0.012\right.$ in. $\left.{ }^{3}\right)$.

\section{Connecting Line}

With the pressurization chamber volume now known, the volume of the connecting line was determined by bombing with the pressurization chamber. The sample chamber was completely filled with water for these tests. However, since the sample chamber has a finite stiffness, it expanded a small amount when pressurized and some nitrogen gas was injected into the sample chamber. Based on a calculated volumetric compliance of $0.0713 \mathrm{cc} / \mathrm{MPa}(0.00003 \mathrm{in} .3 / \mathrm{psi}$ for the sample chamber, the volume of the connecting line was calculated for five double pressurization tests. The average connecting line volume was found to be $23.35 \mathrm{cc}\left(1.425 \mathrm{in} .{ }^{3}\right)$ with a standard deviation of $0.74 \mathrm{cc}\left(0.045 \mathrm{in} .{ }^{3}\right)$. 
Appendix D

Plastic Block Tests 


\section{Appendix D}

\section{Plastic Block Tests}

Tests were conducted in the WHC 306E laboratory to gain additional information about the repeatability of the void fraction instrument results over a wide range of "known" void fractions. Plastic blocks were used to fill up some of the space inside the chamber. These tests were performed during development and were independent of the measurement of system volumes. Because there is uncertainty in the actual void fraction obtained with the plastic blocks, only the data for zero and $100 \%$ void fraction can be used to assess system accuracy. The plastic block void fraction data are valid primarily for assessing repeatability.

These tests were conducted during a period when some water may have been present in the connecting line after testing the wash dry cycles. It was later determined that in the horizontal configuration a small amount of water might be trapped in the connecting line to the line pressure transducer. If the successive void fraction measurements for each set of blocks is examined, there is a slight trend to increasing void fraction, which is consistent with evaporation of some of the trapped water with each venting of the sample chamber and line.

Two methods were used to fill up some of the sample chamber volume. The first attempts used several small separate blocks wedged in to fill up the space. This method left approximately 50 and $20 \%$ void. The second method was to machine single blocks with the same basic shape of the sample chamber only slightly reduced in dimensions. This method left approximately 15,10 and $5 \%$ void. Tests in this series were also run with the sample chamber empty (100\% void) and completely filled with water ( $0 \%$ void).

The "true" void volume was found by submerging the sample chamber under water, closing the cover, and capturing the water trapped in the sample chamber between the blocks. The weight of the trapped water was used to determine the void volume. These tests were conducted before we had perfected the method of getting all of the water out of the sample chamber, and therefore the yoid fractions reported as "true" may be slightly low.

Double pressurization was used for all of the tests reported in this appendix. In all cases the void fractions calculated from the first and second pressurizations were within one tenth of one percent void fraction.

The "true" and calculated void fractions are given in Table D.1. In all cases except for the $100 \%$ void fractions, the calculated void fraction was larger than the "true" void fractions. The largest difference is $1.8 \%$ void fraction for a "true" void fraction of about $15 \%$. It is postulated that, for all tests with plastic blocks, the "true" void fraction as reported in the table was slightly low because of errors in the way the volume was measured. The experience with the measurement of the sample chamber indicated that an under-measurement of about $1 \%$ is possible with the methods used. In all cases, the void fraction measurements for successive test of the same set of blocks varied by a maximum of $0.6 \%$. As noted above, there was a slight tendency to increasing void measurement with each new test, which is consistent with residual water in the connecting line evaporating. These data are shown graphically in Figures D.1 and D.2.

The reported differences between the "true" and calculated void fractions are all less than the design criteria of two percent. While it is not possible to determine with certainty what the 
causes of the differences are, it is postulated that at least part of the errors are associated with the "true" values. The methods used to make these measurements were prone to errors, and the sign of the errors is consistent with the error contributors.

Table D.1 Plastic Block Void Fraction Data

$\begin{array}{rrccc}\begin{array}{c}\text { True" } \\ (\%)\end{array} & \begin{array}{c}\text { 1st Pressurization } \\ (\%)\end{array} & \begin{array}{c}\text { 2nd Pressurization } \\ (\%)\end{array} & \begin{array}{c}\text { 1st Difference } \\ (\%)\end{array} & \begin{array}{c}\text { 2nd Difference } \\ (\%)\end{array} \\ 0.0 & 0.0 & 0.1 & 0.0 & 0.1 \\ 0.0 & 0.6 & 0.7 & 0.6 & 0.7 \\ 0.0 & 0.6 & 0.6 & 0.6 & 0.6 \\ 5.6 & 6.6 & 6.6 & 1.0 & 1.0 \\ 5.6 & 7.0 & 6.9 & 1.4 & 1.3 \\ 5.6 & 7.2 & 7.1 & 1.6 & 1.5 \\ 10.6 & 11.6 & 11.6 & 1.0 & 1.0 \\ 10.6 & 12.0 & 11.9 & 1.4 & 1.3 \\ 10.6 & 12.1 & 12.0 & 1.5 & 1.4 \\ 10.6 & 12.2 & 12.1 & 1.6 & 1.5 \\ 15.4 & 16.8 & 16.9 & 1.4 & 1.5 \\ 15.4 & 17.1 & 17.1 & 1.7 & 1.7 \\ 15.4 & 17.2 & 17.1 & 1.8 & 1.7 \\ 21.5 & 22.2 & 22.2 & 0.7 & 0.7 \\ 21.5 & 22.4 & 22.3 & 0.9 & 0.8 \\ 21.5 & 22.4 & 22.3 & 0.9 & 0.8 \\ 52.1 & 52.8 & 52.7 & 0.7 & 0.6 \\ 52.1 & 52.9 & 53.0 & 0.8 & 0.9 \\ 52.1 & 53.0 & 52.9 & 0.9 & 0.8 \\ 100.0 & 99.4 & 99.3 & -0.6 & -0.7 \\ 100.0 & 100.0 & 100.0 & -0.0 & -0.0 \\ 100.0 & 99.8 & 99.9 & -0.2 & -0.1\end{array}$




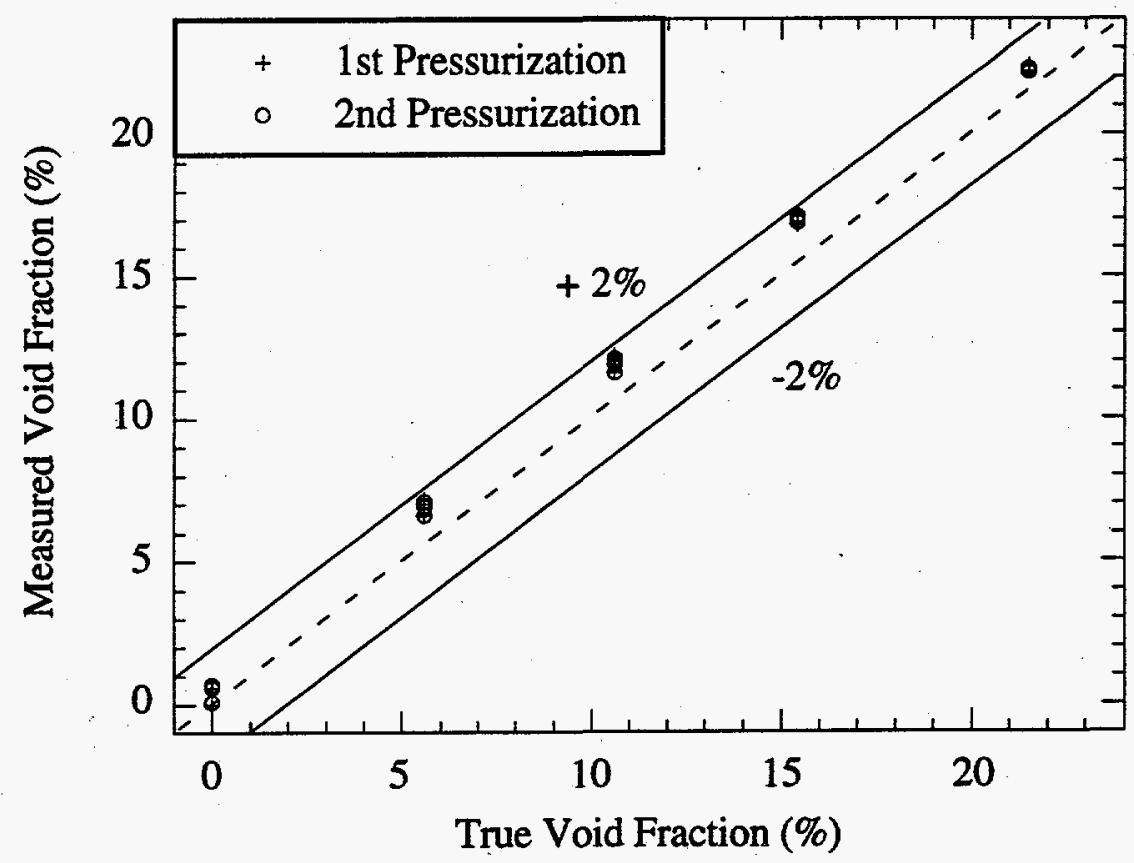

Figure D.1. Results of Plastic Block Tests - Void Fraction Error

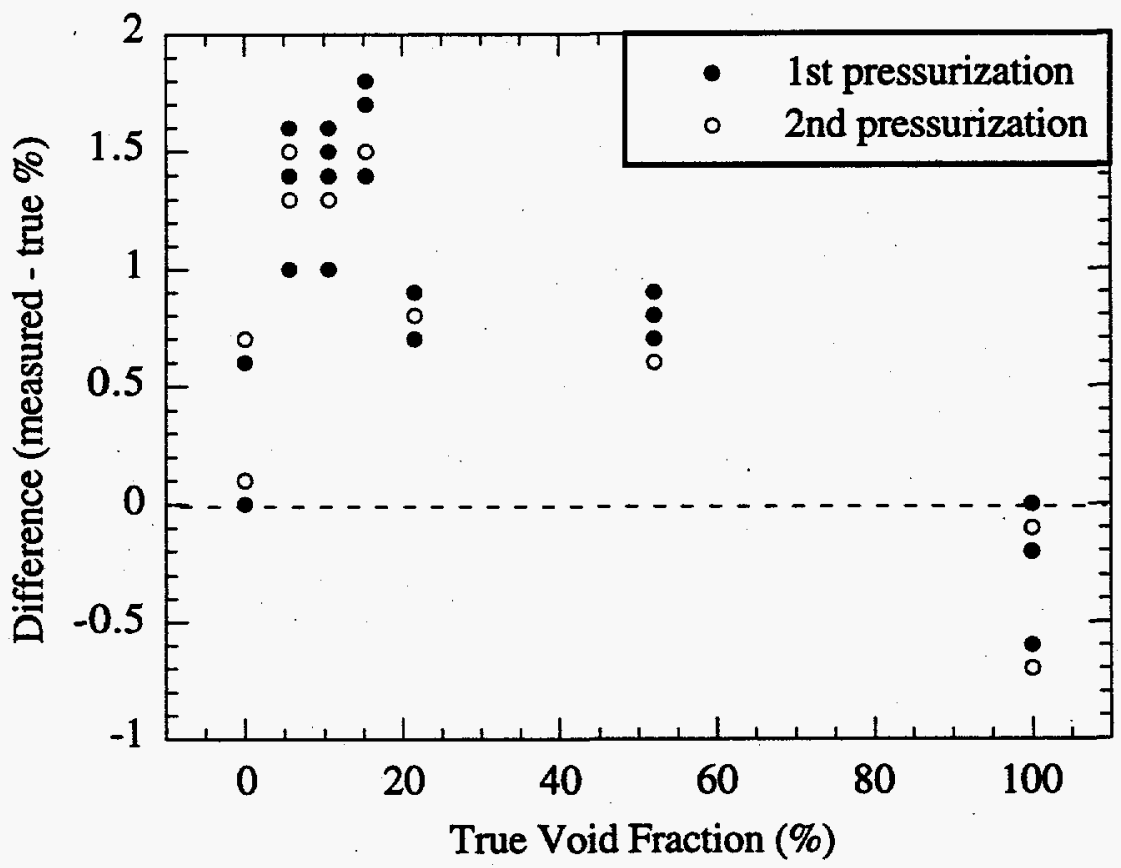

Figure D.2. Plastic Block Tests - Measured Versus True Void Fraction

D.3 
Appendix E

\section{System Error Analysis}




\section{Appendix E}

\section{System Error Analysis}

The following nomenclature will be used to define the volumes and properties in the model:

$0=$ Gas bubbles in the waste sample

$1=\quad$ Pressurization chamber

$2=$ Sample chamber

$3=$ Connecting line

$\mathrm{T}=$ Temperature

$P=$ Pressure

$\mathrm{V}=$ Volume

$\mathrm{N}=$ Number of moles of gas

The subscripts $\mathrm{i}$ and $\mathrm{f}$ indicate initial and final conditions, respectively. For example, $\mathrm{P} 1_{\mathrm{i}}$ is the initial pressure in the pressurization chamber and $\mathrm{T} 3_{\mathrm{f}}$ is the final temperature in the connecting line. All pressures and temperatures are absolute. Pressure and temperature changes are denoted with a $\Delta$; for example, $\Delta \mathrm{P} 1=\mathrm{P} 1_{\mathrm{f}}-\mathrm{P} 1_{\mathrm{i}}$.

The void fraction is calculated from the following equation:

$$
\alpha=\frac{\mathrm{K} 1\left(\frac{\mathrm{P} 1_{i}+\Delta \mathrm{P} 1}{\mathrm{~T} 1_{i}+\Delta \mathrm{T} 1}-\frac{\mathrm{P} 1_{i}}{\mathrm{~T} 1_{i}}\right)+\mathrm{K} 3\left(\frac{\mathrm{P} 3_{\mathrm{i}}+\Delta \mathrm{P} 3}{\mathrm{~T} 3_{\mathrm{i}}+\Delta \mathrm{T} 3}-\frac{\mathrm{P} 3_{\mathrm{i}}}{\mathrm{T} 3_{\mathrm{i}}}\right)+\beta \Delta \mathrm{P} 2 \frac{\mathrm{P} 2_{\mathrm{i}}+\Delta \mathrm{P} 2}{\mathrm{~T} 2_{\mathrm{i}}+\Delta \mathrm{T} 2}}{\frac{\mathrm{P} 2_{\mathrm{i}}}{\mathrm{T} 2_{\mathrm{i}}}-(1+\mathrm{k}) \frac{\mathrm{P} 2_{\mathrm{i}}+\Delta \mathrm{P} 2}{\mathrm{~T} 2_{\mathrm{i}}+\Delta \mathrm{T} 2}}
$$

Define the following term to simplify writing the derivatives:

$$
\mathrm{DEN}=\frac{\mathrm{P} 2_{\mathrm{i}}}{\mathrm{T} 2_{\mathrm{i}}}-(1+\mathrm{k}) \frac{\mathrm{P} 2_{\mathrm{i}}+\Delta \mathrm{P} 2}{\mathrm{~T} 2_{\mathrm{i}}+\Delta \mathrm{T} 2}
$$

Derivatives for the various input parameters are as follows, assuming that the quantities $\Delta \mathrm{T} 1, \Delta \mathrm{T} 2$, and $\Delta \mathrm{T} 3$ are all small relative to $\mathrm{T} 1, \mathrm{~T} 2$, and $\mathrm{T} 3$ :

$$
\begin{gathered}
\frac{\mathrm{d} \alpha}{\mathrm{dP} 1_{\mathrm{i}}}=\frac{-\mathrm{K} 1 \Delta \mathrm{T} 1}{\mathrm{DEN} \mathrm{T} 1^{2}} \\
\frac{\mathrm{d} \alpha}{\mathrm{d} \Delta \mathrm{P} 1}=\frac{\mathrm{K} 1}{\mathrm{DENT} 1}
\end{gathered}
$$




$$
\begin{aligned}
& \frac{\mathrm{d} \alpha}{\mathrm{dP} 2_{\mathrm{i}}}=\frac{\beta \Delta \mathrm{P} 2+\alpha \mathrm{k}}{\mathrm{DENT} 2} \\
& \frac{\mathrm{d} \alpha}{\mathrm{d} \Delta \mathrm{P} 2}=\frac{\beta\left(\mathrm{P} 2_{\mathrm{i}}+2 \Delta \mathrm{P} 2\right)+\alpha(1+\mathrm{k})}{\mathrm{DENT} 2} \\
& \frac{\mathrm{d} \alpha}{\mathrm{dP} 3_{\mathrm{i}}}=\frac{-\mathrm{K} 3 \Delta \mathrm{T} 3}{\mathrm{DEN} \mathrm{T} 3^{2}} \\
& \frac{\mathrm{d} \alpha}{\mathrm{d} \Delta \mathrm{P} 3}=\frac{\mathrm{K} 3}{\mathrm{DEN} \mathrm{T3}} \\
& \frac{\mathrm{d} \alpha}{\mathrm{dT} 1}=\frac{-\mathrm{K} 1 \Delta \mathrm{P} 1}{\mathrm{DEN} \mathrm{T} 1^{2}} \\
& \frac{\mathrm{d} \alpha}{\mathrm{d} \Delta \mathrm{T} 1}=-\mathrm{K} 1 \frac{\mathrm{P} 1_{\mathrm{i}}+\Delta \mathrm{P} 1}{\mathrm{DENT} 1^{2}} \\
& \frac{\mathrm{d} \alpha}{\mathrm{dT} 2}=-\frac{\beta \Delta \mathrm{P} 2 \frac{\left(\mathrm{P} 2_{\mathrm{i}}-\Delta \mathrm{P} 2\right)}{\mathrm{T} 2}-\alpha \mathrm{DEN}}{\mathrm{DEN} \mathrm{T2}} \\
& \frac{\mathrm{d} \alpha}{\mathrm{d} \Delta \mathrm{T} 2}=-[\beta \Delta \mathrm{P} 2+\alpha(1+\mathrm{k})] \frac{\mathrm{P} 2_{\mathrm{i}}+\Delta \mathrm{P} 2}{\mathrm{DEN} \mathrm{T2}{ }^{2}} \\
& \frac{\mathrm{d} \alpha}{\mathrm{dT} 3}=\frac{-\mathrm{K} 3 \Delta \mathrm{P} 3}{\mathrm{DEN} \mathrm{T3}} \\
& \frac{\mathrm{d} \alpha}{\mathrm{d} \Delta \mathrm{T} 3}=-\mathrm{K} 3 \frac{\mathrm{P} 3_{\mathrm{i}}+\Delta \mathrm{P} 3}{\mathrm{DENT3} 3^{2}} \\
& \frac{\mathrm{d} \alpha}{\mathrm{dk}}=\frac{\alpha\left(\mathrm{P} 2_{\mathrm{i}}+\Delta \mathrm{P} 2\right)}{\mathrm{DEN} \mathrm{T} 2} \\
& \frac{\mathrm{d} \alpha}{\mathrm{dK} 1}=\frac{\Delta \mathrm{P} 1}{\mathrm{DEN} \mathrm{T} 1}
\end{aligned}
$$

E.2 


$$
\begin{gathered}
\frac{\mathrm{d} \alpha}{\mathrm{dK} 3}=\frac{\Delta \mathrm{P} 3}{\mathrm{DENT3}} \\
\frac{\mathrm{d} \alpha}{\mathrm{d} \beta}=\frac{\Delta \mathrm{P} 2\left(\mathrm{P} 2_{\mathrm{i}}+\Delta \mathrm{P} 2\right)}{\mathrm{DEN} \mathrm{T} 2}
\end{gathered}
$$

For each of the parameters used to calculate the void fractions, estimates have been made for the error associated with the parameter. Following is a discussion of the bases used to establish each of these error estimates.

\section{Pressures}

The pressures of the pressurization chamber and the connecting line are measured by pressure transducers connected directly to the subject gas volume. These pressure transducers have been calibrated, and the errors for these pressures are based on the calibration data for the transducers. For the full-scale range of these transducers, the differences between the calibration standards and the transducer reading were less than $2.07 \mathrm{kPa}(0.3 \mathrm{psi})$. In addition, all deviations were on the same sign, which means that a $2.07 \mathrm{kPa}(0.3 \mathrm{psi})$ error can also be associated with the differences between initial and final pressure measurements for the same volume.

The pressure of the sample chamber is measured by the pressure transducer connected to the connecting line. This pressure transducer is isolated from the trapped gas in the sample chamber by a one third psi check valve and the waste itself. The waste can have some finite strength that could cause the pressure inside the bubbles to differ from the pressure inside the injected nitrogen gas. The waste strength has been estimated to be low. The deployment of the ball rheometer into Tank 241-SY-101 has shown the strength to be undetectable except in the bottom sludge layer, where it was less than $69 \mathrm{~Pa}(0.01 \mathrm{psi})$. Surface tension and bridging of solid particles have the potential for causing differences between the bubble pressure and the injected nitrogen gas pressure. Both of these effects have been minimized by using a relatively high pressurization pressure. These effects are estimated to be less than a half psi. An error of $6.9 \mathrm{kPa}(1.0 \mathrm{psi})$ was used for the sample chamber pressure.

\section{Temperatures}

The temperatures of the system are measured with transducers that have been calibrated. All of the temperature transducers were calibrated to within $0.5 \mathrm{~K}$ over the entire range they are used in the void fraction instrument (VFI). The temperature transducers in the pressurization chamber are in very close to the nitrogen gas, and an extended period of time is used to ensure that thermal equilibrium is reached. An error of $0.5 \mathrm{~K}$ was used for the pressurization chamber. The sample chamber waste is about $76 \mathrm{~cm}(2.5 \mathrm{ft})$ from the temperature transducers located at the pivot. The temperatures in the tank vary predominately in the vertical direction and very little laterally as seen in the MIT temperature profiles. An error of $1.0 \mathrm{~K}$ was used for the sample chamber. There are several temperature transducers used to measure the temperature of the connecting line since the line starts inside the equipment enclosure and extends through the mast to the sample chamber. An error of $1.0 \mathrm{~K}$ was used for the connecting line temperature. 
The errors in the differences between initial and final temperatures was estimated to be $0.1 \mathrm{~K}$. Since the gases in the individual volumes are in close contact with there environments, the heat transfer from the hardware or waste will quickly bring the gas temperature to the temperature of the local environment. The heat capacity of the gas is negligible for the gas as compared to the hardware or waste so that the gas does not effect their temperatures. The hardware component with the smallest surface-area-to-volume ratio is the pressurization chamber. Analyses and tests were used to demonstrate that the hold times used during testing are more than adequate to reach thermal equilibrium.

\section{System Volumes}

In actuality, the errors used in the calculations are the errors in the volume ratios. The errors in the system volumes are based on the methods used to calculate the volumes. The determination of system volumes is discussed in Appendix $\mathrm{C}$. The volume of the pressurization chamber was determined to have a standard deviation of $0.2 \%$, and an error estimate for the pressurization chamber volume ratio of $0.4 \%$ was used. The error of the connecting line volume factor was estimated at $5.0 \%$.

The compliance of the sample chamber was determined by calculations. An error estimate of $20 \%$ of the calculated value was used.

\section{Real Gas Effect/Soluble Gas Effects}

The parameter ' $k$,' which is used to consider the effects of real gas as opposed to ideal gas behavior and the effects of ammonia solubility, was determined by analysis. An error of $50 \%$ of the calculated value was used. 


\section{Distribution}

No. of

Copies

Offsite

2 DOE Office of Scientific and Technical Information

C. S. Abrams

1987 Virginia

Idaho Falls, ID 83404

E. C. Ashby

225 North Avenue

Boggs Chemistry Building

Georgia Institute of Technology

Atlanta, GA 30332

K. Bandyopadhyay

Building 129

Brookhaven National Laboratory

Upton, NY 11973

N. W. Bibler

Westinghouse Savannah River Co.

Building 773A, Room B132

Box 616

Aiken, SC 29802

D. Campbell

102 Windham Road

Oak Ridge, TN 37830

F. N. Carlson

6965 North, 5th West

Idaho Falls, ID 83401

E. D. Collins

Oak Ridge National Laboratory

P.O. Box 2008

7930, MS-6385

Oak Ridge, TN 37831-6385
No. of

Copies

Morton Corn

Room 6010

School of Hygiene and Public Health

John Hopkins University

615 N. Wolf Street

Baltimore, MD 21205

M. First

Harvard School of Public Health

665 Huntington Avenue

Boston, MA 02115

Charles W. Forsberg

Oak Ridge National Laboratory

P.O. Box 2008, MS-6495

Oak Ridge, TN 37831-6495

E. P. Horwitz

Chemistry Department

Argonne National Laboratory

9700 Cass Avenue

Argonne, IL 60439-4831

Billy C. Hudson

202 Northridge $\mathrm{Ct}$.

Lindsborg, KS 67456

M. S. Kazimi

Massachusetts Institute

of Technology

Department of Nuclear Engineering

77 Massachusetts Avenue

Cambridge, MA 02139

J. L. Kovach

Nuclear Consulting Services, Inc.

P.O. Box 29151

Columbus, OH 43229-0151

Dist. 1 
No of

Copies

B. R. Kowalski

Chemistry Department, BG-10

University of Washington

Seattle, WA 98195

Thomas S. Kress

Oak Ridge National Laboratory

P.O. Box 2009, MS-8088

Oak Ridge, TN 37831-8088

Thomas E. Larson

Los Alamos National Laboratory

MS-P915, DX-DO

P.O. Box 1663

Los Alamos, NM 87545

3 Los Alamos National Laboratory

P.O. Box 1663

Los Alamos, NM 87545

Attn: J. R. White, K555

W. L. Kubic, K575

K. Pasamehmetoglu, K575

D. Meisel

Chemistry Department

Argonne National Laboratory

9700 Cass Avenue

Argonne, IL 60439-4831

T. E. Larson

Los Alamos National Laboratory

MS-P915, DX-DO

P.O. Box 1663

Los Alamos, NM 87545

D. T. Oakley

Waste Policy Institute

Suite 600

555 Quince Orchard Road

Gaithersburg, MD 20878

Don Orth

124 Vivion Drive

Aiken, South Carolina 29803
No of

Copies

F. L. Parker

Vanderbilt University

P.O. Box 1596, Station B

Nashville, TN 37235

D. Pepson

U.S. Department of Energy

Trevion II Building, EM-35

Washington, D.C. 20585-0002

G. E. Schmauch

Air Products and Chemicals, Inc.

7201 Hamilton Boulevard

Allentown, PA 18195-1501

Scott E. Slezak

Sandia National Laboratory

Org. 6471/MS 0741

P.O. Box 5800

Albuquerque, NM 87185-0744

Dana Powers

Sandia National Laboratory

Dept. 6404/MS-0744

P.O. Box 5800

Albuquerque, NM 87815-0744

W. J. Thomson

Dept. of Chemical Engineering

Washington State University

Pullman, WA 99164

J. Tseng

U.S. Department of Energy

Trevion II Building, EM-35

Washington, D.C. 20585-0002

A. S. Veletsos

5211 Paisley

Houston, TX 77096

Dist. 2 
No of

Copies

Onsite

16 DOE Richland Operations Office

M. H. Campbell

S7-73

R. E. Gerton

S7-54

J. M. Gray (10)

S7-54

C. A. Groendyke

S7-54

D. H. Irby

M. F. Jarvis

G. W. Rosenwald

33 Westinghouse Hanford Company

H. Babad

S7-15

W. B. Barton

R. E. Bauer

R2-11

L6-37

T. R. Benegas

C. E. Hanson

H5-09

H5-09

T6-09

D. L. Herting

J. D. Hopkins

G. D. Johnson (5)

N. W. Kirch

J. G. Kristofzski

L. S. Krogsrud

D. C. Larsen

J. A. Lechelt

J. W. Lentsch (5)

R. M. Marusich

N. G. McDuffie

J. E. Meacham

R. E. Mendoza

D. A. Reynolds
No of

Copies
C. A. Rieck
C. P. Shaw
S2-48
T. I. Stokes
H5-09
J. E. Van Beek
H5-09
S2-48
R. J. Van Vleet
H4-64
N. E. Wilkins
R2-11

36 Pacific Northwest Laboratory

J. M. Alzheimer

K5-22

Z. I. Antoniak

J. M. Bates

S. Q. Bennett

K7-15

K7-15

K7-90

P. R. Bredt

P7-25

M. E. Brewster

K7-15

J. W. Brothers

K5-22

J. B. Colson

K5-10

P. A. Gauglitz

P7-41

W. B. Gregory

K7-22

J. D. Hudson

K7-15

K7-15

P8-34

F. E. Panisko

P7-19

M. R. Powell

K7-15

K. P. Recknagle

K7-15

H. C. Reid

P. A. Scott

P7-43

A. Shekarriz

C. L. Shepard

K7-15

K5-25

N. J. Stajduhar

K9-89

C. W. Stewart (10)

K7-15

G. Terrones

K7-15

P7-25

J. M. Tingey

D. S. Trent

K7-15

Information Release (3)

Dist. 3 